\title{
MARIA BEATRIZ REINERT DO NASCIMENTO
}

\section{Características do aleitamento materno no município de Joinville, SC}

\author{
Tese apresentada à Faculdade de \\ Medicina da Universidade de São \\ Paulo para obtenção do título de \\ Doutor e m Ciências \\ Área de concentração: Pediatria \\ Orientadora: Profa. Dra. Sandra \\ Josefina Ferraz Ellero Grisi
}




\title{
Características do aleitamento materno no município de Joinville, SC
}

Tese apresentada à Faculdade de Medicina da Universidade de São Paulo para obtenção do título de Doutor em Ciências

Área de concentração: Pediatria Orientadora: Profa. Dra. Sandra Josefina Ferraz Ellero Grisi

\author{
SÃO PAULO \\ 2009
}


"Se fosse disponibilizada uma nova vacina que pudesse prevenir a morte de um milhão ou mais crianças por ano e que, além disso, fosse barata, segura, de administração oral e não exigisse uma cadeia de frio, esta tornar-seia numa prioridade imediata para a saúde pública.

A amamentação pode fazer tudo isso e mais ainda, mas precisa da sua própria "cadeia quente" de apoios - ou seja, cuidados profissionalizados que permitam às mães ganhar confiança $\mathrm{e}$ Ihes mostrem o que fazer e as protejam de más práticas. Se, na nossa cultura, esta cadeia quente se perdeu ou apresenta falhas, devemos corrigi-la através dos serviços de saúde."

The Lancet 


\section{DEDICATÓRIA}

Marco,

"V ocê é assim um sonho pra mim...

....E u gosto de você. E gosto de ficar com você.

$M$ eu riso é tão feliz contigo.

0 meu melhor amigo é o meu amor."

Tribalistas

Eduardo,

"...0 fato é que um dia eles crescem, abrem sem avisar as asas delicadas e no tempo de um espirro nos deparamos com a envergadura do filhote. 0 gesto se antecipa e anuncia a extensão do salto.

- V olta pro ovo!!, queremos dizer, como na canção, mas não nos ouvem, envolvidos que estão no intenso farfal har das asas debutantes.

...D esprovidos dos antigos recursos, nada nos resta fazer senão admirar 0 vôo destes calouros emplumados, pintainhos que fizemos crescer com nossos mimos e a quem demos asas para que brincassem à nossa volta. "

Rosana Justus Braga

Mario e Hildete,

"... é no seio da família que nós nos formamos para ser o que somos" 


\section{AGRADECIMENTOS}

À Profa. Dra. Sandra Josefina Ferraz Ellero Grisi, pela orientação e apoio em momentos cruciais ao longo do percurso na pós-graduação.

Ao Dr. Hugo Issler, por mais uma oportunidade e pela dedicação na árdua tarefa de supervisionar as diversas fases deste projeto.

Ao Dr. Alexandre Archanjo Ferraro, pela disponibilidade e preciosa ajuda na realização da análise estatística na etapa final do trabalho.

À Dra. Sonia Isoyama Venâncio, pelas sugestões proveitosas e apropriadas.

Ao Dr. Mário Cícero Falcão, pelos importantes comentários.

À Profa. Dra. Sonia Buongemino de Souza, pelo seu parecer criterioso.

À Profa. Dra. Selma Cristina Franco, colega de trabalho na Universidade da Região de Joinville (UNIVILLE), pela amizade e possibilidade de uma acertada parceria.

Ao Prof. Dr. Marco Antonio Moura Reis, meu marido e companheiro no projeto de pesquisa, pelo incondicional apoio, sugestões decisivas e auxílio valioso no uso da estatística e da informática, que permitiram a conclusão deste trabalho.

À Equipe do "Projeto Amamentação e Municípios", do Instituto de Saúde da Secretaria Estadual de Saúde de São Paulo, responsável pelos procedimentos estatísticos necessários ao planejamento e realização da pesquisa. 
À Pró-Reitoria de Pesquisa e Pós-Graduação, da Universidade da Região de Joinville (UNIVILLE), pelo financiamento da pesquisa.

Ao Programa de Qualificação Docente, da Universidade da Região de Joinville (UNIVILLE), pelo permanente suporte.

À Secretaria Municipal de Saúde de Joinville, pelo apoio técnico e logístico durante a coleta de dados.

Às alunas de iniciação científica Fabíola Müller de Oliveira, Milena Furlin Rizzon e Gabrielli Baschung Socha, pela inestimável ajuda durante a fase de coleta e digitação dos dados.

Aos alunos voluntários e funcionários dos postos de vacinação, que participaram com dedicação da coleta de dados.

À funcionária Adriana Trindade Bezerra, do Departamento de Pediatria da Faculdade de Medicina da Universidade de São Paulo, sempre solícita.

Ao Dr. Crésio Romeu Pereira e ao Prof. Dr. Cláudio Leone, pela supervisão dos procedimentos estatísticos na fase de preparo para o Exame de Qualificação. 


\section{SUMÁRIO}

\section{Lista de abreviaturas}

Lista de siglas

Lista de símbolos

Resumo

Summary

1 INTRODUÇÃO. .02

1.1 Amamentação e suas vantagens..............................................

1.2 A amamentação, o ser biológico e a sociedade.....................06

1.3 Amamentação e o mundo atual..........................................10

1.4 Pesquisa e amamentação...................................................16

2 OBJETIVOS

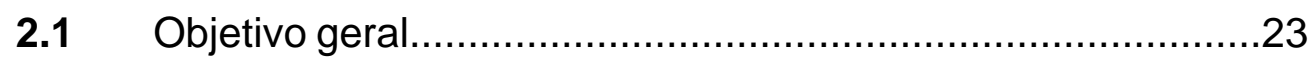

2.2 Objetivos específicos.....................................................23

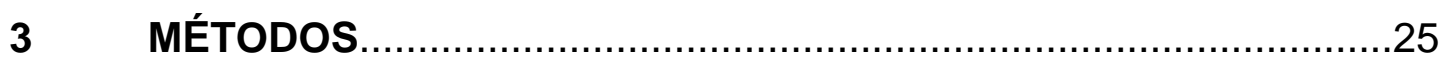

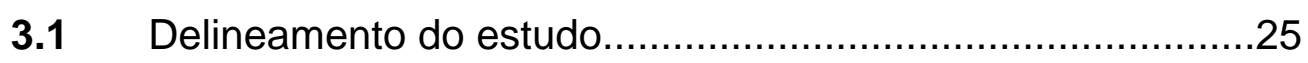

3.2 Características gerais do local de estudo.............................26

3.3 População de estudo e plano amostral.................................28

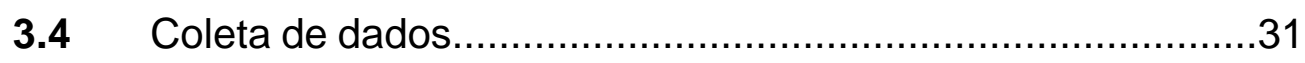

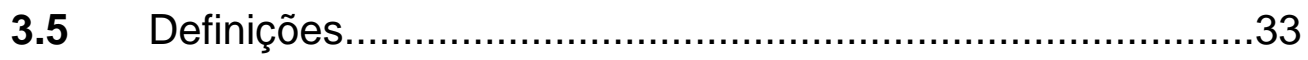

3.6 Variáveis do estudo e sua operacionalização.........................33

3.6.1 Variável dependente..............................................3

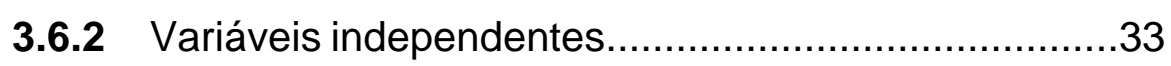

3.6.2.1 Aspectos relacionados ao lactente.....................33

3.6.2.2 Aspectos maternos.............................................

3.6.2.3 Aspectos relacionados à assistência de saúde..34

3.7 Processamento e análise dos dados .35 


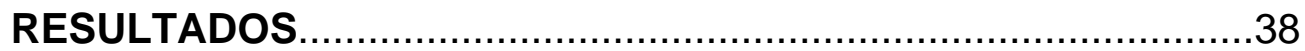

4.1 Características da amostra estudada...............................38

4.2 Prevalência do AM.....................................................40

4.3 Prevalência do AME...................................................42

4.4 Estudo da associação das variáveis relacionadas ao lactente, à mãe e à assistência de saúde com a ausência de AME.....44

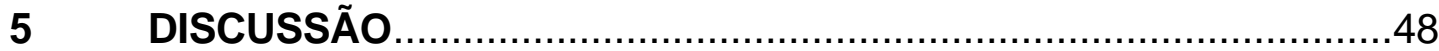

5.1 Prevalência do AM.....................................................48

5.2 Prevalência do AME........................................................53

5.3 Estudo da associação entre a ausência do AME e variáveis relacionadas ao lactente, à mãe e à assistência de saúde em lactentes menores de 6 meses de vida. 60

5.3.1 Aspectos relacionados ao lactente. .61

5.3.1.1 Idade 61

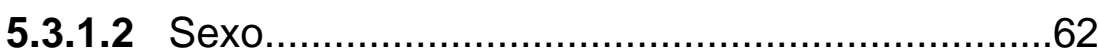

5.3.1.3 Peso de nascimento....................................64

5.3.1.4 Ordem de nascimento..................................66

5.3.1.5 Uso de chupeta.......................................68

5.3.2 Aspectos maternos............................................. 71

5.3.2.1 Idade da mãe............................................71

5.3.2.2 Escolaridade materna..................................73

5.3.2.3 Trabalho materno...........................................75

5.3.3 Aspectos relacionados à assistência de saúde.........79

5.3.3.1 Tipo de parto............................................... 79

5.3.3.2 Local de nascimento do lactente.......................82

5.3.3.3 Local de atendimento do lactente......................85

5.3.3.4 Profissional responsável pelo atendimento de puericultura. .86

5.3.4 Considerações finais. .90 


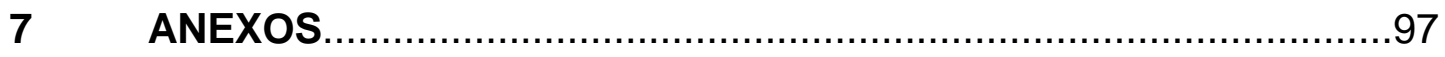

ANEXO A

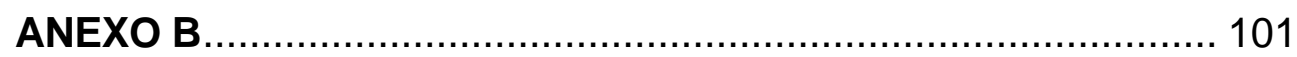

ANEXO C

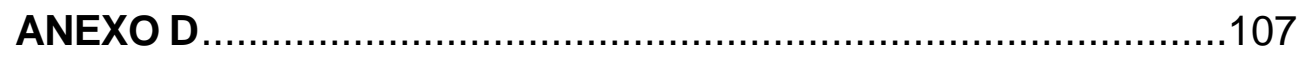

ANEXO E

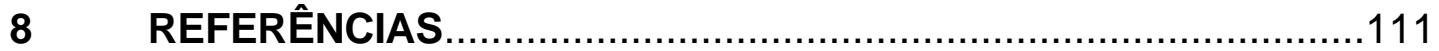

Apêndices 


\section{LISTA DE ABREVIATURAS}

$\begin{array}{ll}\text { AM } & \text { aleitamento materno } \\ \text { AME } & \text { aleitamento materno exclusivo } \\ \text { HAC } & \text { Hospital Amigo da Criança } \\ \text { IHAC } & \text { Iniciativa Hospital Amigo da Criança } \\ \text { LH } & \text { leite humano } \\ \text { PSF } & \text { Programa Saúde da Família } \\ \text { RN } & \text { recém-nascido } \\ \text { RNBP } & \text { recém-nascido de baixo peso }\end{array}$




\section{ㄴISTA DE SIGLAS}

$\begin{array}{ll}\text { IS-SESSP } & \text { Instituto de Saúde da Secretaria Estadual de Saúde de } \\ \text { MDV } & \text { São Paulo } \\ \text { MS } & \text { Maternidade Darcy Vargas } \\ \text { OMS } & \text { Ministério da Saúde } \\ \text { OPAS } & \text { Organização Mundial da Saúde } \\ \text { SINASC } & \text { Organização Panamericana da Saúde } \\ \text { SMS } & \text { Sistema de Informação de Nascidos Vivos } \\ \text { SBP } & \text { Secretaria Municipal de Saúde de Joinville } \\ \text { SUS } & \text { Sociedade Brasileira de Pediatria } \\ \text { UNICEF } & \text { Sistema Único de Saúde } \\ \text { UNIVILLE } & \text { Fundo das Nações Unidas para a Infância } \\ \text { WHO } & \text { Universidade da Região de Joinville }\end{array}$




\section{LISTA DE SÍMBOLOS}

\begin{tabular}{|c|c|}
\hline a & anos \\
\hline$d$ & $\operatorname{dia}(\mathrm{s})$ \\
\hline $\mathrm{DP}$ & desvio-padrão \\
\hline$g$ & grama (s) \\
\hline IC $95 \%$ & intervalo de confiança de $95 \%$ \\
\hline $\mathrm{n}$ & tamanho da amostra \\
\hline n. $\stackrel{o}{2}$ & número \\
\hline $\mathrm{N}$ & número de observações \\
\hline NS & ausência de significância estatística \\
\hline $\mathrm{p}$ & valor de $\mathrm{P}$ \\
\hline $\mathrm{RP}$ & razão de prevalência \\
\hline$=$ & igual \\
\hline$?$ & mais ou menos \\
\hline$?$ & maior ou igual \\
\hline$?$ & menor ou igual \\
\hline$?$ & menor que \\
\hline$?$ & maior que \\
\hline$\%$ & porcentagem \\
\hline
\end{tabular}




\section{RESUMO}

Nascimento, MBR. Características do aleitamento materno no município de Joinville, SC. ?tese?. São Paulo: Faculdade de Medicina, Universidade de São Paulo; 2009. 133p.

O aleitamento materno é o modo mais natural e seguro de alimentação na primeira infância. O leite humano proporciona uma combinação única de nutrientes, células vivas e elementos de defesa, assim como benefícios nutricionais, imunológicos, psicológicos e econômicos reconhecidos e inquestionáveis, tanto a curto como a longo prazo. Como política global de saúde pública, a Organização Mundial da Saúde recomenda que a amamentação seja exclusiva até o sexto mês de vida. Após essa idade, alimentos complementares devem ser iniciados, e o aleitamento materno mantido beneficamente até dois anos ou mais. É essencial tomar conhecimento das condições de saúde, de assistência e de vida de uma determinada população, inclusive àquelas relativas à nutrição infantil, para tanto, o diagnóstico rápido dos índices de aleitamento materno em campanhas de vacinação constitui uma importante estratégia. $\mathrm{O}$ objetivo geral desse estudo foi determinar a prevalência do aleitamento materno entre os lactentes menores de um ano de idade no município de Joinville (SC). Os objetivos específicos foram: caracterizar o tipo de aleitamento entre os lactentes menores de um ano de idade, conhecer a prevalência do aleitamento materno exclusivo em lactentes de quatro e seis meses de vida, descrever a freqüência de utilização de chupetas e mamadeiras, estudar a associação entre a ausência do aleitamento materno exclusivo e variáveis maternas, do lactente e de assistência de saúde em menores de seis meses de vida. Nossa pesquisa foi desenhada como um estudo transversal, com coleta de dados de uma amostra auto-ponderada de 1470 lactentes com idade inferior à um ano, e realizada durante a Campanha Nacional de Vacinação, em agosto de 2005, com a utilização de recordatório alimentar das últimas 24 horas. As variáveis pesquisadas relacionadas ao lactente foram: idade, sexo, peso de nascimento, ordem de nascimento e uso de chupeta. As variáveis maternas analisadas foram: idade, escolaridade e trabalho da mãe. As variáveis estudadas relacionadas à assistência de saúde foram: tipo do parto, local de nascimento e de atendimento do lactente, e profissional responsável pelo atendimento de puericultura. Para avaliar possíveis associações entre o aleitamento materno não-exclusivo até o sexto mês e as variáveis de interesse, foram calculadas as razões de prevalência e o intervalo de confiança de $95 \%$, obtidos pela regressão de Poisson. Os resultados mostraram que a prevalência do aleitamento materno em lactentes com idade inferior a um ano foi de $72,5 \%$. A prevalência de amamentação em menores de seis meses foi de $84,1 \%$, sendo que o índice de aleitamento materno exclusivo foi $43,7 \%$. A prevalência de amamentação em menores de quatro meses foi de $89,8 \%$, sendo que a taxa de aleitamento materno exclusivo foi $53,9 \%$. As freqüências de utilização de chupetas e mamadeiras em lactentes com idade inferior a um ano foram $51,3 \%$ e $51,1 \%$, 
respectivamente. Associaram-se significativamente à ausência de aleitamento materno exclusivo em lactentes menores de seis meses: idade do lactente maior ou igual a 90 dias, uso de chupeta e escolaridade materna menor que 12 anos.

Descritores: Aleitamento Materno. Nutrição do Lactente. Desmame. Estudos Transversais. Prevalência. Epidemiologia. 


\section{SUMMARY}

Nascimento, MBR. Characteristics of breastfeeding in the city of Joinville, SC. ?thesis?. São Paulo: Faculdade de Medicina, Universidade de São Paulo; 2009. 133p.

Breastfeeding is the safest and most natural form of feeding in infancy. Human milk contains a unique combination of nutrients, living cells and defense factors, and the short- and long-term nutritional, immunological, psychological and economic benefits of breastfeeding are well known and unquestionable. As a global public health policy, the World Health Organization recommends exclusive breastfeeding up to the sixth month of life. After that age, complementary foods should be introduced, but breastfeeding should continue until the child is two years or older. Public health policies, particularly those that promote infant nutrition, should be defined according to the health, healthcare and living conditions of a certain population. For this purpose, a rapid evaluation of breastfeeding rates is an important strategy. The general objective of this study was to determine the prevalence of breastfeeding among infants in the city of Joinville, SC. The specific objectives were: to characterize the kind of breastfeeding among infants younger than one year of age, to determine the prevalence of exclusive breastfeeding among infants younger than four and six months of age, to describe the frequency of pacifier and bottle use, to investigate the association between lack of exclusive breastfeeding for infants younger than 6 months and maternal, infant and healthcare variables. The data for this cross-sectional population survey were collected during the National Vaccination Campaign in August 2005 among the persons that accompanied 1470 infants to the vaccination clinics, using a questionnaire with closed questions, most of them about the infant's feeding in the previous 24 hours. The infantile variables investigated were: age, gender, birthweight, infant birth order and use of pacifier. The maternal variables analysed were: age, maternal schooling and occupation. The healthcare variables studied were: mode of delivery, delivery in a Baby-Friendly Hospital, healthcare in public or private service, and preventive healthcare provided by pediatrician or other specialist. To evaluate possible risk factors of non-exclusive breastfeeding up to the sixth month, the Prevalence Ratio calculated by Poisson Regression was used as measure of association in bivariate and multivariate analysis. The results showed an overall rate of breastfeeding of $72.5 \%$. The inquiry revealed that $84,1 \%$ of the infants younger than six months of age had been breastfed in the previous 24 hours, $43.7 \%$ of them exclusively. The inquiry revealed that $89.8 \%$ of the infants younger than four months of age had been breastfed in the previous 24 hours, $53.9 \%$ of them exclusively. Pacifiers and bottles were used by $51.3 \%$ and $51.1 \%$ of the infants. Factors significantly associated with the interruption of exclusive breastfeeding for infants up to six months were: age of 90 days or more, pacifier use and mother educational level of less than 12 years. 
Descriptors: Breastfeeding. Infant Nutrition. Weaning. Cross-Sectional Studies. Prevalence. Epidemiology. 
1. INTRODUCCÃO 


\section{INTRODUCCÃO}

O aleitamento materno (AM) é o modo mais apropriado e seguro de alimentação na primeira infância, proporcionando inúmeros benefícios nutricionais, imunológicos, psicológicos e econômicos, tanto a curto como a longo prazo (AAP, 2005; AHRQ, 2007; Lawrence, 2007). Apesar dessas qualidades, as taxas de AM e de aleitamento materno exclusivo (AME) estão abaixo dos patamares desejados em muitos países (WHO, 2003; Labbok et al., 2006). No sentido de reverter essa situação, a revisão das estratégias de estímulo à prática do aleitamento materno se faz necessária.

Na definição de políticas públicas de saúde para uma população, é essencial considerar as condições de vida e de assistência dos seus membros, inclusive aquelas relativas à nutrição infantil, para o que o diagnóstico dos índices de AM constitui uma importante estratégia (Kitoko et al., 2000).

\subsection{Amamentação e suas vantagens}

Ao menos cinco milhões de mortes que ocorrem no mundo a cada ano poderiam ser evitadas. São mortes de crianças com menos de cinco anos, conseqüência direta ou indireta da desnutrição (UNICEF, 2007).

A prevenção da desnutrição sempre foi o principal foco das pesquisas em nutrição infantil (ESPGHAN, 2008). Uma boa alimentação é determinante para a manutenção de um sistema imunológico mais pujante e, portanto, um organismo menos sujeito a doenças. Crianças saudáveis 
aprendem melhor, e tornam-se pessoas mais fortes, mais produtivas e mais capazes de criar oportunidades, o que pode interromper o ciclo da pobreza e da fome de uma forma sustentável (WHO, 2003). Ainda que a carência de alimentos seja um problema sério em muitas regiões, a falta de conhecimento sobre nutrição infantil e práticas inapropriadas de alimentação são freqüentemente responsáveis pela desnutrição nas crianças pequenas (Heinig, 2001). A falta de apoio social e acesso à educação, mas também crenças, costumes, saúde física e mental dos adultos cuidadores são determinantes dos distúrbios graves da nutrição infantil (Sellen, 2001a). Uma ampla interferência sobre as famílias e comunidades, seria fundamental para promover um bom estado de nutrição e saúde na infância, e mudar essa realidade (Freedman, 2005; WHO, 2005).

Para tanto, em função da importância da mulher na geração e cuidado das crianças em todas as culturas, as questões de gênero merecem atenção especial, pois o acesso restrito ao estudo e a uma alimentação adequada - muito observado em meninas de regiões pobres - interfere negativamente no desenvolvimento de sua prole (Beasley e Amir, 2007). Somente uma profunda transformação nas comunidades e nos sistemas de saúde, necessários a garantir adequado cuidado às mulheres e crianças desde a gravidez, podem melhorar a sobrevivência e o padrão alimentar na infância (WHO, 2005; UNICEF, 2007).

O período transcorrido entre o nascimento e os dois anos de vida é tido como uma fase crítica para a promoção da saúde, crescimento e desenvolvimento (Sguassero et al., 2007). Tanto a nutrição intra-uterina 
quanto a recebida na fase pós-natal podem ter efeitos duradouros e conseqüências na vida adulta, determinando melhor ou pior qualidade de vida dos indivíduos (Nevo et al., 2007).

A contribuição de fatores intra-uterinos para a "programação" metabólica do indivíduo tem sido exaustivamente estudada, o que poderia afetar a suscetibilidade para doenças crônicas na vida adulta (Falcão, 2004). Nesse sentido, parece ser também fundamental a influência da dieta e das primeiras experiências alimentares, particularmente do AM (Balaban e Silva, 2004; Stanner e Smith, 2005; Wyrwoll et al., 2007). Novas evidências têm reforçado a possibilidade da prevenção de doenças do adulto, já na infância, a partir de uma alimentação saudável (Tanner e Finn-Stevenson, 2002; Wyrwoll et al., 2007).

Já são conhecidos os efeitos benéficos a longo prazo do AM, em especial na prevenção da ocorrência de sobrepeso e obesidade, diabete melito, dislipidemias e hipertensão arterial (Rodriguez-Palmero et al., 1999; Martin et al., 2005; Weyermann et al., 2006; Horta et al, 2007; Siqueira e Monteiro, 2007; Mayer-Davis et al., 2008; Simon et al., 2009). A associação entre o uso de leite materno e desenvolvimento cognitivo é demonstrada em muitos estudos (Rao et al., 2002; Slykerman et al., 2005; Caspi et al., 2007; Kramer et al., 2008). Adolescentes e adultos jovens que foram aleitados pelas mães apresentam escores significativamente mais altos em testes de inteligência, bem como melhor performance escolar (Horta et al., 2007). É ainda amplamente reconhecido o efeito facilitador da amamentação no estabelecimento do vínculo mãe-filho (Klaus e Klaus, 1992), o que por sua 
vez, pode influenciar positivamente a capacidade cognitiva. Entre tantos reconhecidos benefícios, a utilização de leite humano (LH), maior fonte de imunidade nos vulneráveis primeiros anos de vida, é a medida isolada mais efetiva para reduzir a mortalidade em crianças menores de cinco anos, trazendo impacto positivo para o desenvolvimento infantil, para as famílias e para a economia (Labbok, 2006).

Como política global de saúde pública, a Organização Mundial da Saúde (OMS) recomenda que a amamentação seja exclusiva até o sexto mês de vida. Após essa idade, alimentos complementares devem ser iniciados, e o AM mantido até dois anos ou mais (WHO, 2003).

Por muito tempo acreditou-se que a pobreza tivesse um efeito protetor sobre a prática da amamentação, por ser um método gratuito de garantir alimentação às crianças e, portanto, acessível às classes desprivilegiadas. Entretanto, ela pode impor risco ao $\mathrm{AM}$, seja porque a mulher pobre precisa deixar sua casa precocemente para o trabalho, ou porque ela não se julga capaz de amamentar exclusivamente, já que sua dieta é inadequada e pouco calórica (Beasley e Amir, 2007). É, justamente em países em desenvolvimento, fundamental a preocupação com o bem estar nutricional das crianças, o que poderia diminuir as sérias conseqüências da má-nutrição e reduzir a mortalidade tão prevalente nestes grupamentos sociais (Lawlor, 2008). 


\subsection{A amamentação, o ser biológico e a sociedade}

Embora sejam públicos e bem divulgados os benefícios do uso do AM, em nenhuma outra área da saúde os hábitos estão em tamanha oposição aos avanços científicos e aos melhores interesses da população. Atualmente, na imensa maioria dos países, mais do que baseada nas diretrizes, a escolha do tipo de alimentação para lactentes e crianças é determinada a partir de fatores culturais e da disponibilidade de outros alimentos (Sellen, 2001b; ESPGHAN, 2008).

Considerando apenas a origem do homem e suas características de mamífero, é difícil explicar o porquê das práticas de amamentação variarem tanto entre indivíduos de mesmo grupo social ou entre populações ao longo do tempo. No decorrer de milhões de anos, os seres humanos desenvolveram táticas variadas para alimentação de suas crias, provavelmente procurando equilibrar o custo metabólico da lactação para a mulher e o risco à sobrevivência da criança. Esta flexibilidade foi importante para a adaptação ao meio-ambiente, mas acabou criando discrepância entre a prática alimentar preconizada como ótima e a realmente praticada em civilizações modernas, reforçando a importância de se levar em consideração o contexto social que envolve o AM (Sellen, 2001b; Buhimschi, 2004).

Muitos estudos etnográficos têm demonstrado o quanto as práticas do AM variam de acordo com as questões de gênero e os sistemas de produção e consumo domésticos, em uma economia cada vez mais globalizada. Sendo assim, as intervenções para melhorar as condições 
dietéticas infantis precisam considerar aspectos tais como a pobreza e a globalização, já que tanto as crenças como os hábitos podem ser modificados, na dependência de aspectos materiais ou de conceitos culturalmente construídos (Sellen, 2001b; Van Esterik, 2002).

A "Estratégia Global para Alimentação do Lactente e da Criança Pequena", da OMS, procura servir, justamente, como um guia para ação dos governos, dos organismos internacionais, dos profissionais de saúde e da sociedade, no sentido de identificar quais intervenções, relacionadas à amamentação e alimentação infantil, que teriam impacto positivo para a modificação da realidade alimentar de nossas crianças (Van Esterik, 2002; WHO, 2003).

Questiona-se, no entanto, se as recomendações atuais seriam compatíveis, aceitáveis ou mesmo passíveis de serem seguidas, levando-se em conta contextos culturais específicos (Sellen, 2001b).

É sabido que por volta dos seis meses de vida, os lactentes estariam prontos para receber outros alimentos além do leite materno, mas em algumas partes do mundo, o processo da alimentação complementar é iniciado mais cedo, ou muito depois deste período. Freqüentemente, esta transição alimentar, com importante significado cultural, vem acompanhada de um declínio no ganho de peso entre os seis e os 18 meses de idade (Van Esterik, 2002).

As práticas alimentares vigentes em muitas regiões parecem estar em desacordo com o processo adaptativo ocorrido ao longo da evolução da espécie humana. Os mamíferos têm como característica principal a presença 
de glândula mamária, capaz de secretar leite para alimentação de suas crias. Essa maneira de alimentar os pequenos filhotes vem sendo observada desde a era Mesozóica, há cerca de cem milhões de anos. Os precursores do homem surgiram há quatro milhões de anos, e o gênero Homo, há dois milhões. A espécie dominante Homo sapiens sapiens existe há 40.000 anos, e informações sobre as sociedades paleolíticas podem nos dar uma noção das dietas utilizadas há pelo menos cem séculos (Coates, 1998).

Abordagens biológicas evolutivas, baseadas em dados de primatas não-humanos, procuram estimar qual seria o tempo natural de amamentação para o filhote do homem. Algumas teorias alegam que o tempo de duração do AM deveria ser entre 2,5 e sete anos. Outras, propõem que a idade na qual poderia haver adaptação ao desmame seria a do surgimento do primeiro dente molar, ou equivalente a um tempo de 1,5 vezes a duração da gestação, ou ao momento em que se triplica ou quadriplica o peso de nascimento, ou ainda, ao ser atingido pelo menos dois terços do peso médio de um adulto. No entanto, é importante ressaltar que nesses estudos não são levados em consideração os efeitos modificadores de parâmetros como a dieta, a atividade laboral, a cultura, a organização social e a tecnologia, tão diferentes na civilização moderna (Sellen, 2001b; Van Esterik, 2002).

Pesquisas antropológicas, ligadas à arqueologia, também procuram demonstrar os processos de lactação, alimentação e desmame a partir de material derivado de esqueletos humanos. A avaliação de crânios préhistóricos, denota arcadas dentárias com bom formato, perfeita oclusão e poucas cáries dentárias, sugerindo que, antes dos dois anos, ocorreria o 
início da ingestão de sólidos, mas que estaria sempre acompanhada da manutenção do AM (Palmer, 1998; Van Esterik, 2002).

Outras evidências arqueológicas, datadas de 3000 AC, são utensílios de cerâmica, representando divindades tais como Ishtar da Babilônia e Ísis do Egito, ligadas à fertilidade e à lactação, sugerindo a importância do ato na época (Coates, 1998). Supõe-se que a utilização de outros líquidos na alimentação de lactentes, além do leite materno, seja uma prática antiga, com base no achado de recipientes próprios para alimentação em jazigos de lactentes construídos por volta de 2000 AC (Lawrence, 1994).

Estudos etnográficos modernos têm sido especialmente importantes para documentar os hábitos dietéticos infantis em sociedades de distintos costumes, e determinar qual seria a norma biológica para a amamentação do ser humano moderno (Coates, 1998). Há relato de que mulheres de tribos aborígines australianas compartilham a cama com seus filhos, e amamentam até os seis anos de idade (Hartmann, 2007). Populações indígenas vêem o nascimento e a amamentação como eventos naturais. Crentes na natureza e na sua própria capacidade, essas mães carregam consigo seus filhos, de forma contínua, o que aumenta o vínculo e o período de lactação (Righard, 2008). Em sociedades de costumes primitivos de Papua Nova Guiné, as mamadas dos lactentes jovens são curtas e freqüentes. As mamas são oferecidas diuturnamente, cerca de quatro vezes por hora e o período de sucção tem duração média de dois minutos. Gradualmente há espaçamento das mamadas, que são mantidas por dois a seis anos (Coates, 1998). 
$\mathrm{Na}$ avaliação das práticas alimentares de 113 grupos populacionais pertencentes a 97 sociedades pré-industriais, a média de idade da introdução de alimentos sólidos está próxima de cinco a seis meses de vida, e a do desmame, por volta dos 24 meses. No entanto, em $70 \%$ dessa amostra, os lactentes recebem outros líquidos antes do sexto mês, e muitas vezes já nas primeiras semanas após o nascimento (Sellen, 2001b).

É curioso notar a proximidade das rotinas dietéticas adotadas por comunidades primitivas e as recomendações atuais acerca da alimentação de primeira infância, o que ajuda a reafirmar a propriedade de tais preceitos, mesmo considerando a diversidade de contextos sociais e ecológicos humanos (Sellen, 2001b).

Fica evidente que os cuidados à criança, bem como os hábitos de AM são ações edificadas socialmente e variam de acordo com o momento histórico, com a economia e a cultura de cada população, tendo conseqüências sociais e distintos significados para cada sociedade (Jóia, 2006). A amamentação deve ser considerada uma questão inerente à maternidade que, mais que determinada biologicamente, é construída sócioculturalmente (Almeida, 1999; Souza e Almeida, 2005).

\subsection{Amamentação e o mundo atual}

Dados do UNICEF demonstram que taxas de iniciação e duração do AM e AME diferem bastante quando comparadas as diversas regiões do planeta (UNICEF, 2007). 
A tabela 1 apresenta dados de alguns trabalhos sobre amamentação, realizados em diferentes continentes, procurando ilustrar a diversidade dos achados nos vários países.

Nos países em desenvolvimento, observou-se, entre 1990 e 2000, um aumento geral de cerca de $15 \%$ das taxas de $\mathrm{AME}$, tanto entre os menores de quatro, quanto entre os menores de seis meses de idade. $\mathrm{O}$ incremento mais significativo acontece na África subsaariana (de 18\% para $38 \%$, enquanto que o Oriente Médio e o norte da África continuam com índices baixos. Grande contraste é observado na América Latina e Caribe onde, enquanto alguns países apresentam taxas de AME até 180 dias muito baixas, tal como a Jamaica (15\%), outros têm conseguido obter resultados animadores, como o Peru (64\%) (Labbok et al., 2006; UNICEF, 2007).

Entretanto, estima-se que em todo o mundo somente $38 \%$ dos lactentes menores de seis meses sejam exclusivamente amamentados, 0 dobro dos $21 \%$ e $19 \%$ observados, respectivamente, na África Central e no Leste Europeu (UNICEF, 2007).

Grande heterogeneidade é observada, até mesmo em um só país, tal como a China, onde diferenças marcantes de cultura e hábitos também se evidenciam nas práticas de AM. Entre as crianças com idade de zero a dois anos, residentes na área rural, observa-se que 98,2\% estão sendo amamentadas, contra 73,0\% na área urbana (Wang et al., 2005). 
Tabela 1. Prevalência de aleitamento materno (AM) e aleitamento materno exclusivo (AME) em 17 países do mundo.

\begin{tabular}{|c|c|c|c|c|c|c|c|c|c|c|c|c|c|}
\hline \multirow[b]{3}{*}{ Local } & \multirow[b]{3}{*}{ Autor } & \multirow[b]{3}{*}{ Tipo de estudo } & \multirow[b]{3}{*}{$\mathbf{n}$} & \multirow[b]{3}{*}{ Idade à análise } & \multicolumn{9}{|c|}{ Prevalência (\%) } \\
\hline & & & & & \multicolumn{2}{|c|}{$1 \mathrm{~m}$} & \multicolumn{2}{|c|}{$3 \mathrm{~m}$} & \multicolumn{2}{|c|}{$4 \mathrm{~m}$} & \multicolumn{2}{|c|}{$6 \mathrm{~m}$} & \multirow{2}{*}{$\begin{array}{r}12 \mathrm{~m} \\
\quad A M\end{array}$} \\
\hline & & & & & AM & AME & AM & AME & $\mathbf{A M}$ & AME & AM & AME & \\
\hline China & Wang et al., 2005 & Transversal & 2015 & 0 a 24 meses & 98,7 & - & - & _ & 96,4 & 24,4 & - & - & 75,1 \\
\hline Nova Zelândia & Schluter et al., 2006 & Coorte & 1376 & 0 a 24 meses & - & - & - & 37,0 & - & - & - & 9,0 & 31,0 \\
\hline Singapura & Foo et al., 2005 & Transversal & 2098 & 0 a 6 meses & 71,6 & - & - & & 29,8 & 7,0 & 21,1 & - & - \\
\hline Taiwan & Shien et al., 2005 & Coorte & 2079 & 0 a 3 meses & 70,6 & 22,3 & 34,1 & 16,7 & - & - & - & - & - \\
\hline Emirados Árabes & Tajir et al., 2006 & Coorte & 221 & 0 a 6 meses & 98,5 & 55,1 & - & - & - & & 83,9 & 13,3 & - \\
\hline Malaui & Kamudoni et al., 2007 & Transversal & 349 & 0 a 12 meses & - & - & - & - & - & 27,5 & - & 7,5 & - \\
\hline Nigéria & Lawoyin et al., 2001 & Transversal & 2794 & 0 a 6 meses & - & 57,4 & - & 48,7 & - & 45,3 & - & 23,4 & - \\
\hline Reino Unido & Wright et al., 2006 & Coorte & 923 & 0 a 12 meses & - & - & - & - & 15,0 & - & - & - & - \\
\hline Holanda & Bulk-Bunschoten et al., 2001 & Coorte & 4438 & 0 a 4 meses & - & - & 39,0 & 26,0 & 33,0 & 21,0 & - & - & - \\
\hline E.U.A. & Li et al., 2005 & Transversal & 3444 & 19 a 35 meses & 63,2 & - & 51,5 & 42,5 & - & - & 35,1 & 13,3 & 16,1 \\
\hline Canadá & Haiek et al., 2007 & Transversal & 632 & 6 meses & 63,0 & 39,0 & 51,0 & 24,0 & 44,0 & 16,0 & 32,0 & 1,0 & - \\
\hline México & Flores et al., 2005 & Coorte & 291 & 0 a 6 meses & - & - & - & - & - & 14,0 & - & 2,0 & - \\
\hline Cuba & Díaz Tabares et al., 2001 & Transversal & 101 & 12 meses & 99,0 & 89,1 & 77,2 & 49,5 & 59,4 & 37,6 & 43,6 & 1,0 & 23,8 \\
\hline Chile & Ilabaca e Atalah, 2002 & Transversal & 490 & 0 a 12 meses & 98,0 & 71,0 & 96,0 & 60,0 & 91,0 & 57,0 & 80,0 & & 40,0 \\
\hline Argentina & Cernadas et al., 2003 & Coorte & 539 & 0 a 6 meses & - & 83,0 & - & - & - & 56,0 & 52,0 & 19,0 & - \\
\hline Uruguai & UNICEF, 2004 & Transversal & 2986 & 0 a 24 meses & - & 79,2 & - & 57,6 & - & 47,5 & & 31,9 & 53,9 \\
\hline Brasil & Sena et al., 2007 & Transversal & 10778 & 0 a 6 meses & 87,3 & 47,5 & - & - & 77,5 & 17,7 & 68,6 & 7,7 & - \\
\hline
\end{tabular}


Na Austrália, apesar de 91,7\% das mulheres estarem amamentando ao término da primeira semana pós-parto, apenas dois terços delas continuam aleitando e $31 \%$ praticam o AME aos quatro meses (Blyth et al., 2004). Imigrantes chinesas vivendo na Austrália, iniciam e mantêm o AM até o sexto mês na mesma proporção que as mulheres australianas, mas introduzem precocemente outros líquidos e sólidos na dieta do lactente jovem, repetindo o padrão cultural de seu país de origem (Li L et al., 2005).

O sucesso na amamentação está sem dúvida relacionado a fatores demográficos, o que pode ser evidenciado na Europa, onde se percebe 0 impacto da imigração e busca de asilo político. Na Holanda, quando avaliado o padrão dietético em relação a origem étnica da mãe, baseada no idioma falado por ela, mulheres fluentes em outras línguas européias que não a holandesa, têm maiores taxas de iniciação e continuação do AM (BulkBunschoten et al., 2008). A Suécia é reconhecida por apresentar altas prevalências de AM e AME. O acompanhamento de 147 lactentes demonstra que todos são exclusivamente amamentados desde o nascimento até 16 semanas. Mas no 6. mês, apenas sete deles estão em AME e dois, desmamados (Aarts et al., 2003).

As últimas estatísticas revelam um aumento da freqüência de AM nos Estados Unidos. Pelo menos $71,4 \%$ dos lactentes são levados ao peito em algum momento. Embora na primeira semana, $63,4 \%$ deles estejam recebendo exclusivamente leite materno, no $3 . \circ$ e $6 .$. mês esses percentuais caem para $42,5 \%$ e $13,3 \%$ (Li R et al., 2005). Interessante ponderar que também nesse país, os aspectos étnicos e econômicos têm impacto sobre a 
amamentação (Bonuck et al., 2005). Entre afro-americanos, as taxas são menores, com apenas $51,1 \%$ dos lactentes tendo oportunidade de mamar ao peito (Li et al., 2003; Li R et al., 2005).

Apesar das civilizações hispânicas serem reconhecidamente próamamentação, uma característica das imigrantes latinas vivendo em solo norte-americano é a aculturação, ou seja, a assimilação de traços da cultura local, inclusive no que tange a alimentação (Libbus, 2000). Apenas 50,3\% das porto-riquenhas ali radicadas relatam amamentar (Anderson et al., 2004). Uma pesquisa qualitativa com famílias de descendentes, predominantemente mexicanos vivendo em Denver, demonstra que embora muitas das mulheres tenha a intenção de amamentar, o tempo de AM é curto (Bunik et al., 2006).

Apesar dos esforços governamentais em criar um programa específico para melhorar a saúde e nutrição de crianças de famílias pobres, no México, a prevalência de AM ainda é baixa. Mesmo em localidades rurais, a introdução precoce de outros alimentos é comum, e a proporção de lactentes que recebe o LH como fonte exclusiva de alimentação decresce de $50 \%$ aos cinco dias para $14 \%$ aos quatro meses, e para $2 \%$, aos seis (Flores et al., 2005).

Pesquisa descritiva realizada em Cuba, envolvendo 101 lactentes com um ano de idade, demonstra que todos são inicialmente amamentados, e $24 \%$ deles continuam em AM ao completar o 1. aniversário (Díaz Tabares et al., 2001). 
$\mathrm{Na}$ América do Sul, o aumento de taxas de AM também têm sido observadas, especialmente no Chile, Argentina e Uruguai (Ilabaca e Atalah, 2002a; Cernadas et al., 2003; UNICEF, 2004). No Brasil, tem-se notado uma tendência de aumento da prática da amamentação. Entre 1989 e 1996, a prevalência do AM entre menores de quatro meses aumentou de $73,5 \%$ para $85,4 \%$, e entre menores de doze meses passou de $27,5 \%$ para $37,1 \%$. Entre 1996 e 1999, a duração mediana do AM subiu de sete para dez meses (Réa, 2003a).

As taxas de amamentação são discretamente mais elevadas na zona rural que na urbana brasileira, respectivamente $60 \%$ contra $58 \%$ entre lactentes de zero a seis meses, e $39 \%$ contra $34 \%$ entre os de sete a 12 meses. Essas diferenças têm diminuído de modo substancial nas últimas décadas (Wenzel, 2008). Especificamente na área urbana, a freqüência de AM é aceitável, mas a de AME, é preocupante. Ao serem comparadas as prevalências de $A M$ e $A M E$, há redução de $21 \%$ e $84 \%$, quando medidas respectivamente no 1. e e no $6 .$. mês de vida (Sena et al., 2007a).

Sabe-se que o AM está sujeito a pressões econômicas e sociais, assim, a mulher que escolhe amamentar precisa de apoio da família, comunidade e sociedade para atingir seu objetivo e dar ao seu filho o melhor início de vida. No sentido de salvaguardar a infância, são necessárias políticas públicas de saúde capazes de promover uma mudança de comportamento em relação à alimentação infantil, através da utilização de mensagens claras, com informações consistentes sobre AM e AME, prevendo ações factíveis de serem desenvolvidas com os recursos 
disponíveis, e coerentes com a cultura da população (Cattaneo et al., 2000; Bhandari et al., 2005). Mas, para uma melhor elaboração e execução dessas estratégias, há de se fazer primeiro uma avaliação da realidade em amamentação em cada local, conhecendo sua prevalência e duração através de pesquisas (Cattaneo et al., 2000).

Há grande dificuldade na avaliação dos resultados de pesquisas em amamentação, em função da multiplicidade de indicadores, definições e métodos utilizados nas suas realizações.

\subsection{Pesquisas e amamentação}

Sendo parte do processo de desenvolvimento de um saber, a pesquisa embasa uma tomada de decisão e permite um exercício profissional responsável (Hewat, 1998; Massad et al., 2004). Pesquisa em amamentação não é diferente. Não seriam as bases para a prática e a educação em AM apenas a intuição, a experiência pessoal, a paixão ou a tradição, mas sim conhecimentos gerados ou validados a partir de dados coletados e interpretados através da sistematização de métodos (Hewat, 1998).

A metodologia quantitativa, caracterizada por objetividade, medidas e controles, é um tradicional método de pesquisa utilizada pelas ciências biológicas e sociais (Hewat, 1998). Instrumentos quantitativos são imprescindíveis para a gênese e teste de novas hipóteses (Massad et al., 2004), sendo a avaliação das práticas em saúde pública fundamental para o 
processo de tomada de decisão em intervenções populacionais (Habicht et al., 1999; Souza SB, 2008).

Os estudos descritivos servem para planejamento de serviços de saúde, e em especial, os estudos transversais ou de prevalência, que são mais rápidos, simples e baratos (Ilabaca e Atalah, 2002b; Pérez-Escamilla, 2008), são indicados para a determinação da freqüência do $A M$, consideradas amostras de tamanho apropriado (Leone, 2008). Nesse tipo de pesquisa, como os sujeitos são selecionados independentemente de estarem expostos a um fator de risco ou de apresentarem o evento em estudo, pode haver dificuldade em ser definida a causalidade (Massad et al., 2004; Souza JMP, 2008).

Embora um estudo de corte transversal não constitua, portanto, o desenho mais adequado para se determinar uma associação de causa e efeito na busca por fatores relacionados ao sucesso do AM (Leone, 2008), muitas pesquisas desse tipo estão descritas na literatura (Carvalhaes et al., 1998; Venancio et al., 2002; Vannuchi et al., 2005; França et al., 2007) e podem fornecer informações de boa qualidade (Issler, 1992).

Os resultados dos estudos epidemiológicos de prevalência, na maior parte das vezes, apresentam a razão de chances ("odds ratio") como a medida de estimativa de risco. Essa prática pode ser decorrente da preferência dos autores ou da maior disponibilidade de programas de computador para o cálculo desse teste estatístico, especialmente para a criação de modelos de regressão logística. Entretanto, para esse tipo de pesquisa, julga-se ser mais apropriada a avaliação direta da prevalência 
relativa ou razão de prevalência (Zochetti et al., 1997; Barros e Hirakata, 2003; Petersen e Deddens, 2008).

A razão de prevalência $(\mathrm{RP})$, que afere a prevalência do evento nos expostos em relação à prevalência no grupo não exposto, é uma medida de risco só passível de ser estimada em pesquisas de delineamento transversal (Massad et al., 2004). Embora não seja errada a utilização da razão de chances, observa-se que essa superestima a RP em situações em que o desfecho se apresenta com elevada prevalência (Zochetti et al., 1997; Barros e Hirakata, 2003; Petersen e Deddens, 2008).

Tal como citado anteriormente, grande parte dos estudos publicados não definem claramente as categorias de AM utilizadas. Para melhor caracterizar os tipos de $\mathrm{AM}$, o respeito às recomendações formuladas pelo Grupo de Trabalho em AM da OMS em 1991, que define indicadores e uma metodologia específica para avaliar as práticas da amamentação, têm sido sugerido. A uniformização, a partir da utilização desses indicadores-chave da amamentação e dos artifícios próprios para avaliá-los, permite o acompanhamento da situação do AM em determinado local, trazendo assim a possibilidade de serem realizadas futuras comparações, não só em um mesmo país, mas entre regiões distintas (OPAS/OMS, 1991; Giugliani, 1998; Vieira et al., 1998).

A padronização é a grande vantagem da utilização dos indicadores recomendados pela OMS (Anexo A) e do "status quo", o qual valoriza a idade atual da criança e as informações alimentares nas 24 horas anteriores à coleta dos dados. Mas serve também para a prevenção de erros 
decorrentes da imprecisão dos dados recuperados da memória do informante (Engebretsen et al., 2007). No entanto, deve ser reconhecido que a utilização de recordatório alimentar de 24 horas pode superestimar a prevalência de $\mathrm{AM}$, embora seja útil para o diagnóstico rápido dos determinantes da amamentação (Aidam et al., 2005; Engebretsen et al., 2007).

Um aspecto interessante sobre a investigação científica na área da lactação humana é que o AM está presente em todos os países, e apesar das práticas de alimentação infantil variarem enormemente entre as diversas culturas ao redor do mundo, alguns fatores que afetam direta ou indiretamente a amamentação são comuns a vários locais (Heinig, 2001; Wenzel, 2008).

Os levantamentos sobre aleitamento natural podem ser realizados em grande escala, com dados representativos de um país ou continente, mas a maior parte dos estudos publicados dizem respeito às tendências locais ou regionais do padrão de $\mathrm{AM}$, envolvendo apenas segmentos específicos da população de uma cidade ou região (Wenzel, 2008).

É bem conhecida a dificuldade de estabelecimento de um padrãoouro para avaliação nutricional de populações (Sales et al., 2006). A realização de inquéritos domiciliares é uma estratégia desde há muito empregada em pesquisas na área tanto de sociologia como de epidemiologia. Existem registros brasileiros já das primeiras décadas do século 20 , demonstrando a utilização desse tipo de estudo como fonte de obtenção de dados sócio-demográficos e epidemiológicos (Barata, 2006). 
O diagnóstico das práticas de amamentação pode ser efetivado por meio de inquéritos populacionais, nos quais uma porção representativa das crianças é estudada no próprio domicílio (Wayland, 2004). Em função do emprego de métodos mais apurados, elevado tempo de aplicação e necessidade de profissionais experientes em todas as fases da investigação, levantamentos abrangentes sobre consumo alimentar em domicilio têm alto custo operacional e são de difícil reprodução (Sales et al., 2006).

Assim, para se investigar a prevalência do AM em municípios brasileiros, de forma rápida e com um custo relativamente baixo, muitos trabalhos têm sido realizados com a coleta de dados na Campanha Nacional de Multivacinação. A escolha desse momento é compreensível, já que em um curto período há acesso a um grande número de lactentes, tornando a pesquisa operacionalmente mais prática (Venancio et al., 2002; Audi et al., 2003; Camilo et al., 2004; Vieira et al., 2004; Carvalhaes et al., 2007; Silva et al., 2007).

Quando a cobertura vacinal obtida durante a campanha é alta, a utilização de estratégias para diminuir o risco de perda de crianças menores de um ano é adotada, e uniformidade e confiabilidade na coleta de dados são garantidas, esse tipo de investigação é vista como bastante adequada (Venancio, 2002).

Considerando a importância da amamentação, especialmente de maneira exclusiva, para a sobrevivência, o desenvolvimento e o crescimento infantil, e que para a elaboração de programas efetivos de estímulo ao aleitamento natural é imprescindível conhecer a realidade de cada local, 
justifica-se a necessidade de se determinar a situação do AM no primeiro ano de vida no município de Joinville (SC). 
2. OBJETIVOS 


\section{OBJETIVOS}

\subsection{GERAL:}

? Determinar a prevalência do AM entre os lactentes menores de um ano de idade no município de Joinville (SC).

\subsection{ESPECÍFICOS:}

?? Caracterizar o tipo de aleitamento entre os lactentes menores de um ano de idade.

?? Verificar a prevalência do AME em lactentes com idade inferior a 4 e 6 meses.

?? Descrever a freqüência de utilização de chupetas e mamadeiras entre os lactentes menores de um ano de idade.

?? Estudar a associação entre a ausência do AME e variáveis maternas, do lactente e de assistência de saúde em lactentes menores de 6 meses de vida. 
3. METODOLOGIA 


\section{MÉTODOS}

\subsection{Delineamento do estudo}

Trata-se de um estudo transversal, do tipo inquérito populacional, cuja coleta de dados foi realizada na Campanha Nacional de Vacinação, em agosto de 2005, entre as mães ou responsáveis por crianças menores de um ano de idade que compareceram aos postos de vacinação do município de Joinville (SC).

Esta metodologia, utilizando dados da população de lactentes imunizados nos Dias Nacionais de Vacinação, passou a ser muito empregada nos últimos anos, já tendo sido validada em pesquisas populacionais realizadas anteriormente em municípios brasileiros, sob orientação dos pesquisadores do "Projeto Amamentação e Municípios" do Instituto de Saúde da Secretaria Estadual de Saúde de São Paulo (ISSESSP). Desde 1998, quando esse projeto foi implantado, o IS-SESSP vem trabalhando na assessoria para realização de pesquisas em campanha de vacinação, dentro e fora do estado de São Paulo (Venancio, 2002).

Em Joinville (SC), esta estratégia é adequada devido à alta cobertura obtida em campanhas em anos anteriores, e atingindo $99 \%$ das crianças menores de cinco anos em ambas as etapas da Campanha de Vacinação de 2005.

Sendo parte de Projeto de Pesquisa de Demanda Interna da PróReitoria de Pesquisa e Pós-Graduação da Universidade da Região de 
Joinville (UNIVILLE), denominado "Freqüência e determinantes do aleitamento materno no município de Joinville, SC: subsídios para a efetivação de práticas promotoras de saúde", essa pesquisa foi autorizada pelo Instituto de Saúde/SES/SP e pela Secretaria Municipal de Saúde de Joinville, tendo sido aprovada pelo Comitê de Ética em Pesquisa da UNIVILLE e Comissão de Ética para Análise de Projetos de Pesquisa (CAPPesq) da Faculdade de Medicina da Universidade de São Paulo (USP) (Apêndices).

\subsection{Características gerais do local de estudo}

Joinville é a maior cidade do estado de Santa Catarina, atualmente com uma população de 490.000 habitantes; localizada na região norte do estado, encontra-se a $180 \mathrm{~km}$ de Florianópolis e $135 \mathrm{~km}$ de Curitiba (PR). É uma cidade com economia baseada na indústria metalúrgica e têxtil. Possui um conjunto de indicadores sociais que mostram um bom padrão de qualidade de vida, sendo o décimo terceiro colocado no Índice de Desenvolvimento Humano no Brasil, e apresentando alguns indicadores de saúde semelhantes aos de países desenvolvidos, como coeficiente de mortalidade infantil de 7,4 por mil e esperança de vida de 76 anos (SMS, 2008).

O número de crianças nascidas vivas em 2007 foi de 7137, ocorrendo $49,5 \%$ de partos por via alta, com um índice de recém-nascidos de baixo peso de $7,5 \%$. A proporção de mulheres com sete ou mais consultas de pré-natal foi de $72,1 \%$ (SMS, 2008). 
Os serviços de saúde pública são regionalizados e hierarquizados segundo o Sistema Único de Saúde (SUS). O SUS-Joinville é composto pelos serviços de vigilância à saúde, pela rede assistencial básica (unidades básicas de saúde), de referência (ambulatórios especializados e hospitais), e pelo sistema de atenção médica de emergência. A atenção básica consta, atualmente, com uma rede de 56 unidades básicas de saúde, com 36 equipes do Programa Saúde da Família (PSF), das quais cinco possuem equipes de Saúde Bucal. Das 20 unidades que funcionam segundo o modelo convencional, 14 delas agregam à equipe 0 trabalho de agentes comunitários de saúde. A cobertura populacional da Estratégia de Saúde da Família e da Estratégia de Agentes Comunitários de Saúde é de 75,7\%, assistindo respectivamente a 32,9\% e $42,8 \%$ da população joinvilense (SMS, 2008).

Há um conjunto de serviços ambulatoriais e hospitalares que realizam atenção especializada e oferecem suporte no diagnóstico e tratamento de doenças e condições específicas. Além disso, há três ProntoAtendimentos que funcionam 24 horas. A rede hospitalar pública compreende três hospitais, dois de atendimento geral e uma maternidade, a Maternidade Darcy Vargas (MDV), que é um "Hospital Amigo da Criança" desde 1994 e dispõe de banco de leite humano. Existem, também, quatro hospitais particulares, sendo dois deles conveniados ao SUS (SMS, 2008).

Nos últimos 15 anos, muitas atividades de promoção e apoio ao AM têm sido desenvolvidas no município, tais como a organização regular de 
cursos de manejo da lactação e comemoração anual da Semana Mundial de AM.

\subsection{População de estudo e plano amostral}

Baseado nos dados do Sistema de Informação de Nascidos Vivos (SINASC) de Joinville em 2003 e nas projeções populacionais realizadas no município, estima-se que a população infantil menor de um ano de idade seja cerca de 7.000 crianças.

Para este porte de município, a coleta de dados é feita por meio de uma amostra por conglomerados, com cerca de 1000 a 1500 crianças (n), visando obter número mínimo de 300 crianças menores de quatro meses.

De posse dos dados do mapa da $1^{\text {a }}$. fase do Dia Nacional de Vacinação do ano 2005, e considerando que o número de crianças é diferente nos diversos postos de vacinação (conglomerados), a amostra foi selecionada mediante sorteio em duas etapas, com probabilidade proporcional ao tamanho dos conglomerados.

Na primeira etapa, foram sorteados os postos de vacinação. Todos os postos do município foram arrolados segundo a ordem do mapa de vacinação de 2005. O número de crianças vacinadas segundo o mapa de vacinação, ou seja, o tamanho de cada posto, foi organizado em intervalos de números acumulados até o total de elementos. Seguiu-se o sorteio sistemático de N/a (número de crianças por número de postos desejados), identificando-se os números sorteados e os respectivos postos. Foram 
selecionados 29 conglomerados, sendo que um dos postos, com grande número de crianças a vacinar, foi sorteado mais de uma vez (Quadro 1).

Na segunda etapa, o sorteio foi desenvolvido na própria fila de vacinação de cada posto escolhido. Definiu-se o intervalo através da razão entre o número de crianças atendidas no posto em 2005 e o número de crianças desejadas para a amostra por posto (Quadro 1). Esperava-se pelo menos 40 crianças por posto ou 80 , caso ele tivesse sido sorteado duas vezes. O sorteio da primeira criança para iniciar a coleta de dados em cada posto, foi realizado pela equipe de entrevistadores no próprio local. Para permitir a padronização dos registros e evitar a perda de sujeitos na fila de vacinação, garantindo a confiabilidade dos dados obtidos, os lactentes alvo foram identificados com adesivos coloridos e um formulário para anotação das crianças vacinadas foi preenchido (Anexo B). Cada posto de vacinação recebeu um formulário específico, baseado na fração amostral a ser respeitada naquele local. Nos campos claros foi registrada a letra "X" a cada lactente vacinado com idade inferior a um ano. Nos campos escuros, foi anotada a letra "E", que correspondia às crianças cujos acompanhantes deviam ser entrevistados. Caso houvesse recusa em participar da pesquisa por parte do acompanhante, era marcada a letra "R" e o próximo da fila devia ser entrevistado (Anexo B).

Para o presente estudo adotou-se processo de amostragem probabilística, onde todos os elementos da população têm a mesma chance de serem sorteados. A probabilidade de um elemento pertencer a amostra é 
dada por n/N (1200/7000), que é a proporção dos elementos da população que serão observados, representada por $f$ (fração amostral=1/6).

Quadro 1 - Processo de Amostragem por sorteio dos postos de vacinação e das crianças na fila, Joinville (SC), 2005

\begin{tabular}{|c|c|c|c|c|c|}
\hline$\angle O C A L$ & REGIONAL & TIPO & $\begin{array}{c}\text { Total de vacinados } \\
\text { (1ํㅡㄹ etapa } 2005)\end{array}$ & $\begin{array}{l}\text { Fração } \\
\text { amostral }\end{array}$ & Pulo \\
\hline PS Aventureiro I & Aventureiro & Posto & 171 & $1 / 4$ & 1 sim 3 não \\
\hline PS Parque Joinville & Aventureiro & Posto & 146 & $1 / 3$ & 1 sim 2 não \\
\hline PS CSU Iririu & Aventureiro & Posto & 134 & $1 / 3$ & 1 sim 2 não \\
\hline PSF Santa Barbara & Aventureiro & PSF & 59 & todas & todas \\
\hline PS Boa Vista & Boa Vista & Posto & 205 & $1 / 2$ & 1 sim 1 não \\
\hline PS Jardim Iririu & Boa Vista & Posto & 140 & $1 / 3$ & $1 \operatorname{sim} 2$ não \\
\hline PSF Dom Gregório & Boa Vista & PSF & 115 & $1 / 2$ & 1 sim 1 não \\
\hline PS PSF CAIC Espinheiros & Boa Vista & PSF & 69 & todas & todas \\
\hline PS PAM Bucarein & Centro & Posto & 119 & $1 / 3$ & 1 sim 2 não \\
\hline PS Morro do Meio & Centro & Posto & 60 & todas & todas \\
\hline PS Costa e Silva & Costa e Silva & Posto & 233 & $1 / 3$ & 1 sim 2 não \\
\hline PS Bom Retiro & Costa e Silva & Posto & 119 & $1 / 3$ & $1 \operatorname{sim} 2$ não \\
\hline PS Willy Schossland & Costa e Silva & Posto & 40 & todas & todas \\
\hline PS Fatima & Fatima & Posto & 200 & $1 / 5$ & 1 sim 4 não \\
\hline PS Petrópolis & Fatima & Posto & 184 & $1 / 4$ & 1 sim 3 não \\
\hline PS CSU Itaum & Fatima & Posto & 93 & $1 / 2$ & 1 sim 1 não \\
\hline PS Floresta & Floresta & Posto & 136 & $1 / 4$ & 1 sim 3 não \\
\hline PS Boehmerwaldt II & Floresta & Posto & 76 & todas & todas \\
\hline PS Itinga & Floresta & Posto & 71 & todas & todas \\
\hline PS Jarivatuba & Jarivatuba & Posto & 199 & $1 / 4$ & 1 sim 3 não \\
\hline PS Adhemar Garcia & Jarivatuba & Posto & 148 & $1 / 3$ & 1 sim 2 não \\
\hline PSF Estevao de Matos & Jarivatuba & PSF & 123 & $1 / 3$ & 1 sim 2 não \\
\hline PSF Paranaguamirim & Jarivatuba & PSF & 119 & $1 / 3$ & 1 sim 2 não \\
\hline Escola Amador Aguiar & Jarivatuba & Equipe & 48 & todas & todas \\
\hline PS Rio Bonito & Pirabeiraba & Posto & 36 & todas & todas \\
\hline Unidade Sanitaria Central & Unidade Sanitaria & Equipe & 50 & todas & todas \\
\hline PS Vila Nova & Vila Nova & Posto & 114 & $1 / 2$ & 1 sim 1 não \\
\hline PS Glória & Vila Nova & Posto & 62 & todas & todas \\
\hline
\end{tabular}

A fração amostral $f$ decomposta manteve-se constante a partir da expressão: $f=f_{1} \cdot f_{2}$, onde:

$f_{1}$ corresponde à fração amostral do primeiro sorteio (postos de vacinação)

$f_{2}$ corresponde à fração amostral do segundo sorteio (crianças do posto) 
Desta forma, os postos maiores tiveram maior probabilidade de serem sorteados na primeira etapa, e as crianças dos postos menores tiveram maior probabilidade de sorteio na segunda, caracterizando uma amostra eqüiprobabilística ou autoponderada (Kalton, 1983; Silva, 1998; Venancio, 2002).

\subsection{Coleta de dados}

Os pesquisadores da equipe do projeto foram habilitados pelo ISSESSP no primeiro semestre de 2005. O curso de treinamento, com duração de oito horas, visava a capacitação para a coleta de dados no município, com orientações sobre a metodologia de pesquisa, amostragem, capacitação de supervisores de campo e entrevistadores. Três alunos do Curso de Medicina da UNIVILLE foram recrutados e selecionados como bolsistas de iniciação científica, e capacitados para atuarem como supervisores da pesquisa.

Durante a primeira etapa da Campanha de Vacinação, em junho de 2005, foi realizado um estudo-piloto, em condições idênticas às da pesquisa oficial, com intuito de avaliar as condições de campo.

Além disso, foram arregimentados e treinados alunos de cursos superiores e técnicos da área da saúde existentes no município, assim como enfermeiras, auxiliares de enfermagem e agentes comunitários para atuarem como entrevistadores. Para garantir uniformidade de abordagem no inquérito aplicado na fila de vacinação, e confiabilidade nos resultados obtidos, além do treinamento intensivo, foi utilizado material escrito para orientar estes 
participantes (Manual de supervisores e de entrevistadores do "Projeto Amamentação e Municípios") (Apêndices) (Venancio, 2002). Foi fornecido certificado de participação a todos eles.

Estimou-se a necessidade de treinar dois entrevistadores para cada 50 crianças menores de um ano; três entrevistadores para postos nos quais foi previsto um número maior que 50 crianças e $20 \%$ a mais de pessoas para repor possíveis faltas. Julgou-se importante treinar as enfermeiras, bem como os auxiliares de enfermagem das salas de vacinas de todos os postos de vacinação participantes. Foram treinados 207 entrevistadores.

As entrevistas foram realizadas após assinatura de consentimento informado (Anexo C). O instrumento de coleta de dados consistiu de questionário com perguntas fechadas, em sua maioria, sobre a alimentação da criança nas 24 horas precedentes, seguindo a recomendação da OMS (1991) para levantamentos sobre amamentação (Anexo D). Pretendeu-se, dessa forma, evitar erros decorrentes da memória do informante. Além disso, foram incluídos dados sobre características sócio-demográficas maternas e sobre a assistência de saúde. Um bloco de questões se referia especificamente a informações maternas, assim essas perguntas foram aplicadas somente se o acompanhante fosse a mãe da criança. As perguntas relativas ao consumo de alimentos investigavam a utilização de leite materno, outros leites, água, chás e suco de frutas, bem como de alimentos complementares transicionais e comida da família (SBP, 2006). Outros alimentos, que eventualmente fizessem parte do cardápio da criança, 
também foram investigados, tais como biscoitos, "salgadinhos", queijo tipo petit-suisse, refrigerantes, etc...

\subsection{Definições}

As definições de aleitamento materno utilizadas foram aquelas recomendadas pela OMS (OPAS/OMS, 1991).

Aleitamento Materno: a criança recebe leite materno associado ou não a outros leites, líquidos, alimentos sólidos ou semi-sólidos.

Aleitamento Materno Exclusivo: o lactente é alimentado exclusivamente com leite humano, diretamente do peito ou ordenhado, e não recebe nenhum outro líquido ou sólido, com exceção de vitaminas, suplementos minerais ou medicamentos.

Aleitamento Materno Predominante: o lactente recebe leite materno, mas também água, chás, suco de frutas ou fluidos rituais.

Alimentação em Mamadeira: é aquela recebida por lactentes cujos alimentos e líquidos são oferecidos em mamadeira.

Uso de Bico ou Chupeta: diz respeito aos lactentes que os utilizam.

\subsection{Variáveis do estudo e sua operacionalização}

\subsubsection{Variável dependente:}

\subsubsection{Aleitamento Materno Exclusivo}

\subsubsection{Variáveis independentes:}

\subsubsection{Aspectos relacionados ao lactente:}


a) Idade: calculada a partir da data de nascimento e categorizada em < 90 dias e ? 90 dias.

b) Sexo: classificado em masculino ou feminino.

c) Peso ao nascimento: coletado da carteira de vacinação do lactente, apresentado em gramas (g) e categorizado em $<2.500$ e $? 2.500 \mathrm{~g}$.

d) Ordem de nascimento: é o número de ordem de nascimento do lactente em questão, classificado em primeiro filho ou não.

e) Uso de chupeta: diz respeito a utilização de chupeta; categorizado em sim ou não.

\subsubsection{Aspectos maternos:}

a) Idade da mãe: apresentada em anos completos e categorizada em <20, 20-25, 26-35 e >35 anos.

b) Escolaridade materna: apresentada em anos completos e classificada em até 4 anos, 5-8 anos, 9-11 anos e 12 anos ou mais.

c) Trabalho materno: categorizado o trabalho atual fora do lar como sim ou não.

3.6.2.3 Aspectos relacionados à assistência de saúde:

a) Tipo do parto: classificado em vaginal ou cesariana. 
b) Local de nascimento do lactente: categorizado como sendo em "Hospital Amigo da Criança" ou outro.

c) Local de atendimento do lactente: classificado em atendimento em serviço público ou privado.

d) Profissional responsável pelo atendimento de puericultura: categorizado em Pediatra ou NãoPediatra.

\subsection{Processamento e análise dos dados}

Os dados foram armazenados em microcomputador do tipo PC, com o uso do software AMAMUNIC 2.0, desenvolvido pelos pesquisadores do "Projeto Amamentação e Municípios" do IS-SESSP. O banco de dados foi complementado e teve sua consistência revisada através do uso do software EpiData Entry? v. 3.1. O estudo descritivo foi realizado com o software EpiInfo? v. $6.04 \mathrm{~b}$ e as análises univariada e multivariada de fatores de risco para a ausência do AME foram realizadas com o software STATA? 10.0 .

As variáveis relacionadas aos lactentes, às mães, à assistência de saúde e de práticas alimentares foram descritas através de proporções, médias e seus respectivos desvios-padrão. As estimativas principais foram as prevalências de AM e AME em faixas etárias com intervalos de 30 dias desde o nascimento, com destaque para os 4, 6 e 12 meses de idade, expressas em proporções e respectivos intervalos de confiança de 95\%.

Para avaliar possíveis associações entre o AM não-exclusivo até o sexto mês e as variáveis de interesse, foram calculadas as razões de 
prevalência e o intervalo de confiança de $95 \%$, obtidos pela regressão de Poisson. Todas as variáveis que se associaram à ausência do AME com nível de significância inferior a 0,10 na análise univariada, foram inseridas no estudo multivariado, ajustando-se assim, reciprocamente, de forma a permitir que fosse conhecido o efeito independente de cada uma delas. $\mathrm{O}$ modelo final incluiu apenas as variáveis independentes que mantinham associação com o desfecho em nível de significância inferior a 0,05 à análise multivariada. A regressão de Poisson tem sido considerada adequada para a definição da razão de prevalência em estudos transversais, tanto para análises univariadas quanto para a construção do modelo multivariado (Petersen e Deddens, 2008).

Considerando que supostamente a freqüência de uso de chupeta seja maior em lactentes mais jovens, o que poderia levar a interferência da idade sobre o uso de chupeta, foi estudada a ocorrência de interação entre uso de chupeta e idade das crianças sobre o AME. Esta análise foi realizada através do likelihood-ratio test (ou teste de razão de verossimilhança) enquanto eram comparados dois diferentes modelos de regressão, um considerando a existência e outro a inexistência de interação (Anexo E). 
4. RESULTADOS 


\section{RESULTADOS}

\subsection{Características da amostra estudada}

O inquérito populacional desenvolvido baseou-se em 1470 entrevistas, cuja maioria $(88,2 \%)$ foi realizada com as mães dos lactentes. A população de estudo constituiu-se então, de 1470 lactentes com idade inferior a um ano, sendo $50,0 \%$ do sexo masculino e $50,0 \%$ do sexo feminino.

A tabela 2 apresenta algumas características da população de estudo e sua distribuição conforme as categorias definidas.

A faixa de peso variou entre $940 \mathrm{~g}$ e $5450 \mathrm{~g}$, com média de $3209 \mathrm{~g}$ (DP $=? 537,3 \mathrm{~g})$. A idade oscilou entre dois e 364 dias, com média de 165 dias $(\mathrm{DP}=? 102,5$ dias). A maior parte dos lactentes $(52,3 \%)$ tinha irmãos vivos. As chupetas e mamadeiras foram utilizadas, respectivamente, por $51,3 \%$ e $51,1 \%$ dos lactentes. De todas as 744 crianças que usavam mamadeira, apenas $5(0,7 \%)$ recebiam leite materno ordenhado como única fonte de alimentação.

A idade materna variou de 14 a 47 anos, com uma média de 26,6 anos ( $\mathrm{DP}=$ ? 6,5 anos). No que diz respeito à ocupação materna, 52,9\% trabalhava fora do seu domicílio. O grau de instrução materno variou de analfabeta até educação superior completa, sendo que 90,6\% estudaram além da $4 .{ }^{\text {a }}$ série do ensino fundamental, com $13,5 \%$ cursando ou portando diploma de instituição de ensino superior. 
Tabela 2 - Características sócio-demográficas e de saúde da população estudada $(n=1470)$, Joinville, 2005

\begin{tabular}{|c|c|}
\hline VARIÁVEIS & $\mathrm{N}(\%)$ \\
\hline \multicolumn{2}{|l|}{ Sexo } \\
\hline Masculino & $735(50,0)$ \\
\hline Feminino & $735(50,0)$ \\
\hline \multicolumn{2}{|c|}{ Peso ao nascimento ${ }^{a}$ (gramas) } \\
\hline$<1500$ & $12(0,8)$ \\
\hline $1500-1999$ & $24(1,6)$ \\
\hline $2000-2499$ & $75(5,1)$ \\
\hline $2500-3000$ & $320(21,9)$ \\
\hline ? 3000 & $1027(70,4)$ \\
\hline \multicolumn{2}{|l|}{ Idade (dias) } \\
\hline$<120$ & $568(38,6)$ \\
\hline $120-179$ & $271(18,4)$ \\
\hline $180-299$ & $427(29,0)$ \\
\hline $300-364$ & $204(13,9)$ \\
\hline \multicolumn{2}{|c|}{ Ordem de Nascimento? ${ }^{\mathrm{b}}$ (1..$\left.^{\text {filho}}\right)$} \\
\hline Sim & $617(47,7)$ \\
\hline Não & $676(52,3)$ \\
\hline \multicolumn{2}{|c|}{ Uso de chupeta $^{\mathrm{C}}$} \\
\hline Sim & $753(51,3)$ \\
\hline Não & $715(48,7)$ \\
\hline \multicolumn{2}{|c|}{ Uso de mamadeira ${ }^{d}$} \\
\hline Sim & $744(51,1)$ \\
\hline Não & $712(48,9)$ \\
\hline \multicolumn{2}{|c|}{ Idade materna? ${ }^{\mathrm{e}}$ (anos) } \\
\hline$<20$ & $196(15.1)$ \\
\hline $20-25$ & $419(32.4)$ \\
\hline $26-35$ & 547 (42.3) \\
\hline ? 36 & $132(10.2)$ \\
\hline \multicolumn{2}{|c|}{ Escolaridade materna? ${ }^{\dagger}$ (anos) } \\
\hline ? 4 & $119(9,4)$ \\
\hline $5-8$ & $418(33,1)$ \\
\hline $9-11$ & $566(44,8)$ \\
\hline ? 12 & $160(12,7)$ \\
\hline \multicolumn{2}{|c|}{ Trabalho Materno? ${ }^{g}$} \\
\hline Do lar & $599(47,1)$ \\
\hline Informal & $249(19,6)$ \\
\hline Formal & $423(33,3)$ \\
\hline \multicolumn{2}{|l|}{ Tipo de parto ${ }^{\mathrm{h}}$} \\
\hline Vaginal & $796(54,3)$ \\
\hline Cesariana & $665(45,4)$ \\
\hline \multicolumn{2}{|c|}{ Local de Nascimento - HAC' } \\
\hline Sim & $1047(71,4)$ \\
\hline Não & $420(28,6)$ \\
\hline \multicolumn{2}{|c|}{ Local de Atendimento } \\
\hline PSF & $284(20,2)$ \\
\hline UBS & $605(43,1)$ \\
\hline Privado & $515(36,7)$ \\
\hline \multicolumn{2}{|c|}{ Profissional Responsável pela Puericultura ${ }^{k}$} \\
\hline Pediatra & $1114(79,3)$ \\
\hline Não-pediatra & $290(20,7)$ \\
\hline
\end{tabular}

? em 1296 entrevistas cujos informantes eram as mães; ${ }^{a} 12$ casos sem informação; ${ }^{b} 3$ casos sem informação; ' 2 casos sem informação; ${ }^{d} 14$ casos sem informação; ${ }^{\text {e }} 2$ casos sem informação; ${ }^{\dagger} 33$ casos sem informação; ${ }^{g} 25$ casos sem informação; ${ }^{h} 9$ casos sem informação; 3 casos sem informação; ${ }^{j} 66$ casos sem informação; ${ }^{k} 66$ casos sem informação. 
Ocorreram $54,3 \%$ de partos vaginais e $45,4 \%$ de cesarianas, com os nascimentos acontecendo em Hospital Amigo da Criança em 71,4\% dos casos. As consultas de puericultura foram realizadas em $63,3 \%$ das vezes na rede pública, e o pediatra foi o responsável pelo acompanhamento em $79,3 \%$ dos pacientes.

\subsection{Prevalência do AM}

Estimativas da freqüência do AM em função da idade dos lactentes com idade inferior a 12 meses são detalhadas na tabela 3 . O gráfico 1 evidencia a curva de AM nas idades selecionadas.

A imensa maioria dos lactentes foi amamentada nos dois primeiro meses de vida, respectivamente $96,6 \%$ e $94,6 \%$ deles. Houve um decréscimo progressivo nas taxas de AM ao longo dos intervalos etários seguintes. Essa proporção diminuiu para $83,0 \%$ aos 120 , para $72,9 \%$ aos 180 , e para $52,3 \%$ aos 365 dias.

Tabela 3 - Freqüência de AM e IC95\% por faixa etária em menores de 12 meses, Joinville, 2005

\begin{tabular}{lcccc}
\hline \multicolumn{5}{c}{$A M$} \\
Idade (dias) & $\mathbf{N}$ & $\%$ & IC 95\% & Total \\
$0-29$ & 115 & 96,6 & $91,6-99,1$ & 119 \\
$30-59$ & 140 & 94,6 & $89,6-97,6$ & 148 \\
$60-89$ & 128 & 86,5 & $79,9-91,5$ & 148 \\
$90-119$ & 127 & 83,0 & $76,1-88,6$ & 153 \\
$120-149$ & 110 & 71,9 & $64,1-78,9$ & 153 \\
$150-179$ & 86 & 72,9 & $63,9-80,7$ & 118 \\
$180-209$ & 78 & 64,5 & $55,2-73,0$ & 121 \\
$210-239$ & 63 & 63,6 & $53,4-73,1$ & 99 \\
$240-269$ & 59 & 54,1 & $44,3-63,7$ & 109 \\
$270-299$ & 54 & 55,1 & $44,7-65,2$ & 98 \\
$300-329$ & 48 & 51,6 & $41,0-62,1$ & 93 \\
$330-364$ & 58 & 52,3 & $42,6-61,8$ & 111 \\
\hline
\end{tabular}


Gráfico 1 - Distribuição do AM por faixa etária em menores de 12 meses em Joinville, 2005

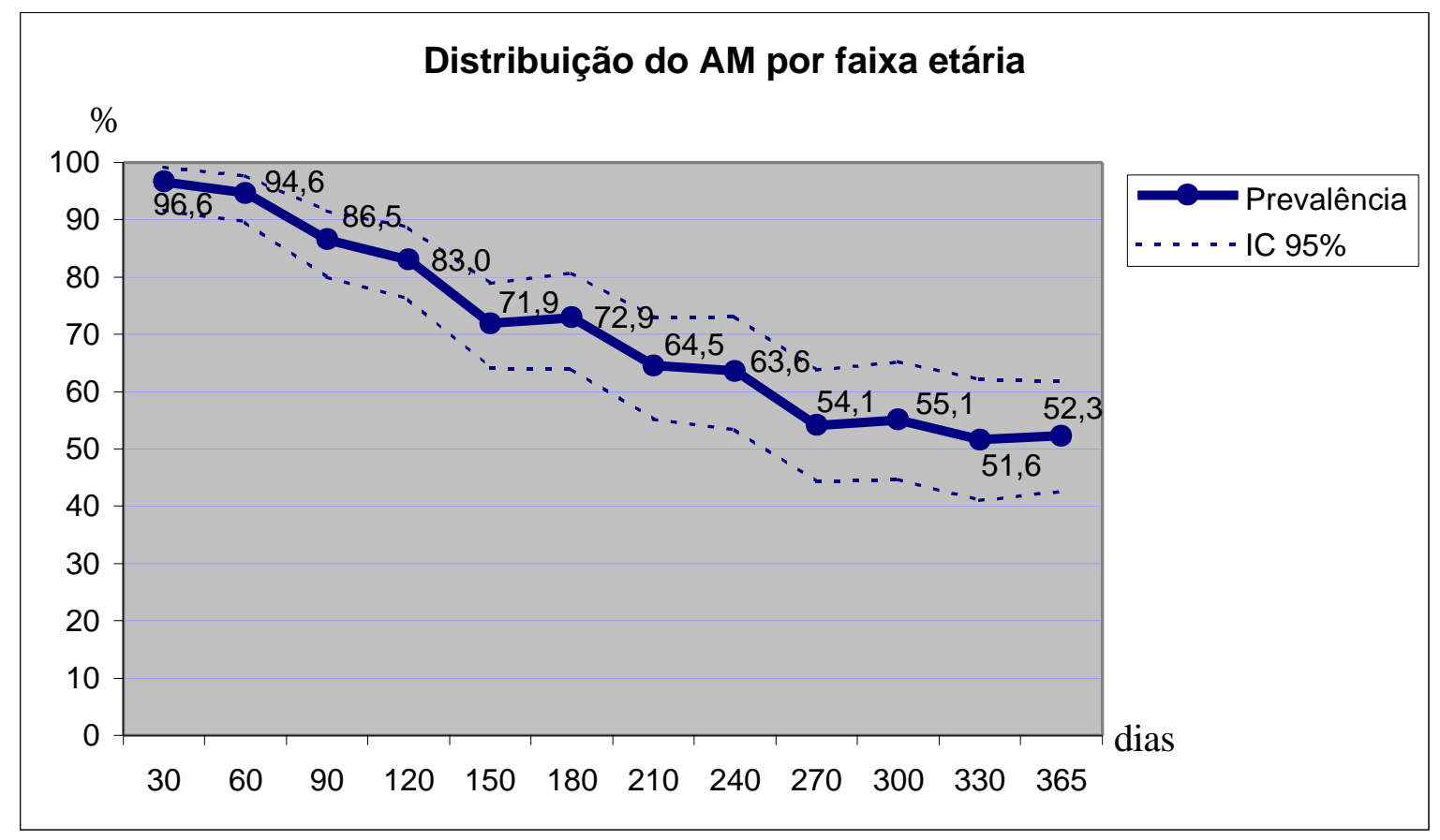

A tabela 4 apresenta a prevalência do AM, conforme as faixas etárias em crianças menores de 12 meses. Dos 1470 lactentes estudados, 1066 (72,5\%) estavam sendo amamentados nas 24 horas que antecederam a pesquisa. Entre os menores de seis meses e quatro meses, respectivamente $84,1 \%$ e $89,8 \%$ estavam em AM.

Tabela 4 - Prevalência do AM de acordo com a faixa etária, em menores de 12 meses, Joinville, 2005

\begin{tabular}{|c|c|c|c|}
\hline \multirow{3}{*}{ Modo de aleitamento } & \multicolumn{3}{|c|}{ Idade } \\
\hline & $<12$ meses & $<6$ meses & $<4$ meses \\
\hline & $\mathrm{N}(\%)$ & $\mathrm{N}(\%)$ & $\mathrm{N}(\%)$ \\
\hline \multicolumn{4}{|l|}{ AM } \\
\hline Sim & $1066(72,5)$ & $706(84,1)$ & $510(89,8)$ \\
\hline Não & $404(27,5)$ & $133(15,9)$ & $58(10,2)$ \\
\hline
\end{tabular}




\subsection{Prevalência do AME}

$\mathrm{Na}$ tabela 5, estão apresentadas as freqüências de utilização de LH exclusivo em determinadas faixas etárias nos menores de seis meses, com os respectivos intervalos de confiança (IC95\%). O gráfico 2 demonstra a curva de AME em função da idade para os mesmos lactentes.

O percentual de lactentes alimentados exclusivamente com LH é $71,2 \%$ no primeiro mês, mas ficou evidenciado um nítido decréscimo das prevalências no decorrer do primeiro semestre de vida. As taxas foram decrescendo ao longo de todas as faixas de idade, sendo que aos 120 dias, a proporção estimada foi $44,2 \%$ e, aos 180 dias, $13,3 \%$.

Tabela 5 - Freqüência de AME e IC95\% por faixa etária, em menores de seis meses, Joinville, 2005

\begin{tabular}{lcccc}
\hline \multicolumn{5}{c}{$A M E$} \\
\hline Idade (dias) & $\mathbf{N}$ & $\%$ & IC 95\% & Total \\
$0-29$ & 84 & 71,2 & $62,1-79,2$ & 118 \\
$30-59$ & 89 & 61,0 & $52,5-68,9$ & 146 \\
$60-89$ & 68 & 46,3 & $38,0-54,7$ & 147 \\
$90-119$ & 65 & 44,2 & $36,0-52,6$ & 147 \\
$120-149$ & 46 & 31,3 & $23,9-39,5$ & 147 \\
$150-179$ & 15 & 13,3 & $7,6-20,9$ & 113 \\
\hline
\end{tabular}

A tabela 6 demonstra a prevalência do AME, conforme as faixas etárias em crianças menores de seis meses. Entre os lactentes com idade inferior a seis meses e quatro meses, respectivamente $43,4 \%$ e $53,9 \%$ recebiam leite materno exclusivo. 
Gráfico 2 - Distribuição do AME por faixa etária em menores de seis meses em Joinville, 2005

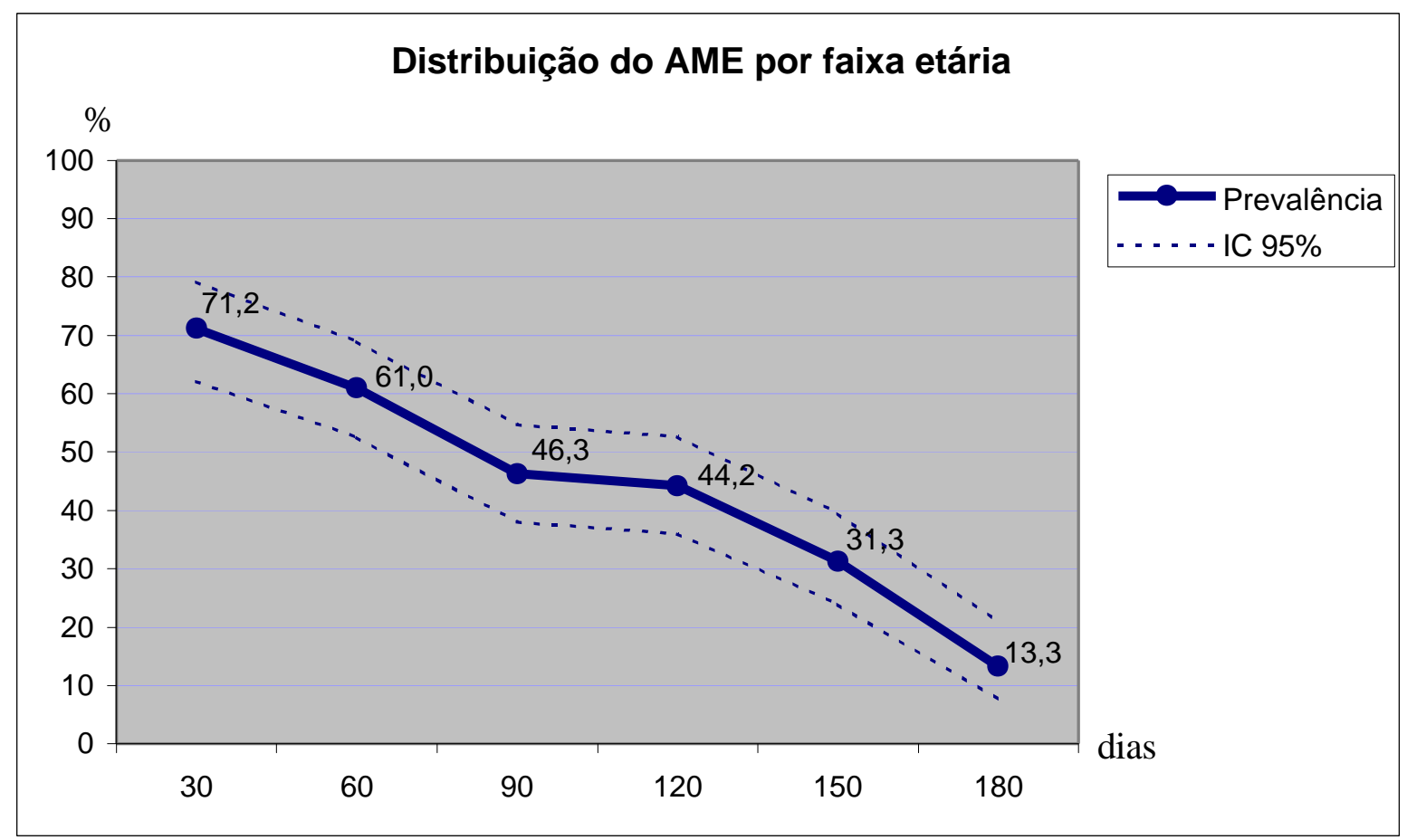

Tabela 6 - Prevalência do AME de acordo com a faixa etária, em menores de seis meses, Joinville, 2005

\begin{tabular}{lcccc}
\hline & \multicolumn{5}{c}{ Idade } \\
\cline { 2 - 5 } Modo de aleitamento & $<6$ & meses & $<4$ & meses \\
\cline { 2 - 5 } & $\mathrm{N}$ & $(\%)$ & $\mathrm{N}$ & $(\%)$ \\
\hline \multirow{2}{*}{ AME } & & & & \\
Sim & 367 & $(43,7)$ & 306 & $(53,9)$ \\
Não & 472 & $(56,3)$ & 262 & $(46,1)$ \\
\hline
\end{tabular}




\subsection{Estudo da associação das variáveis relacionadas ao lactente, à mãe e à assistência de saúde com a ausência de AME}

\section{Análise univariada}

A tabela 7 sumariza a influência das variáveis relacionadas aos lactentes, suas mães e à assistência de saúde sobre o AME.

A maior idade do lactente, a utilização de chupeta, o trabalho materno e a escolaridade materna mais baixa foram fatores significativamente associados ao aleitamento não-exclusivo entre os lactentes com idade inferior a seis meses $(p<0,001, p<0,001, p=0,036$ e $p=0,013)$

O likelihood-ratio test não evidenciou a ocorrência de interação entre o uso de chupeta e a idade das crianças sobre a freqüência de ausência de $\operatorname{AME}(p=0,479)$, o que permitiu a inclusão das duas variáveis no estudo multivariado (Anexo E).

\section{Análise multivariada}

A tabela 8 apresenta o modelo final, que foi reduzido às variáveis significativamente associadas ao AM não-exclusivo até o sexto mês: idade do lactente, uso de chupeta, escolaridade materna e trabalho materno $(p<$ $0,001, p<0,001, p=0,013$ e $p=0,218)$. 
Tabela 7 - Variáveis estudadas e sua associação com a ausência do AME, Joinville, 2005

\begin{tabular}{|c|c|c|c|c|c|}
\hline \multicolumn{6}{|c|}{$\underline{\mathrm{AME} \text { em lactentes }<6 \mathrm{~m}}$} \\
\hline VARIÁVEL & $\begin{array}{l}\text { Não } \\
\text { N (\%) }\end{array}$ & $\begin{array}{l}\operatorname{Sim} \\
N(\%)\end{array}$ & $\mathrm{RP}$ & IC 95\% & $\begin{array}{c}\text { Valor de } \\
\mathrm{P}\end{array}$ \\
\hline \multicolumn{6}{|l|}{ Idade (dias) } \\
\hline $\begin{array}{l}? 90 \\
<90\end{array}$ & $\begin{array}{l}281(69,0) \\
170(41,4)\end{array}$ & $\begin{array}{l}126(31,0) \\
241(58,6)\end{array}$ & $\begin{array}{l}1,67 \\
1,00\end{array}$ & $\begin{array}{c}\text { 1,38-2,02 } \\
---\end{array}$ & $<0,001$ ? \\
\hline \multicolumn{6}{|l|}{ Sexo } \\
\hline $\begin{array}{l}\text { Masculino } \\
\text { Feminino }\end{array}$ & $\begin{array}{l}228(55,9) \\
244(56,6)\end{array}$ & $\begin{array}{l}180(44,1) \\
187(43,4)\end{array}$ & $\begin{array}{l}0,97 \\
1,00\end{array}$ & $\begin{array}{c}0,81-1,17 \\
---\end{array}$ & 0,793 \\
\hline \multicolumn{6}{|c|}{ Peso de nascimento } \\
\hline $\begin{array}{l}<2500 \mathrm{~g} \\
? 2500 \mathrm{~g}\end{array}$ & $\begin{array}{r}37(66,1) \\
433(55,6)\end{array}$ & $\begin{array}{r}19(33,9) \\
346(44,4)\end{array}$ & $\begin{array}{l}1,21 \\
1,00\end{array}$ & $\begin{array}{c}\text { 0,86-1,70 } \\
---\end{array}$ & 0,255 \\
\hline \multicolumn{6}{|c|}{$\begin{array}{l}\text { Ordem de nascimento } \\
\text { (1..- filho) }\end{array}$} \\
\hline $\begin{array}{l}\text { Sim } \\
\text { Não }\end{array}$ & $\begin{array}{l}199(56,4) \\
210(53,3)\end{array}$ & $\begin{array}{l}154(43,6) \\
184(46,7)\end{array}$ & $\begin{array}{l}1,05 \\
1,00\end{array}$ & $\begin{array}{c}0,86-1,28 \\
---\end{array}$ & 0,595 \\
\hline \multicolumn{6}{|c|}{ Uso de chupeta } \\
\hline $\begin{array}{l}\text { Sim } \\
\text { Não }\end{array}$ & $\begin{array}{l}299(71,5) \\
171(40,8)\end{array}$ & $\begin{array}{l}119(28,5) \\
248(59,2)\end{array}$ & $\begin{array}{l}1,78 \\
1,00\end{array}$ & $\begin{array}{c}\text { 1,47-2,16 } \\
---\end{array}$ & $<0,001$ ? \\
\hline \multicolumn{6}{|c|}{ Idade materna (anos) } \\
\hline $\begin{array}{l}<20 \\
? 20\end{array}$ & $\begin{array}{r}60(56,6) \\
350(54,5)\end{array}$ & $\begin{array}{r}46(43,4) \\
292(45,5)\end{array}$ & $\begin{array}{l}1,04 \\
1,00\end{array}$ & $\begin{array}{c}\text { 0,79-1,38 } \\
---\end{array}$ & 0,733 \\
\hline \multicolumn{6}{|c|}{ Escolaridade materna (anos) } \\
\hline $\begin{array}{l}<12 \\
? 12\end{array}$ & $\begin{array}{r}362(57,4) \\
38(39,2)\end{array}$ & $\begin{array}{l}269(42,6) \\
59(60,8)\end{array}$ & $\begin{array}{l}1,00 \\
0,63\end{array}$ & 0,44-0,90 & $0,013 ?$ \\
\hline \multicolumn{6}{|c|}{ Trabalho Materno } \\
\hline $\begin{array}{l}\text { Sim } \\
\text { Não }\end{array}$ & $\begin{array}{r}81(66,4) \\
317(50,9)\end{array}$ & $\begin{array}{r}40(33,6) \\
290(49,1)\end{array}$ & $\begin{array}{l}1,30 \\
1,00\end{array}$ & $\begin{array}{c}1,01-1,66 \\
---\end{array}$ & $0,036 ?$ \\
\hline \multicolumn{6}{|l|}{ Tipo de parto } \\
\hline $\begin{array}{l}\text { Cesariana } \\
\text { Vaginal }\end{array}$ & $\begin{array}{l}210(56,6) \\
261(56,4)\end{array}$ & $\begin{array}{l}161(43,4) \\
202(43,6)\end{array}$ & $\begin{array}{c}0,97 \\
1,0\end{array}$ & $\begin{array}{c}\text { 0,81-1,16 } \\
---\end{array}$ & 0,744 \\
\hline \multicolumn{6}{|c|}{ Local de Nascimento - HAC } \\
\hline $\begin{array}{l}\text { Não } \\
\text { Sim }\end{array}$ & $\begin{array}{l}144(58,8) \\
328(55,4)\end{array}$ & $\begin{array}{l}101(41,2) \\
264(44,6)\end{array}$ & $\begin{array}{l}0,94 \\
1,00\end{array}$ & $\begin{array}{c}\text { 0,77-1,15 } \\
---\end{array}$ & 0.572 \\
\hline \multicolumn{6}{|c|}{ Local de Atendimento } \\
\hline $\begin{array}{l}\text { Privado } \\
\text { Público }\end{array}$ & $\begin{array}{l}160(55,9) \\
286(55,7)\end{array}$ & $\begin{array}{l}126(44,1) \\
228(44,3)\end{array}$ & $\begin{array}{l}0,99 \\
1,00\end{array}$ & $\begin{array}{c}\text { 0,81-1,21 } \\
---\end{array}$ & 0,953 \\
\hline \multicolumn{6}{|c|}{$\begin{array}{l}\text { Profissional Responsável } \\
\text { pela Puericultura }\end{array}$} \\
\hline $\begin{array}{l}\text { Não-pediatra } \\
\text { Pediatra }\end{array}$ & $\begin{array}{l}102(63,7) \\
344(54,4)\end{array}$ & $\begin{array}{r}66(39,3) \\
288(45,6)\end{array}$ & $\begin{array}{l}0,88 \\
1,00\end{array}$ & $\begin{array}{c}\text { 0,70-1,10 } \\
---\end{array}$ & 0,287 \\
\hline
\end{tabular}


Tabela 8 - Variáveis estudadas e sua associação com a ausência do AME, reciprocamente ajustadas, Joinville, 2005

\begin{tabular}{lccc}
\hline VARIÁVEL & RP bruto (IC 95\%) & & \\
\hline $\begin{array}{l}\text { Uso de chupeta } \\
\text { (sim vs não) }\end{array}$ & $1,69(1,37-2,09)$ & $<0,001$ & $?$ \\
$\begin{array}{l}\text { Idade } \\
\text { (meses) (<3 vs ?3) }\end{array}$ & $1,53(1,24-1,88)$ & $<0,001$ & $?$ \\
$\begin{array}{l}\text { Escolaridade materna } \\
\text { (anos) (<12 vs ?12) }\end{array}$ & $0,63(0,44-0,91)$ & 0,013 & $?$ \\
$\begin{array}{l}\text { Trabalho materno } \\
\text { (sim vs não) }\end{array}$ & $1,17(0,91-1,52)$ & 0,218 & NS \\
\hline
\end{tabular}

? significância estatística

NS ausência de significância estatística 
5. DISCUSSÃO 


\section{DISCUSSÃO}

A discussão dos resultados deste trabalho está dividida em quatro partes. Inicialmente, discorremos sobre a prevalência do AM e do AME. A seguir, examinamos cada uma das variáveis dependentes e sua associação com a ausência do AME em lactentes menores de 6 meses de vida. Por fim, apresentamos algumas considerações finais.

\subsection{Prevalência do AM}

Foi objetivo geral desse trabalho determinar a prevalência do AM entre os lactentes menores de um ano de idade no município de Joinville.

A tabela 9 apresenta o comportamento do AM ao longo dos meses no primeiro ano de vida, em alguns estudos brasileiros, em comparação com o nosso. Em Joinville, a prevalência do AM segundo a idade da criança foi de $96,6 \%$ no primeiro mês, $83,0 \%$ no quarto mês, $72,9 \%$ no sexto mês e 52,3\% ao completar o primeiro ano de vida. Esse declínio com o passar do tempo, também é observado na capital federal, considerados lactentes até o sexto mês de vida (Sena et al., 2002), bem como em 25 capitais brasileiras e no Distrito Federal, no ano de 1999 (Sena et al., 2007a). Mas chama atenção, que nossos índices são melhores que os encontrados na região nordeste do país, em três cidades mineiras, em São José do Rio Preto (SP), em Itupeva (SP), em Guarapuava (PR) e em Itaúna (MG) (Lima e Osório, 
2003; Silveira e Lamounier, 2004; Figueiredo et al., 2004; Minagawa et al., 2005; Gomes, 2005; Chaves et al., 2007).

Em outros estudos, realizados em Botucatu (SP), Campinas (SP), Rio Branco (AC) e Pelotas (RS), respectivamente apenas $26,7 \%, 33,3 \%, 38,0 \%$ e $39,0 \%$ das crianças estão sendo amamentadas ao completar o primeiro ano de vida (Carvalhaes et al., 1998; Camilo et al., 2004; Wayland, 2004; Victora et al., 2008).

Tabela 9 - Freqüência do AM de acordo com a faixa etária, em menores de 12 meses, na amostra de estudo em Joinville e em alguns trabalhos da literatura

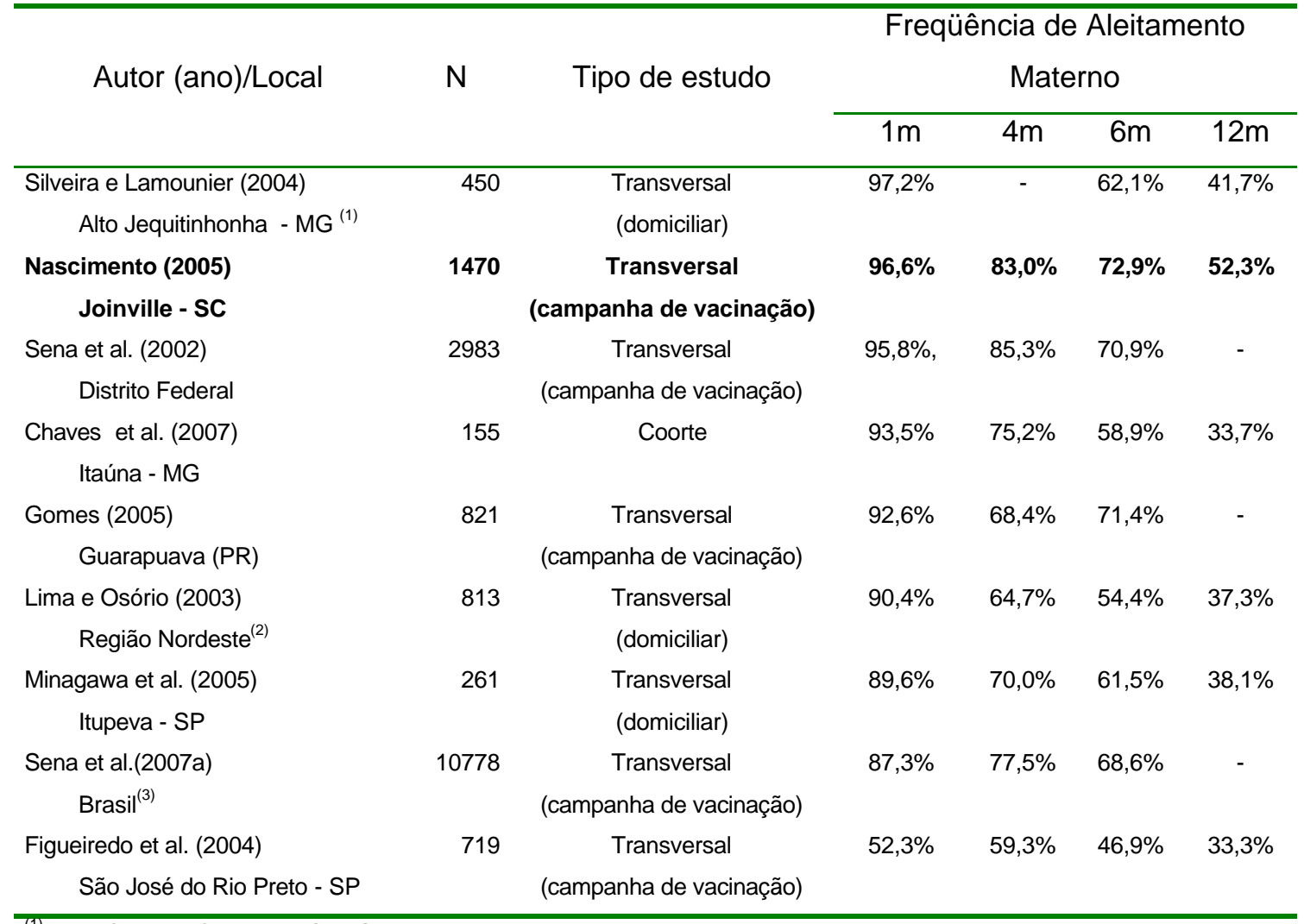

\footnotetext{
(1) Municípios de Carbonita, São Gonçalo do Rio Preto e Datas.

(2) Rio Grande do Norte, Paraíba, Pernambuco, Alagoas, Sergipe e Bahia.

(3) 25 capitais de estados brasileiros e Distrito Federal.
} 
Para tentar justificar as diferenças encontradas entre os índices de AM, deve ser lembrado que existem variações metodológicas e temporais entre as pesquisas comparadas. Algumas, como a nossa, trabalham com amostras de crianças vacinadas em campanhas de vacinação, originárias de diversos estratos sociais e econômicos. Outra diferença, está no tipo de instrumento empregado para a coleta das informações, posto que são descritos questionários semi-estruturados, do tipo utilizado em nosso estudo, ou o uso de dados secundários obtidos a partir de observações anteriores.

A época de realização da pesquisa também é importante, pois ao nos depararmos com as taxas de AM descritas no presente estudo, estamos diante de um fenômeno corrente no nosso país com um todo, que é o discreto, mas progressivo avanço na prática da amamentação. No que diz respeito a essa evolução da prática do $\mathrm{AM}$ no Brasil, alguns resultados da literatura merecem ser comentados. A Pesquisa Nacional de Demografia e Saúde (PNDS), realizada em 2006, traça um perfil da criança pequena e da mulher brasileira e confirma que as taxas de AM, apesar de abaixo do preconizado, vêm lentamente crescendo. Em crianças com idade inferior a três anos, a duração mediana da amamentação associada a outros alimentos aumenta de 7 meses, em 1996, para 9,3 meses, em 2006. As mamadas durante o primeiro dia de vida são mais comuns atualmente, beneficiando $99,5 \%$ dos recém-nascidos, contra 70,8\% deles contabilizados dez anos antes (MS, 2008).

De modo geral, tem sido observado aumento da freqüência do AM, com tendência de desmame mais tardio. Comparando-se dados brasileiros 
de três décadas, em um período de 25 anos entre 1974 e 1999, esse acréscimo é de $40 \%, 150 \%, 200 \%$ e $240 \%$, conforme a idade da criança é um mês, quatro, seis ou 12 meses de vida, respectivamente (Sena et al., 2007b). Mas continuam pesando as diferenças regionais e estaduais muito marcantes, exercendo influência importante sobre os indicadores sociais (MS, 2008). A avaliação de crianças com menos de dois anos detecta uma duração mediana do AM de apenas 112 dias no estado de Pernambuco, mas de 6,4 meses em Campinas (SP) (Camilo et al., 2004; Vasconcelos et al., 2006).

Embora a região Norte apresente a maior prevalência de AM nas diferentes idades, a região Sul destaca-se com as maiores freqüências de AME (Sena et al., 2007a). Considerada a faixa de zero a seis meses de idade, a região Sudeste tem prevalência de $\mathrm{AM}$ de $51 \%$. Já para a faixa dos sete a doze meses, a região Centro-Oeste demonstra prevalência de $28 \%$. Estas são as mais baixas prevalências de AM no país, para tais faixas etárias. (Wenzel, 2008).

Em Cuiabá (MT), no centro-oeste brasileiro, entre os anos de 1999 e 2004, há aumento da prevalência de AM em menores de um ano, especialmente nos grupos de lactentes com idade inferior a um mês e superior a nove meses, com incrementos de $8,7 \%$ e $21,1 \%$, respectivamente. No entanto, já ao findar o primeiro ano de vida, $40 \%$ das crianças não recebem mais o leite materno. (Silva et al., 2007).

Confrontados os resultados de três estudos transversais investigando a alimentação de menores de um ano realizados em 1995, 1999 e 2004, em 
Botucatu (SP), verifica-se que a duração mediana da amamentação aumenta de 5,5 meses para 8,4 meses (Ferreira et al., 2007).

Também no interior de São Paulo, mais precisamente em Ribeirão Preto, o tempo médio de amamentação é progressivamente maior, passa de 48 para 87, 100 e 111 dias respectivamente, quando feita a comparação entre os anos de 1970, 1980, 1990 e 2000 (Del Ciampo et al., 2006).

Em Pelotas (RS), ao serem comparados dados de diferentes períodos, verifica-se que no ano de 1982, metade dos lactentes é desmamado por volta de 3,1 meses, enquanto que em 1993, isso passa acontecer aos 4 meses e em 2004, aos 6,8 meses de idade (Victora et al., 2008).

Com a finalidade de uma comparação mais adequada da situação de AM de Joinville com a de outras localidades, como demonstra a tabela 10, decidimos analisar algumas publicações brasileiras de natureza transversal, dos últimos 10 anos, com dados obtidos a partir de recordatório alimentar de 24 horas e coletados em Campanha Nacional de Multivacinação.

Ainda assim, as taxas de iniciação e manutenção de AM em Joinville despontaram como das melhores dentre as descritas nos vários estudos apresentados anteriormente. Para explicar as taxas iniciais de AM, cabe pensar que um "Hospital Amigo da Criança" na cidade, com profissionais capacitados, promovendo e apoiando a prática da amamentação, possivelmente desempenhou papel importante. Não podem ser esquecidos, no entanto, os aspectos sócio-culturais da população local. 
Tabela 10 - Prevalência do AM em menores de 12 meses, na amostra de estudo em Joinville e em alguns trabalhos da literatura

\begin{tabular}{|c|c|c|c|}
\hline Autor (ano)/ Local & $\mathrm{N}$ & Tipo de estudo & Prevalência do AM em < 12 m \\
\hline Ramos et al. (2008) & 1963 & Transversal & $80,2 \%$ \\
\hline Estado do Piauí $^{(1)}$ & & (campanha de vacinação) & \\
\hline França et al. (2007) & 920 & Transversal & $74,0 \%$ \\
\hline Cuiabá (MT) & & (campanha de vacinação) & \\
\hline Nascimento (2005) & 1470 & Transversal & $72,5 \%$ \\
\hline Joinville - SC & & (campanha de vacinação) & \\
\hline Vieira et al. (2004) & 2319 & Transversal & $69,2 \%$ \\
\hline Feira de Santana (BA) & & (campanha de vacinação) & \\
\hline Gomes (2005) & 821 & Transversal & $68,9 \%$ \\
\hline Guarapuava (PR) & & (campanha de vacinação) & \\
\hline Vannuchi et al. (2005) & 2002 & Transversal & $62,4 \%$ \\
\hline Londrina (PR) & & (campanha de vacinação) & \\
\hline Audi et al. (2003) & 679 & Transversal & $61,6 \%$ \\
\hline Itapira (SP) & & (campanha de vacinação) & \\
\hline Kitoko et al. (2000) & & Transversal & $59,4 \%$ \\
\hline Florianópolis (SC) & 990 & (campanha de vacinação) & \\
\hline Pereira et al. (2004) & 1715 & Transversal & $55,5 \%$ \\
\hline Ribeirão Preto (SP) & & (campanha de vacinação) & \\
\hline Camilo et al. (2004) & 1708 & Transversal & $54,9 \%$ \\
\hline Campinas (SP) & & (campanha de vacinação) & \\
\hline Kitoko et al. (2000) & & Transversal & $50,7 \%$ \\
\hline João Pessoa (PB) & 950 & (campanha de vacinação) & \\
\hline
\end{tabular}

\subsection{Prevalência do AME}

Informações sobre a prática da amamentação exclusiva estão facilmente acessíveis na literatura nacional e internacional nos últimos anos.

A tabela 11 compara as freqüências AME encontradas em diversas localidades brasileiras. Os dados obtidos em Joinville demonstraram que as prevalências estimadas para essa modalidade de amamentação aos 30, 90, 120 e 180 dias são, respectivamente, $71,2 \%, 46,3 \%, 44,2 \%$ e $13,3 \%$. A proporção de neonatos amamentados exclusivamente foi elevada. A taxa de manutenção do AME na nossa amostra permaneceu estável e maior que em 
quase todos os outros estudos entre o $3^{\circ} .^{\circ}$ e $4 .^{\circ}$ mês. A partir de então, foi observada uma queda acentuada na amamentação exclusiva entre o 4 . e 6. ำ mês de vida, mas conservando-se em patamar semelhante aos descritos nos artigos listados.

Tabela 11 - Freqüência do AME de acordo com a faixa etária, em menores de 6 meses, na amostra de estudo em Joinville e em alguns trabalhos da literatura

\begin{tabular}{|c|c|c|c|c|c|c|}
\hline \multirow[b]{2}{*}{ Autor (ano)/Local } & \multirow[b]{2}{*}{$\mathrm{N}$} & \multirow[b]{2}{*}{ Tipo de estudo } & \multicolumn{4}{|c|}{ Freqüência de $\mathrm{AME}$} \\
\hline & & & $1 \mathrm{~m}$ & $3 m$ & $4 m$ & $6 m$ \\
\hline $\begin{array}{l}\text { Silva e Souza (2005) } \\
\text { Lins (SP) }\end{array}$ & 255 & $\begin{array}{l}\text { Transversal } \\
\text { (consultórios) }\end{array}$ & - & - & $61,2 \%$ & - \\
\hline $\begin{array}{l}\text { Faleiros et al. (2005) } \\
\text { Pelotas (RS) }\end{array}$ & 112 & Coorte & $95,0 \%$ & $64,0 \%$ & $53,0 \%$ & $35,0 \%$ \\
\hline $\begin{array}{l}\text { Nascimento (2005) } \\
\text { Joinville - SC }\end{array}$ & 839 & $\begin{array}{c}\text { Transversal } \\
\text { (campanha de vacinação) }\end{array}$ & $71,2 \%$ & $46,3 \%$ & $44,2 \%$ & $13,3 \%$ \\
\hline $\begin{array}{l}\text { Gomes (2005) } \\
\text { Guarapuava (PR) }\end{array}$ & 415 & $\begin{array}{c}\text { Transversal } \\
\text { (campanha de vacinação) }\end{array}$ & $62,9 \%$ & $45,1 \%$ & $29,1 \%$ & $16,4 \%$ \\
\hline $\begin{array}{l}\text { Mascarenhas et al. (2006) } \\
\text { Pelotas (RS) }\end{array}$ & 973 & Coorte & - & $39 \%$ & - & - \\
\hline $\begin{array}{l}\text { Silveira e Lamounier (2004) } \\
\text { Alto Jequitinhonha - } \mathrm{MG}^{(1)}\end{array}$ & 98 & $\begin{array}{l}\text { Transversal } \\
\text { (domicilliar) }\end{array}$ & $60,0 \%$ & $13,6 \%$ & - & $0,84 \%$ \\
\hline $\begin{array}{r}\text { Sena et al. (2002) } \\
\text { Distrito Federal }\end{array}$ & 2983 & $\begin{array}{c}\text { Transversal } \\
\text { (campanha de vacinação) }\end{array}$ & $56,4 \%$ & - & $26,8 \%$ & $12,8 \%$ \\
\hline $\begin{array}{l}\text { Minagawa et al. (2005) } \\
\quad \text { Itupeva (SP) }\end{array}$ & 261 & $\begin{array}{l}\text { Transversal } \\
\text { (domiciliar) }\end{array}$ & $47,7 \%$ & - & $11,3 \%$ & - \\
\hline $\begin{array}{l}\text { Sena et al.(2007a) } \\
\text { Brasil }^{(2)}\end{array}$ & 10778 & $\begin{array}{c}\text { Transversal } \\
\text { (campanha de vacinação) }\end{array}$ & $47,5 \%$ & - & $17,7 \%$ & $7,7 \%$ \\
\hline $\begin{array}{l}\text { Figueiredo et al. (2004) } \\
\text { São José do Rio Preto - SP }\end{array}$ & 396 & $\begin{array}{c}\text { Transversal } \\
\text { (campanha de vacinação) }\end{array}$ & $36,4 \%$ & - & $11,1 \%$ & $3,1 \%$ \\
\hline
\end{tabular}

Os melhores indicadores são relatados por Faleiros et al. (2005), que trabalhando com uma equipe altamente motivada para a preservar o AME, desenvolve acompanhamento ambulatorial e domiciliar de uma população carente, em uma área peculiar da periferia da cidade de Pelotas (RS). É 
exceção, também, a descrição de prevalência de $61,2 \%$ de AME aos 4 meses de idade de na cidade paulista de Lins (Silva e Souza, 2005).

Apesar de haver variações metodológicas e geográficas, as diferenças encontradas podem ser explicadas, em parte, pela heterogeneidade entre as populações analisadas. Mas no que diz respeito ao AME, a época de realização das pesquisas é especialmente importante, pois as vantagens dessa prática só passaram a ser mais ressaltadas nos últimos 20 anos. Como amamentar exclusivamente depende de variáveis sociais, econômicas e culturais presentes na vida das mulheres e das suas comunidades, a diminuição das barreiras que impedem que o AME seja a norma, pode demorar a ser percebida.

\subsubsection{Prevalência do AME em lactentes menores de quatro meses \\ O índice "porcentagem de AME em menores de 120 dias" foi} sugerido pela OMS para descrever a amamentação exclusiva, na época em que essa prática era recomendada até os quatro ou seis meses.

Quando se busca a literatura nacional referente a pesquisas em amamentação exclusiva de lactentes brasileiros com idade inferior a quatro meses com utilização de recordatório alimentar de 24 horas, em campanhas de vacinação, de acordo com a tabela 12, verifica-se que o índice de AME de 53,9\%, encontrado em crianças joinvilenses, foi pouco superior aos de Florianópolis (SC), Itapira (SP), Feira de Santana (BA), Guarapuava (PR) e Cuiabá (MT) (Kitoko et al., 2000; Audi et al., 2003; Vieira et al., 2004; Gomes, 2005; França et al., 2007). 
O achado também superou os indicadores do município de Londrina (PR) e de 136 cidades do estado de São Paulo (Vannuchi et al., 2005; Venancio et al., 2008), sendo muito melhor que os encontrados em João Pessoa (PB), São José do Rio Preto (SP), Ribeirão Preto (SP) e no Estado da Paraíba (Kitoko et al., 2000; Figueiredo et al., 2004; Pereira et al., 2004; Vianna et al., 2007).

Tabela 12 - Prevalência do AME de acordo com a faixa etária, em menores de 4 meses, na amostra de estudo em Joinville e em alguns trabalhos da literatura

\begin{tabular}{|c|c|c|c|}
\hline Autor (ano)/ Local & $\mathrm{N}$ & Tipo de estudo & Prevalência de AME em $<4$ m \\
\hline Nascimento (2005) & 568 & Transversal & $53,9 \%$ \\
\hline Joinville (SC) & & (campanha de vacinação) & \\
\hline Vieira et al. (2004) & 1224 & Transversal & $48,3 \%$ \\
\hline Feira de Santana (BA) & & (campanha de vacinação) & \\
\hline Gomes (2005) & 276 & Transversal & $46,4 \%$ \\
\hline Guarapuava (PR) & & (campanha de vacinação) & \\
\hline Kitoko et al. (2000) & 287 & Transversal & $46,3 \%$ \\
\hline Florianópolis (SC) & & (campanha de vacinação) & \\
\hline Audi et al. (2003) & $346^{(1)}$ & Transversal & $45,0 \%$ \\
\hline Itapira (SP) & & (campanha de vacinação) & \\
\hline França et al. (2007) & 205 & Transversal & $41,0 \%$ \\
\hline Cuiabá (MT) & & (campanha de vacinação) & \\
\hline Venancio et al. (2008) & 15562 & Transversal & $35,4 \%$ \\
\hline Estado de São Paulo ${ }^{(2)}$ & & (campanha de vacinação) & \\
\hline Vannuchi et al. (2005) & 642 & Transversal & $29,3 \%$ \\
\hline Londrina (PR) & & (campanha de vacinação) & \\
\hline Kitoko et al. (2000) & 285 & Transversal & $23,9 \%$ \\
\hline João Pessoa (PB) & & (campanha de vacinação) & \\
\hline Vianna et al., 2007 & 3696 & Transversal & $22,4 \%$ \\
\hline Estado da Paraíba ${ }^{(3)}$ & & (campanha de vacinação) & \\
\hline Figueiredo et al. (2004) & 265 & Transversal & $21,1 \%$ \\
\hline São José do Rio Preto (SP) & & (campanha de vacinação) & \\
\hline Pereira et al. (2004) & 554 & Transversal & $18,8 \%$ \\
\hline Ribeirão Preto (SP) & & (campanha de vacinação) & \\
\hline
\end{tabular}

\footnotetext{
(1) Lactentes menores de 6 meses

(2) 136 municípios.

(3) 70 municípios.
} 
Do mesmo modo, outras pesquisas publicadas trazem resultados com índices inferiores ao nosso. Estudo realizado em 84 municípios paulistas revela que somente em um terço deles a prevalência do AME em lactentes com menos de quatro meses é maior que 20\% (Venancio et al., 2002). Também em São Paulo, de uma amostra de 317 de lactentes de até 12 meses, que freqüentam os Centros de Saúde Escola do município, $42,2 \%$ dos menores de 90 dias mama exclusivamente (Souza et al., 1999).

Para justificar as variações encontradas, cabe pensar que além do aspecto temporalidade, fatores sócio-econômicos e culturais específicos de cada local, estejam relacionados às taxas de AME descritas nos vários estudos. Pode-se levantar a hipótese de que o bom resultado obtido em Joinville esteja associado aos programas de incentivo existentes na cidade, bem como às condições de vida da população local.

\subsubsection{Prevalência do AME em lactentes menores de seis meses}

A partir de 2001, quando a utilização do LH como único alimento passou a ser recomendada até o 6. mês de vida, o emprego do indicador "porcentagem de AME em menores de 180 dias" passa a ter mais importância.

Para que fosse possível a comparação das freqüências do AME em lactentes com idade inferior a seis meses, os resultados de alguns estudos nacionais, com metodologia idêntica, são confrontados com o nosso.

De acordo com a tabela 13 , o resultado de $43,7 \%$ dos menores de 180 dias em AME, em Joinville, mostrou-se semelhante aos descritos em Campinas (SP), Feira de Santana (BA), Guarapuava (PR) e no estado do 
Piauí (Camilo et al., 2004; Vieira et al., 2004; Gomes, 2005; Ramos et al., 2008). Mas foi melhor que os encontrados em Itapira (SP), Cuiabá (MT) e no estado de São Paulo (Audi et al., 2003; França et al., 2007; Venancio et al., 2008), e bastante superior aos descritos nas cidades de São José do Rio Preto (SP), Ribeirão Preto (SP), Londrina (PR) e no estado da Paraíba, respectivamente (Figueiredo et al., 2004; Pereira et al., 2004; Vannuchi et al., 2005; Vianna et al., 2007).

Tabela 13 - Prevalência do AME em menores de 6 meses na amostra de estudo em Joinville em alguns trabalhos da literatura

\begin{tabular}{|c|c|c|c|}
\hline Autor (ano)/ Local & $\mathrm{N}$ & Tipo de estudo & Prevalência de AME em $<6$ m \\
\hline Nascimento (2005) & 839 & Transversal & $43,7 \%$ \\
\hline Joinville (SC) & & (campanha de vacinação) & \\
\hline Ramos et al. (2008) & 1093 & Transversal & $41,4 \%$ \\
\hline Estado do Piauí $i^{(1)}$ & & (campanha de vacinação) & \\
\hline Vieira et al. (2004) & 1224 & Transversal & $38,5 \%$ \\
\hline Feira de Santana (BA) & & (campanha de vacinação) & \\
\hline Camilo et al. (2004) & $1708^{(2)}$ & Transversal & $38,1 \%$ \\
\hline Campinas (SP) & & (campanha de vacinação) & \\
\hline Gomes (2005) & 415 & Transversal & $37,3 \%$ \\
\hline Guarapuava (PR) & & (campanha de vacinação) & \\
\hline França et al. (2007) & 275 & Transversal & $34,5 \%$ \\
\hline Cuiabá (MT) & & (campanha de vacinação) & \\
\hline Audi et al. (2003) & 346 & Transversal & $30,1 \%$ \\
\hline Itapira (SP) & & (campanha de vacinação) & \\
\hline Venancio et al., 2008 & 26241 & Transversal & $26,8 \%$ \\
\hline Estado de São Paulo ${ }^{(3)}$ & & (campanha de vacinação) & \\
\hline Vannuchi et al. (2005) & 988 & Transversal & $21,0 \%$ \\
\hline Londrina (PR) & & (campanha de vacinação) & \\
\hline Vianna et al., 2007 & 5744 & Transversal & $16,6 \%$ \\
\hline Estado da Paraíba ${ }^{(4)}$ & & (campanha de vacinação) & \\
\hline Figueiredo et al. (2004) & 396 & Transversal & $15,9 \%$ \\
\hline São José do Rio Preto (SP) & & (campanha de vacinação) & \\
\hline Pereira et al. (2004) & 850 & Transversal & $12,7 \%$ \\
\hline Ribeirão Preto (SP) & & (campanha de vacinação) & \\
\hline
\end{tabular}

\footnotetext{
(1) 45 municípios.

(2) Lactentes menores de 24 meses.

(3) 136 municípios.

(4) 70 municípios.
} 
No Brasil, de modo geral, apesar de $96,4 \%$ das mulheres afirmarem que levaram o filho ao peito pelo menos uma vez, a utilização do LH como única fonte de alimentação para lactentes de até seis meses de vida é descrita em 39,8\% deles (MS, 2008).

Entretanto, resultados distintos são descritos em algumas localidades. Por exemplo, em área rural do interior do Maranhão, ao serem avaliadas as práticas alimentares entre 118 crianças com idades entre seis e 24 meses, apesar de $89,8 \%$ das mães terem oferecido o peito aos filhos em algum momento, apenas $2,6 \%$ delas o faziam de modo exclusivo até o sexto mês de vida (Sousa e Araújo, 2005).

Observando-se as tabelas 12 e 13, a redução do índice de AME nos menores de 180 dias, quando comparada com o dos menores de 120, é possivelmente devida a características próprias das populações envolvidas, mas sugere um possível impacto protetor da licença-maternidade até os quatro meses, segundo a legislação vigente no Brasil.

Apesar dos indicadores encontrados nessa investigação apontarem uma situação semelhante, ou até melhor de AM e AME em Joinville quando comparada a outras localidades e municípios brasileiros, o que se supõe poder estar associado às características sócio-demográficas e estrutura de assistência à saúde aqui observadas, eles ainda permanecem aquém das recomendações da OMS/UNICEF (WHO, 2003).

Acreditamos, também, que os resultados encontrados em Joinville podem ser um reflexo da implantação de ações de incentivo à amamentação exclusiva quando, a partir da parceria entre a Maternidade Darcy Vargas, a 
Secretaria Municipal de Saúde, as sociedade médicas locais e a UNIVILLE, procura-se divulgar a importância do aleitamento natural na comunidade joinvilense.

\subsection{Estudo da associação entre a ausência do AME e variáveis relacionadas ao lactente, à mãe e à assistência de saúde em lactentes menores de 6 meses de vida.}

Pesquisas têm tentado identificar fatores relacionados à prática da amamentação exclusiva, tais como sexo e peso de nascimento da criança, tipo de parto, local de nascimento e de seguimento ambulatorial, uso de chupetas, idade e escolaridade materna, local de criação da mãe, experiência prévia com AM, situação socioeconômica e conjugal materna, paridade, trabalho materno, entre outros (Venancio et al., 2002; Escobar et al., 2002; Ludvigsson, 2003a; Simon et al., 2003; Blyth et al., 2004; Peters et al., 2005; Pisacane et al., 2005; Venancio e Monteiro, 2006).

Uma maior duração do AME está significativamente associada a atitudes maternas positivas em relação ao aleitamento natural, ao apoio familiar, ao bom vínculo mãe-filho, à técnica de sucção apropriada e à ausência de problemas mamilares, assim como à escolaridade materna e ao tempo de amamentação anterior (Cernadas et al., 2003). Descreve-se que o início precoce das mamadas, dentro da primeira hora após o parto, aumenta a duração do AM, exclusivo ou não (Ekström et al., 2003).

Diferentemente do descrito na literatura, nesse estudo, apenas a idade do lactente, o uso de chupeta e a escolaridade materna foram fatores 
significativamente associados ao AM não-exclusivo, o que merece reflexão adicional.

\subsubsection{Aspectos relacionados ao lactente}

\subsubsection{Idade}

Não obstante seja reconhecido que o $A M E$ e a introdução de alimentos complementares apropriados em tempo oportuno são críticos para um adequado crescimento e desenvolvimento das crianças, é observado que o abandono da amamentação exclusiva com a utilização de outras fontes nutricionais ocorre de forma muito mais precoce que o recomendado, e é intensificada com o progredir da idade do lactente.

$\mathrm{Na}$ Argentina, Albarenque et al. (2005), estudando 601 lactentes menores de um ano, relatam que o consumo de chás, sucos e papas de frutas e verduras são iniciados respectivamente nos $1 . .^{\circ}, 2 . \circ$ e $3 .$. meses de vida. Kalanda et al. (2006), avaliando 458 díades mãe-filho que praticavam o AM na República do Malauí, descrevem que em média a introdução de água

e chás acontece aos 2,5 meses, de mingau aos 3,4 meses e de frutas e verduras aos 4,5 meses.

Vieira et al. (2004), entrevistando 2.323 mães em Feira de Santana (BA), revelam que água, chás, sucos e alimentos semi-sólidos são fornecidos a crianças amamentadas já no primeiro mês de vida na proporção de $7,3 \%, 23,2 \%, 2,7 \%$ e 2,7\%. Entre 679 nascidos na cidade de Itapira (SP), Audi et al. (2003) relatam que o consumo de água e chá até o 3. mês é de 
$23,6 \%$ e $24,8 \%$, e de suco de frutas, sopa de legumes e mingau até o 6. mês é respectivamente de $35,9 \%, 28,7 \%$ e $21,0 \%$. No Maranhão, Souza e Araújo (2005), trabalhando com 118 lactentes de uma comunidade rural, mostram que durante o 1.9 mês de vida água ou chás, espessantes e fórmula infantil já fazem parte da dieta de 57,6\%, 10,2\% e 10,1\% deles.

Pelo que foi exposto acima, nota-se claramente, que a descontinuidade do AME aumenta progressivamente com a idade do lactente. Em nosso estudo, ter idade a partir do $3 .{ }^{\circ}$ mês diminuiu significativamente a possibilidade de uso do LH como única fonte alimentar. Ainda que se mantendo em um patamar um pouco mais alto, nossa população apresentou uma queda na prevalência da amamentação exclusiva parecida com a descrita por outros autores.

É de se supor que a introdução prematura de outros alimentos, interferindo com a alimentação exclusiva ao peito, esteja relacionada a fatores econômicos, sociais e culturais, bem como sofra a influência dos meios de comunicação e das estratégias de marketing da indústria de leites e sucedâneos alimentares.

\subsubsection{Sexo}

Os relatos da literatura relativos à influência do sexo do $\mathrm{RN}$ sobre o comportamento materno em relação ao AM são conflitantes.

Em pesquisa realizada na Noruega, onde é avaliada uma coorte de 1192 lactentes, há descrição de que os do sexo masculino têm desmame mais precoce que os do sexo oposto (Pande et al., 1997). Na Austrália, 
mulheres que dão à luz a neonatos masculinos estão mais propensas a abandonar o AM antes mesmo da alta hospitalar (Scott et al., 2001).

Ludvigsson e Ludvigsson (2005), trabalhando com dados de 10.205 lactentes suecos, não descrevem maior chance de lactação exclusiva entre mães de lactentes femininos ou masculinos. Entre 315 díades mãe-filho chilenas, não é encontrada associação significativa entre o gênero e o abandono da amamentação exclusiva aos três meses de idade (Barría et al., 2008). O AME também não está relacionado ao sexo da criança nem na Turquia (Yesildal et al., 2008), nem na Argentina (Cernadas et al., 2003). Não houve diferença estatisticamente significativa na duração do AME por sexo entre 291 lactentes avaliados no México (Flores et al., 2005).

Mesmo no Brasil, os achados não são coincidentes. Venâncio e Monteiro (2006), estudando 34.435 lactentes de 111 municípios do estado de São Paulo, descrevem que àquelas do sexo feminino são amamentados de forma exclusiva em maior número que os do sexo oposto. Contudo, o gênero não é fator relacionado à interrupção do $\mathrm{AME}$, antes dos 3 meses de idade, entre 973 lactentes da cidade gaúcha de Pelotas (Mascarenhas et al., 2006). Não há diferença entre a duração mediana do AM de meninos e meninas originários da região nordeste do país (Lima e Osório, 2003). Também Silveira e Lamounier (2006) não detectam associação entre duração do AM e sexo entre 450 lactentes de Minas Gerais.

Nossos resultados coincidiram com o descrito pela maior parte dos autores que, no que diz respeito a opção pelo $\mathrm{AME}$, não percebem a existência de tratamento diferencial dado pelas mães aos seus filhos na 
dependência do sexo. É de se supor que a preferência da mãe pela amamentação exclusiva, para meninos ou meninas, pode estar relacionada, portanto, a aspectos culturais e fatores psicológicos.

\subsubsection{Peso ao nascimento}

Muitos são os fatores para o baixo peso ao nascer, e esses lactentes podem apresentar condições médicas associadas à prematuridade ou à própria condição determinante do peso ao nascimento, capazes de interferir com o estabelecimento da lactação.

Em uma amostra de conveniência de um hospital universitário do Oriente Médio, composta por 400 lactentes com idade entre seis e 24 meses, nascer com menos de $2500 \mathrm{~g}$ é fator identificado como associado à interrupção precoce do AM (Shiva e Padyabm, 2008).

A avaliação de uma porção representativa de lactentes australianos detecta que aqueles nascidos prematuramente ou com idade gestacional entre 37 e 39 semanas de idade gestacional estão mais propensos a problemas na amamentação quando comparados com os nascidos com 40 semanas ou mais. Nessa população, também o risco de desmame precoce é maior (Donath e Amir, 2008). No entanto, outro estudo realizado na Austrália não detecta impacto do peso ao nascer no aleitamento exclusivo por ocasião da alta hospitalar (Scott et al., 2006).

Entre 539 díades mãe-filho da Argentina, não é encontrada associação significativa entre o peso de nascimento e a duração do AME (Cernadas et al., 2003). 
No Brasil, a exemplo de outros países, tem sido observado um maior percentual de baixo peso ao nascer em regiões com maior desenvolvimento econômico, provavelmente decorrente do aumento do número de recémnascidos prematuros sobreviventes (Andrade et al., 2008).

Ao comparar a duração mediana do AM entre lactentes da região Nordeste brasileira de três diferentes categorias de peso, àqueles nascidos com mais de 3000g são amamentados por 209,1 dias contra 169,8 dias nos com peso entre 2500 e $2999 \mathrm{~g}$, e 166,2 dias nos menores que $2500 \mathrm{~g}$, mas essa diferença não é estatisticamente significativa (Lima e Osório, 2003). Achado similar é descrito para o estado de Pernambuco (Vasconcelos et al., 2006).

O peso inferior a $2500 \mathrm{~g}$ não está relacionado ao abandono do AME em lactentes de até quatro e seis meses, respectivamente nas cidades paulistas de Botucatu e Itapira (Audi et al., 2003; Carvalhaes et al., 2007), nem a duração do AM na região do Alto Jequitinhonha, em Minas Gerais (Silveira e Lamounier, 2006). Entre os fatores relacionados ao abandono da amamentação exclusiva antes dos 3 meses de idade, no município gaúcho de Pelotas, não está descrito o baixo peso ao nascimento (Mascarenhas et al., 2006).

Em Itaúna, Minas Gerais, ao serem estudados os filhos de 246 mulheres selecionadas na maternidade do município, uma menor duração de amamentação exclusiva foi observada entre os nascidos com baixo peso (Chaves et al., 2007). 
Embora o baixo peso do neonato diminua significativamente a chance de uma mulher iniciar a amamentação, e esteja relacionado com um menor tempo de AME, esse não foi fator de abandono da amamentação exclusiva entre os lactentes menores de 180 dias que compreenderam a nossa população de estudo.

Venancio e Monteiro (2006) comprovam que viver em uma cidade que implementa ações de incentivo ao AM reduz o efeito negativo do baixo peso ao nascer sobre a suspensão do AME antes do sexto mês de vida. Acreditamos que o programa de estímulo ao AM para prematuros desenvolvido na maternidade pública de Joinville (Nascimento e Issler, 2005), teve forte influência na continuidade do AME no município, também nos recém-nascidos de baixo peso.

\subsubsection{Ordem de nascimento}

Embora primíparas possam tender a iniciar mais a amamentação de forma exclusiva que multíparas, elas costumam mantê-la por menos tempo. Mas a literatura diverge bastante sobre a influência da presença de irmãos sobre o AM.

Nenhuma associação entre a duração do AME e paridade é encontrada quando da avaliação de 597 mulheres da Argentina, acompanhadas durante o primeiro semestre de vida de seus filhos (Cernadas et al., 2003). Ao medir a duração do período de lactação exclusiva entre 194 primíparas e 294 multíparas suecas, Ekström et al. 
(2003) constatam que o número de crianças existentes na família não influencia a decisão de manter o AME.

A análise de 545.837 nascimentos, durante o período de cinco anos em Nova Jersey, nos Estados Unidos, revela que a amamentação exclusiva é significativamente mais freqüente após o primeiro parto (Kruse et al., 2005). Contudo, entre 315 mães chilenas entrevistadas pela primeira vez até 48 horas e pela segunda, aos três meses pós-parto, ser primípara diminui significativamente a chance de continuar a aleitar exclusivamente ao peito (Barría et al., 2008).

Em 111 municípios do estado de São Paulo, a avaliação dos dados de 34.435 lactentes com idade inferior a seis meses, mostra que a utilização do LH como fonte exclusiva de alimentação é mais freqüente em multíparas (Venâncio e Monteiro, 2006). Da mesma forma, em Londrina e Cuiabá, ser primípara está associado a uma maior chance de interrupção do AME antes de 180 dias de vida (Vannuchi et al., 2005; França et al., 2007).

Posto que não tenhamos encontrado significância estatística entre a ordem de nascimento e a amamentação não-exclusiva, os resultados aqui obtidos foram diferentes dos encontrados em outras localidades brasileiras.

Sabe-se que um dos fatores que colaboram para a manutenção do AME é o conhecimento das genitoras acerca dessa prática (Melo et al., 2002), assim, pode-se cogitar que o incentivo e apoio ao aleitamento natural no nosso município devam ter contribuído para minimizar o efeito da experiência prévia como estímulo para amamentação dos filhos subseqüentes de forma exclusiva. 


\subsubsection{Uso de chupeta}

Muito tem sido discutido a cerca do uso de chupetas, que está vinculado tanto à prática do $\mathrm{AM}, \mathrm{AME}$, como também do desmame.

A amamentação determina um efeito benéfico sobre 0 desenvolvimento da cavidade oral da criança, favorecendo a correta oclusão e o alinhamento dos dentes. O mecanismo de sucção ao peito fortalece os órgãos fonoarticulatórios, estimulando o apropriado estabelecimento de suas funções (Neiva et al., 2003; Peres et al., 2007a). É descrito que hábitos de sucção não nutritiva, levando a deformidade da cavidade oral, são responsáveis por oclusopatias (Peres et al., 2007a; Peres et al., 2007b).

A exposição de lactentes amamentados à chupetas e bicos artificiais, com possíveis efeitos adversos à saúde em geral, também não é recomendada pelo risco dos prejuízos ao AM (Howard, 2003). A chance de desmame é sabidamente maior entre os usuários de bicos artificiais (Victora et al., 1993; Tomasi et al., 1994; Santos Neto et al., 2008), pois nestes casos há diminuição da freqüência e duração das mamadas, além da "confusão de bicos", especialmente nas mulheres com dificuldades no AM (Victora et al., 1997). Entretanto, este constitui hábito cultural entre os lactentes brasileiros (Lamounier, 2003), que foi confirmado em $51,3 \%$ dos menores de um ano aqui estudados.

É alto o percentual de mulheres no nosso país que tem a intenção de comprar e utilizar chupetas, $80 \%$ e $60 \%$ respectivamente, entre 143 primíparas avaliadas na cidade de Recife (Melo et al., 2002). Isso pode ser decorrente de falta de informação e conhecimento sobre AM (Melo et al., 
2002), mas especialmente porque as mães consideram-na uma ótima alternativa para acalmar o filho (Sertório e Silva, 2005).

No Nordeste do Brasil, quando estudados lactentes nascidos com peso menor que $3000 \mathrm{~g}$, aproximadamente $60 \%$ deles utilizam chupetas e têm um risco 1,9 vezes maior de desmame precoce que os não-usuários de bicos (Cunha et al., 2005). No Sul do Brasil, quando estudada população egressa de "Hospital Amigo da Criança", 61,6\% usa chupeta desde a primeira semana de vida. Cerca de 2/3 dos lactentes em uso de bico artificial deixa de ser amamentado exclusivamente ao final do segundo mês de vida (Soares et al., 2003).

Outro estudo brasileiro, envolvendo 220 binômios mãe-filho saudáveis, comprova que o uso de chupetas durante o primeiro mês está associado com o término do AME antes dos seis meses de vida (Espírito Santo et al., 2007).

No estado de São Paulo, na avaliação de 22.188 lactentes com idade inferior a quatro meses verifica-se que o oferecimento de bicos é precoce, pois $53,9 \%$ dos menores de um mês já o utilizam. A prevalência do uso de chupeta é de $61,3 \%$, variando de $32,8 \%$ a $78,4 \%$ nas 111 cidades estudadas. Uma maior freqüência de utilização de mamadeira é encontrada em crianças que tem o costume de sugar de forma não nutritiva (Cotrin et al., 2002). Esse fenômeno também é observado no município de Porto Alegre, onde usar bico artificial na primeira semana de vida está associado ao emprego de mamadeira aos 30 dias (França et al., 2008). 
Essas observações são concordantes com os achados do nosso estudo, pois apenas $5(0,67 \%)$ dos 744 lactentes que usavam mamadeira recebiam LH ordenhado de forma exclusiva. Ramos et al. (2008) descrevem que a proporção de crianças em AME é $68,4 \%$ contra 5,2\%, na dependência de estar ou não utilizando mamadeira.

O hábito do uso de chupetas deve ser considerado um marcador de dificuldades no AM, colocando a necessidade de que o profissional de saúde se conscientize dos efeitos prejudiciais deste costume sobre a amamentação e a saúde da criança (Lamounier, 2003; Joana Briggs Institute, 2006). Entretanto, vale ressalvar que tanto o $\mathrm{AM}$ como a utilização de bicos têm sido associados a uma diminuição na incidência de morte súbita (Nelson et al., 2005; Li et al., 2006), indicando que a orientação sobre o uso das chupetas deve incluir seus potenciais riscos e benefícios.

Percebemos na nossa pesquisa que, em concordância com as descrições da literatura, os lactentes que usavam chupetas tiveram maior chance de interrupção do $\mathrm{AME}$ antes dos seis meses de vida que àqueles que não tinham esse hábito. Ainda que em circunstâncias e culturas diferentes, o uso universal de bicos para substituir ou complementar os cuidados maternos e satisfazer a necessidade de sucção do lactente, interfere negativamente na amamentação. 


\subsubsection{Aspectos maternos}

\subsubsection{Idade da mãe}

A prática do AM depende da realidade concreta de cada mulher, e em geral, aquelas mais velhas têm melhor conhecimento sobre amamentação.

Comparando-se mulheres de 20 ou mais anos com as mais jovens, as primeiras também apresentam atitudes mais positivas em relação ao AM (Marrone et al., 2008). Relata-se que mães com mais idade amamentam por tempo mais prolongado, seja de forma exclusiva ou parcial, sobretudo quando têm maior prole ou experiência prévia bem sucedida de amamentação (Faleiros et al., 2006).

Park et al. (2003) e Spear (2006) relatam menores taxas de iniciação de $\mathrm{AM}$ entre adolescentes quando comparadas com a média das mulheres nos Estados Unidos, e da mesma forma Kruse et al. (2005) confirmam que mães americanas mais jovens estão menos propensas à prática do AME que as mais velhas. Na Inglaterra, dados de 11.286 lactentes com nove meses de idade demonstram que a baixa idade materna na primeira gestação está negativamente associado ao AM (Griffiths et al., 2005). Na cidade de Havana, em Cuba, o abandono da amamentação é mais freqüente em mulheres com idade inferior a 20 anos e superior a 35 (Menendéz et al., 1999). 
Pesquisas brasileiras também correlacionam a baixa idade materna com a interrupção precoce do AME. Em Porto Alegre, se a mãe tem menos de 20 anos, o risco do lactente ser aleitado exclusivamente por um curto período de tempo é maior (Espírito Santo et al., 2007). Venancio e Monteiro (2006) descrevem que aumenta a chance de praticar o AME com o incremento da idade da nutriz.

Esses resultados são discordantes daqueles apresentados por outros autores. Entre 100 adolescentes canadenses de Manitoba, Mossman et al. (2008) descrevem que 84\% delas iniciam o AM, achado comparável aos $82,2 \%$ encontrados para mulheres adultas da mesma província. Há descrição de que os adolescentes têm atitudes positivas a respeito da amamentação (Goulet et al., 2003), e que a possibilidade de apoio efetivo da família e dos profissionais de saúde facilita a manutenção do AM (Dykes et al., 2003).

$\mathrm{Na}$ análise de 349 mulheres de descendência latina vivendo nos Estados Unidos, a idade inferior a 25 anos foi um fator positivamente associado ao AME durante a permanência na maternidade (Newton et al., 2009).

No nosso estudo, não foi encontrada diferença significativa entre os grupos de amamentação exclusiva e não exclusiva no que diz respeito a idade materna. Para justificar os achados desse trabalho, pode-se pensar que as campanhas em prol do aleitamento natural no nosso município permitiram às jovens mães estarem em contato com um ambiente propício para exercitarem a prática. 


\subsubsection{Escolaridade materna}

A escolaridade materna é um dos fatores que pode afetar a motivação para o amamentar.

Ela é geralmente descrita correlacionada tanto com as taxas de iniciação como as de duração do AM, influenciando no desmame precoce (Menéndez et al., 1999; Escobar et al., 2002; Zaghloul et al., 2004; Grjibovski et al., 2005; Volpini e Moura, 2005).

Entre estudantes universitários americanos sem filhos, 111 dos quais mulheres e 50 homens, conforme aumenta o número de anos cursados na faculdade, melhor é a atitude diante da amamentação, o que tem influência direta sobre a intenção de amamentar no futuro (Marrone et al., 2008).

Outras pesquisas também têm demonstrado que o fator educação afeta a motivação para utilizar o LH como único alimento. Na Dinamarca, quando fatores sócio-demográficos são analisados em relação à persistência do $A M E$, apenas o grau de instrução da mãe permanece estatisticamente significativo (Kronborg et al., 2004). No Chile, a amamentação exclusiva no 3. mês de vida está fortemente associada ao nível educacional da mãe (Barría et al., 2008). Da mesma forma na Espanha, a prevalência da amamentação exclusiva aos quatro meses é maior nas nutrizes com nível universitário que nas não-universitárias (Suaréz Gil et al., 2000). Nutrizes suecas com educação superior estão mais propensas a continuar amamentando exclusivamente aos quatro meses pós-parto (Ludvigsson e Ludvigsson, 2005). 
Entre mulheres americanas com diploma universitário, as taxas de AME aos seis meses foram $9 \%$ maiores que as encontradas entre as que possuem o ensino médio completo (Li R et al., 2005). Um estudo conduzido na Itália, envolvendo um total de 400 mulheres mostra que nutrizes com nível educacional baixo ou intermediário estão mais propensas a abandonar - AME quando comparadas com àquelas que estudaram pelo menos 14 anos (Ummarino et al., 2003). Na Noruega, a associação entre AME e grau de instrução também é observada, com um maior número de lactentes nascidos de mães que possuem 13 ou mais anos de estudo recebendo leite materno de forma exclusiva (Lande et al., 2003). Mulheres argentinas com nível superior de educação amamentam exclusivamente em maior freqüência que àquelas com nível primário, 21,1\% contra 13,6\% respectivamente (Cernadas et al., 2003).

Em um estudo brasileiro, filhos de mulheres que concluíram o ensino superior tem maior chance de serem amamentados exclusivamente até quatro meses de vida (Damião, 2008). No estado de São Paulo, um aumento de quase duas vezes na freqüência de AME é observado entre os lactentes filhos de mães com terceiro grau completo ou incompleto, quando comparados a filhos de mães com menos que o ensino fundamental (Venancio e Monteiro, 2006).

Alguns estudos realizados, no entanto, mostram resultados diferentes. No México, o seguimento de uma coorte de 111 lactentes até o 6.ำ mês demonstra que somente o grupo de mulheres que cumpriu de um a seis anos de estudo formal tem maior possibilidade de aleitar exclusivamente 
até essa idade (Delgado-Becerra et al., 2006). Entre 380 mães de crianças menores de 4 meses vacinadas na cidade paulista de Botucatu, o grau de instrução materno, assim como outros fatores demográficos e socioeconômicos, não influenciou na manutenção do AME até essa idade (Carvalhaes et al., 2007). Achado semelhante é descrito para 162 crianças entre zero e 24 meses da Turquia, onde a educação materna não está estatisticamente associada ao AME nos primeiros seis meses de vida (Yesildal et al., 2008).

Nesse estudo observamos que mães com maior grau de instrução tenderam a amamentar exclusivamente, talvez pela possibilidade de um maior acesso a informações sobre as vantagens do AME.

\subsubsection{Trabalho materno}

Entre os fatores sócio-demográficos que influenciam a decisão das mulheres de optar pela amamentação exclusiva, o trabalho fora do lar é geralmente citado.

Há relatos de que a perspectiva de trabalhar já diminui a probabilidade de uma mulher iniciar a amamentação (Libbus e Bullock, 2002). Razões ligadas ao emprego são as principais indicadas por mulheres de Singapura para abandonar a lactação, e àquelas que trabalham fora de casa têm 1,6 vezes mais chance de desmamar antes dos dois meses pósparto quando comparadas com as donas de casa (Ong et al., 2005).

Mesmo sabendo que a manutenção da lactação após a volta às atividades laborais exige grande comprometimento da mulher, a maior parte 
delas acredita ser um esforço válido em prol da saúde do filho (Tully, 2005). Trinta e cinco entre 46 gestantes empregadas em quatro diferentes organizações inglesas desejam manter o AM após o retorno ao batente, mas muitas delas acham difícil conciliar as duas tarefas, e temem não ter apoio dos empregadores e não encontrar estrutura adequada no local de trabalho (Kosmala-Anderson e Wallace, 2006).

Também na África, a ocupação materna é considerada uma barreira ao AME. Um estudo qualitativo, analisando a opinião de 35 mulheres de Gana, descreve que é consenso que nutrizes trabalhadoras não dispõem de tempo suficiente para amamentar unicamente ao peito, seja por uma curta licença-maternidade ou por falta de ambiente apropriado (Otoo et al., 2009).

Para continuar amamentando exclusivamente, as mães que têm emprego fixo necessitam de creches no ambiente de trabalho, pausas para amamentar ou pelo menos um local para expressão e armazenamento do leite humano ordenhado (Rea et al., 1999; McCarter-Spaulding, 2008). Um estudo qualitativo envolvendo 30 funcionárias da Universidade Estadual de Campinas, reforça a importância das creches e da possibilidade de dar de mamar durante o expediente na manutenção do AME (Osis et al., 2004).

No entanto, nem sempre os empregadores percebem o aleitamento natural como suficientemente importante para que sejam desenvolvidas ações para promovê-lo nos locais de trabalho (Libbus e Bullock, 2002; Johnston e Espósito, 2007). Por esse motivo, poucas empresas têm políticas específicas para o AM ou salas de amamentação (Brown et al., 2001). 
Além de vontade política, há necessidade de real esforço para que a partir da alteração da estrutura organizacional das empresas, com o envolvimento de pessoas-chave e mudanças progressivas, as funcionárias lactantes possam ser melhor acolhidas (Mlay et al., 2004; Worugji e Etuk, 2005; Click, 2006; Heinig, 2007). Quando programa de apoio ao AM é desenvolvido no ambiente de trabalho, as nutrizes empregadas em período integral gastam menos de uma hora diária com a ordenha mamária para a manutenção da produção láctea, demonstrando a viabilidade desse procedimento, com interferência mínima na produtividade (Slusser et al., 2004).

É sabido que o tempo decorrido entre o parto e o retorno ao emprego é o mais importante preditor da redução do tempo de AME, pois quanto mais cedo a volta às atividades laborais mais precoce é a introdução de outros alimentos e, conseqüentemente, o desmame (Calnen, 2007). No Brasil, desde 1988, a licença maternidade tem duração de 120 dias, mas ainda assim as mulheres que desejam combinar amamentação e trabalho encontram muitos obstáculos (Réa et al., 1997; Vianna et al., 2007).

Na cidade de São Paulo, um estudo exploratório em 13 indústrias, demonstra que $97 \%$ das mulheres trabalhadoras iniciam a amamentação, e que a maioria delas utiliza o período de licença-maternidade para amamentar (Réa et al., 1997). Entre mães paraibanas que têm vínculo empregatício formal e filho com idade inferior a quatro meses, ter direito à licença-maternidade aumenta significativamente a freqüência de amamentar exclusivamente (29,6\% vs. 8,9\%) (Vianna et al., 2007). 
Quando avaliada a saúde de 716 puérperas americanas às 5 semanas pós-parto, elas apresentam muitas queixas ainda decorrentes da gravidez e da parturição, indicando que há necessidade de maior tempo de repouso e recuperação do que o tradicional período de puerpério (McGovern et al., 2006). É descrita a necessidade da permanência da mãe junto de seu filho nos primeiros meses de vida, o que além de aumentar a prevalência do AME, causa impacto a longo prazo na saúde física e mental da díade. (Calnen, 2007). Uma extensão do período de afastamento pós-parto de três para seis meses no Chile, implicaria em aumento do custo social para que 0 benefício fosse ofertado a todas as trabalhadoras formais. No entanto, facilitando-se o AME, estima-se que deva ocorrer menor utilização dos serviços de saúde pelos lactentes com idade inferior a um ano, menor consumo de fórmula infantil e diminuição do uso das creches, portanto o gasto real cairia para menos de um terço do valor inicial (Aedo, 2007).

Não há dúvida de que o retorno ao trabalho pode afetar a amamentação, pois a mulher tem que enfrentar uma dupla jornada. Além do emprego fixo, há o trabalho doméstico e a responsabilidade de nutrir o filho. Assim, deve-se ver com otimismo a possibilidade de ampliação da licençamaternidade de quatro para seis meses no Brasil, a partir do projeto de autoria da senadora Patrícia Saboya, elaborado em parceria com a Sociedade Brasileira de Pediatria (SBP), e que foi sancionado pelo presidente Luiz Inácio Lula da Silva em 2008 (Gusmão, 2008). Trata-se de um investimento vantajoso ao empregador no futuro, proporcionando diminuição do absenteísmo e dos custos para o sistema de saúde, maior 
produtividade e bem-estar das funcionárias durante o trabalho (Raju, 2006; Calnen, 2007).

Ao contrário do que esperávamos, o trabalho materno atual não esteve associado à interrupção do AME entre as crianças com idade inferior a seis meses. Essa observação é discordante da maior parte dos achados da literatura. É de se supor que condições locais favoráveis à manutenção do aleitamento, como, por exemplo, o respeito à licença maternidade, existência de creches, permissão para a amamentação ou ordenha no local e horário do trabalho possam ter interferido positivamente e levado ao sucesso do AME.

\subsubsection{Aspectos relacionados à assistência de saúde}

\subsubsection{Tipo do parto}

A assistência humanizada ao parto e nascimento vem sendo muito discutida, com o intuito de melhorar a atenção prestada à parturiente e estimular o parto natural, mas o contínuo aumento das taxas de operação cesariana tem sido observado em diversos países.

O efeito dessa prática sobre as primeiras mamadas e a continuidade do amamentar ainda é incerto (Patel et al., 2003). Há relatos de que a via de parto interfere diretamente no estabelecimento da lactação. Ao serem comparadas 97 mulheres australianas submetidas à operação cesariana com outras 88 , que pariram por via baixa, as primeiras produzem 
significativamente menos leite nos seis dias que sucedem a parturição (Evans et al., 2003).

$\mathrm{Na}$ literatura, todavia, as descrições são bastante variadas. $\mathrm{Na}$ Austrália, observa-se que fatores biomédicos, entre eles o tipo de parto, estão mais relacionados ao AME na alta hospitalar que fatores psicossociais (Scott et al., 2006). Esse também é o resultado de um estudo transversal, envolvendo 1603 mulheres gregas, realizado por Pechlivani et al. (2005). Entre 400 binômios mãe-filho iranianos uma proporção expressivamente maior de mulheres submetidas ao parto cesáreo interrompe o AM antes dos seis meses quando comparadas com as que têm parto natural (Shiva e Padyabm, 2008). Na Turquia, a taxa de amamentação exclusiva nos primeiros 180 dias é de $24,2 \%$ para lactentes nascidos por partos vaginais espontâneos e 11,8\% nos casos de cesarianas $(p=0,038)$ (Yesildal et al., 2008)

Já no Chile, não houve diferença estatisticamente significativa entre os grupos nascidos por via alta ou baixa no que diz respeito ao AME (Barría et al., 2008). Achado semelhante é descrito para 539 mães argentinas (Cernadas et al., 2003), e para 376 africanas (Aidam et al., 2005). No Reino Unido, 393 parturientes com dilatação completa do colo uterino, mas que necessitam operações obstétricas do tipo cesariana ou extração a fórcipe, são comparadas para observação da persistência do AME às seis semanas pós-parto, não sendo encontradas diferenças entre os grupos (Patel et al., 2003). 
No Brasil, os índices de partos cesarianos são altos (Potter et al., 2008), especialmente quando comparados serviços privados com públicos, com descrição de prevalências tão discrepantes quanto 84,3\% e 18,9\% respectivamente para cada uma das categorias de hospitais (Almeida et al., 2008).

Na região Nordeste do país, ao serem avaliados 813 menores de até 25 meses de idade, embora a duração mediana do AM seja diferente entre os nascidos de parto normal e os nascidos por parto operatório (212,1 dias versus 169,5 dias), essa diferença não é estatisticamente significativa (Lima e Osório, 2003). Já Audi et al. (2003), investigando 679 lactentes de Itapira $(\mathrm{SP})$, relatam que a cesariana está associada à interrupção do AME nos primeiros seis meses de vida nessa população.

Sabe-se que uma proporção maior de mulheres parindo por via vaginal inicia mamada ao peito de modo mais precoce que as submetidas ao parto cesáreo (Boccolini et al., 2008; Silveira et al., 2008). Esse contato mãefilho, imediatamente após o nascimento, promove uma maior prevalência de AME aos seis meses de vida (Ossandón et al., 2000).

Nosso trabalho mostrou, contudo, que o parto operatório não foi determinante para o abandono do AME até o 6.ำ mês de vida. Acreditamos que o apoio e incentivo para as puérperas permanecerem junto ao filho no centro obstétrico, bastante comum nos hospitais públicos e privados de Joinville, pode ter sido determinante para o estabelecimento e manutenção do AME independente do tipo de parto. 


\subsubsection{Local de nascimento do lactente}

A "Iniciativa Hospital Amigo da Criança" (IHAC) foi idealizada para estimular as maternidades na promoção, proteção e apoio ao aleitamento natural.

Tomando por base os ditames dos "Dez Passos para o Sucesso do Aleitamento Materno", e a partir da capacitação de profissionais de saúde para modificações de rotinas e procedimentos, essa metodologia propõe-se a prevenir o desmame precoce (Lamounier, 1998; Yawman, 2003; Philipp e Merewood, 2004).

Em todo o mundo, pelo menos em 156 países, mais de 20 mil hospitais já receberam o título de "Hospital Amigo da Criança" (HAC), mas nem 500 deles estão localizados em países desenvolvidos (Hofvander, 2005; Philipp e Radford, 2006; UNICEF, 2009).

$\mathrm{Na}$ literatura, embora a implantação da IHAC esteja sendo relacionada com o aumento da freqüência de $A M$ e AME entre a população assistida por estas instituições, diferenciando-as daquelas que não implantaram tal iniciativa, alguns estudos reconhecem que esse incremento está especialmente associado ao início da amamentação, exclusiva ou não, e nem sempre à sua duração. Entre 336 lactentes nascidos em Boston, Massachusetts (EUA), Merewood et al. (2007) descrevem que apesar de as taxas de AM intra-hospitalar serem maiores que a média americana a partir da implementação dos "Dez Passos para o Sucesso do Aleitamento Materno", a exclusividade e a duração do AM não são. Entre 17.359 neonatos da Inglaterra, quando se compara egressos ou não de unidades 
com serviços materno-infantis credenciadas pelo UNICEF, o início do AM é significativamente mais freqüente nos primeiros, mas a sua prevalência ao 1.ำ mês é semelhante nos dois grupos (Bartington et al., 2006).

Outros estudos mostram que a adoção da IHAC prolonga o AM e o AME. Na Rússia, entre anos de 1999 e 2003, a prevalência do AM entre lactentes de seis a 12 meses aumentou 50\% nas áreas servidas por HAC, contra apenas $24 \%$ nas outras regiões (Abolyian, 2006). Questionários respondidos por mães de 2.861 lactentes suíços, de até 11 meses de idade, demonstram que aqueles nascidos em maternidades com melhor adesão às práticas Amigas da Criança recebem leite materno exclusivo por um período mais longo (Merten et al., 2005).

Em um estudo de intervenção, envolvendo 16.491 díades mãe-filho em hospitais da Bielo-Rússia, Kramer et al. (2001) observam que os nascidos nos estabelecimentos de saúde com programa de incentivo à amamentação implementado exibem maiores prevalências de AME aos três e seis meses de vida. Também no Chile, depois da implantação da IHAC, houve aumento significativo da prevalência de amamentação exclusiva no 6.ำ mês (Ossandón et al., 2000).

No Brasil, existem pelo menos 337 unidades hospitalares credenciadas como HAC (Lamounier et al., 2008), e de acordo com Araújo e Schmitz (2007) a aderência aos 10 passos preconizados pela IHAC é alta, variando de $91 \%$ a $99 \%$.

Em Montes Claros (MG), onde todas as maternidades do município são Amigas da Criança, a duração mediana do AME passa de 27 dias para 
3,5 meses, após a implantação da IHAC (Caldeira e Gonçalves, 2007). Já a análise comparativa de dois modelos para promoção do AME testados em Pernambuco, demonstra que ações unicamente intra-hospitalares estão associadas a altas taxas de utilização de LH como único alimento durante o período de internação, mas a manutenção do estímulo e apoio, com visitas domiciliares, é que vai garantir a exclusividade da amamentação por tempo mais prolongado (Coutinho et al., 2005). Da mesma forma, Braun et al. (2003) verificando as freqüências de AME entre lactentes nascidos no Hospital de Clínicas de Porto Alegre, antes e depois do título de HAC, percebem que as altas taxas iniciação não são mantidas no decorrer dos meses.

Em Joinville, diferentemente da maior parte dos artigos publicados, não foi observada diferença significativa entre as taxas de AME dos nascidos no HAC e aquelas dos nascidos em outros hospitais da cidade. Apesar das duas outras maternidades do município não serem detentoras do título, estas também promovem e apóiam a amamentação de modo regular, bem como referenciam nutrizes com problemas na lactação para o Banco de Leite Humano localizado na maternidade pública. É sabido que nos municípios com hospitais com programas oficiais de estímulo ao AM, estes funcionam como facilitadores da disseminação de informações consistentes sobre a importância do LH na alimentação infantil (Venancio et al., 2002). 


\subsubsection{Local de atendimento do lactente}

A assistência ao crescimento e desenvolvimento das crianças, para a promoção da saúde e prevenção de doenças, pode ser realizada tanto nos serviços públicos, como privados de saúde. Em nosso meio, o atendimento de puericultura pelo SUS é geralmente levado a cabo nas unidades básicas de saúde, e pelo sistema de saúde suplementar, nas clínicas ou consultórios médicos particulares.

Silva e Souza (2005), em um estudo transversal envolvendo 255 lactentes entre quatro e 12 meses de vida, originários de três postos de saúde municipais e de cinco consultórios particulares da cidade de Lins, no interior do estado de São Paulo, observam que o local de seguimento ambulatorial como fator determinante do AM não exclusivo aos seis meses não foi estatisticamente significativo.

Lactentes de até 180 dias, usuários do serviço público de saúde de Londrina (PR), apresentam duas vezes mais chance de abandono do AME que os atendidos pelo sistema de saúde suplementar (Vanucchi et al., 2005).

Entre 1.708 lactentes menores de dois anos, na cidade em Campinas, há descrição de que se as consultas de puericultura são realizadas na rede pública o risco de desmame é menor que nos acompanhados em consultório privado (Camilo et al., 2004).

Dados de 111 municípios do estado de São Paulo demonstram que o atendimento do lactente em serviço privado determina maior chance de AME em menores de seis meses, mas apenas nas cidades que não implementam ações municipais pró-amamentação. Essas ações seriam importantes para 
diminuir as desigualdades sociais que interferem com a manutenção do AME (Venancio, 2002).

Sabe-se que mesmo em comunidades de baixo nível socioeconômico, intervenções específicas podem aumentar a prevalência da amamentação exclusiva. No Maranhão, em lactentes de três meses de idade atendidos pela Pastoral da Criança, a taxa de AM exclusivo e predominante é $54,2 \%$, mais que o dobro dos $24,7 \%$ encontrados em lactentes que não recebem esse atendimento (Neumann et al., 2002).

Nessa pesquisa, o abandono do AME não esteve associado ao acompanhamento de puericultura ser realizado na rede pública ou privada de saúde. Possivelmente, o Banco de Leite Humano existente na cidade, sendo referência estadual, teve papel importante como difusor de informações e centro de incentivo ao AM. Ele é responsável pelo atendimento de mães que necessitam orientação na amamentação e que são encaminhadas tanto da rede pública de saúde, como dos hospitais e consultórios privados.

\subsubsection{Profissional responsável pelo atendimento de puericultura}

É sabido que tanto a atitude positiva, quanto o conhecimento e a experiência em manejo clínico da amamentação do profissional de saúde são capazes de influenciar a decisão materna de optar pelo aleitamento natural. 
Entre os fatores associados com o início do AM de 506 mulheres de origem chinesa, residentes na Austrália, o apoio de médicos e enfermeiras foi estatisticamente significativo (Li et al., 2004).

A recomendação e encorajamento por parte dos médicos durante o pré-natal e pós-parto são cruciais (Kovach, 2002; ACOG, 2007; Dhandapany et al., 2008), mas deve haver uniformidade nas informações repassadas às mães por toda a equipe de cuidados de saúde (Harris e Hall, 2007). Infelizmente, os profissionais de saúde continuam não prestando uma assistência tão competente e integral como a desejada e esperada pelas mulheres nutrizes (Dillaway e Douma, 2004).

O pediatra generalista, ao cuidar do ser humano em desenvolvimento, trabalha com prevenção, visando a saúde além do período da infância, pois ser um adulto saudável depende de cuidados adequados nas fases iniciais da vida (Cabana e Atkinson-McEvoya, 2007). A importância do pediatra como responsável pela nutrição de lactentes e crianças, e especialmente, pela promoção do AME está bem documentada (AAP, 2005). Não obstante, ao comparar os conhecimentos, as atitudes e as práticas pediátricas no que diz respeito a amamentação nos anos de 1995 e 2004, Feldman-Winter et al. (2008) relatam que recentemente, apesar de um maior número de pediatras recomendar o AME e seguir as políticas próaleitamento dos hospitais, um grupo significativo deles não acredita que as vantagens da lactação natural superem suas dificuldades ou inconveniências, e nem que todas as mulheres são capazes de amamentar. 
Cabe salientar que a avaliação de sete livros-texto americanos de pediatria, realizada por Philipp et al. (2004), demonstra que, embora todos identifiquem o AM como o modo mais natural e seguro de alimentação para a criança pequena, eles contêm erros e informações ultrapassadas, bem como recomendações inconsistentes sobre a lactação natural. Dessa forma, os pediatras são insuficientemente preparados para orientar as mães nessa área do conhecimento. É sabido, também, que se o pediatra recomenda suplementação com fórmula infantil pelo baixo ganho de peso do lactente ou se ele considera que seu incentivo para uma amamentação mais prolongada não é importante para a mãe, as nutrizes têm maior risco de abandono do AME às 12 semanas pós-parto (Taveras et al., 2004).

A educação em AM parece motivar aumento no cumprimento das políticas da IHAC, nas taxas de AME intra-hospitalar e na credibilidade nas vantagens da lactação natural, porém não afeta a atitude do profissional diante da amamentação (Martens, 2000). Um estudo randomizado, envolvendo 33 pediatras e nutricionistas servidores da saúde do município de São Paulo, demonstra que após um curso de capacitação sobre alimentação infantil há aumento do conhecimento sobre aconselhamento em nutrição na infância, AM e alimentação complementar, com conseqüente expressivo progresso na qualidade da anamnese alimentar, mas essa intervenção não foi efetiva nem em melhorar a avaliação nem a orientação nutricional (Bassichetto e Réa, 2008).

Há necessidade de maior educação e treinamento dos pediatras no manejo clínico da lactação e aconselhamento em AM, para que estimulem e 
apóiem a decisão consciente das famílias sobre a alimentação de seus filhos, com conseqüente incremento nos índices de amamentação (Réa, 2003; Philipp et al., 2004; Bueno e Teruya, 2004). Santiago et al. (2003), avaliando 101 crianças em Uberaba (MG), descreve que se o lactente é acompanhado por pediatra sem treinamento em manejo clínico da lactação, a chance de abandono do AME aos quatro meses é significativamente maior que quando esse seguimento é realizado por equipe multiprofissional de amamentação ou por pediatra treinado em AM.

Há evidência de uma discreta primazia do PSF sobre as atividades de unidades básicas tradicionais, especialmente por determinar maior vínculo e envolvimento comunitário (Conill, 2008). Também é descrito que o PSF é uma estratégia facilitadora da promoção e do apoio ao AM (Faleiros et al., 2005). Caldeira et al. (2008) verificam que o treinamento das equipes de Saúde da Família, de Montes Claros (MG), no manejo clínico da amamentação foi eficaz em aumentar significativamente a duração mediana do AME de 104 para 125 dias.

Verificou-se nesta pesquisa que não houve diferença significativa em relação à prática do AME entre os pacientes atendidos por pediatra ou por médicos de Saúde da Família, porque os esses últimos receberiam maior treinamento em serviço, já incorporado em suas atividades habituais, incluindo capacitações em manejo clínico do AM. 


\subsection{Considerações finais}

De maneira geral, os resultados encontrados nesse estudo foram bastante animadores, justificando e valorizando os investimentos e esforços pró-amamentação desenvolvidos regularmente há mais de dez anos no município de Joinville, tais como a promoção da Semana Mundial de AM, manutenção de um "Hospital Amigo da Criança" com Banco de Leite, oferta de treinamento segundo a metodologia do curso de 20 horas do UNICEF para profissionais de maternidades e realização de pesquisas sobre AM. Venancio e Monteiro (2006) consideram que as cidades que promovem pelo menos quatro ações em favor do AM, aumentam a chance de suas crianças serem amamentadas exclusivamente nos primeiros seis meses de vida.

A confiança materna na amamentação precisa ser estimulada, pois é sabido que muitas mulheres abandonam o AME mais pelas dificuldades encontradas e por falta de apoio, que por escolha própria (Dennis, 1999). A motivação é fundamental para a decisão de amamentar, mas esta depende das crenças pessoais da mulher e do apoio que ela recebe de sua família e da sociedade. A educação e o aconselhamento em amamentação têm grande impacto sobre a nutrição infantil, já que populações mais informadas e esclarecidas costumam ser mais motivadas e ter melhores condições para nortear suas ações de forma a fazerem escolhas mais benéficas à saúde (Heinig, 2004; Moreira, 2007).

Com o intuito de melhorar os indicadores de saúde, há real necessidade de incrementar os programas de proteção, promoção e apoio ao AME, tornando-os mais atraentes, especialmente, para as famílias menos 
privilegiadas (Aidam et al., 2005). Nesse contexto, o desenvolvimento de ações que se proponham a ensinar e estimular a adoção de hábitos saudáveis é ainda mais importante (Moreira, 2007).

O acesso à informação é portanto essencial para a mudança dos hábitos alimentares na infância. Costumes deletérios, tal como o uso de chupetas e mamadeiras - embora fortemente enraizados na cultura popular podem ser modificados ante a intervenção de profissionais de saúde apropriadamente capacitados a lidar com os problemas da lactação, à luz das características culturais de suas comunidades (Cunha et al., 2005).

Mais que simples mensagens de estímulo, a nutriz necessita soluções realistas para superar as barreiras à amamentação, e deve ser munida de todas as informações e ferramentas para acreditar que o AM é uma opção viável (Heinig, 2009). A amamentação ainda é incentivada como um ato natural, decorrente do instinto materno, apesar de já ter sido reconhecido que esse fenômeno é culturalmente determinado (Araújo e Almeida, 2007). O AM precisa ser aprendido tanto pela mulher quanto pelo profissional assistente, de maneira especial o pediatra, cujos saberes devem ser sempre atualizados (Abrão, 2006; OlaOlorun e Lawoyin, 2006).

Cuidado especial deve ser tomado para que seja garantida a educação continuada dos membros da equipe de saúde, pois são eles que no contato com as mães, seguros de suas habilidades e conhecimentos em AM, serão efetivos em informá-las e convencê-las a optar pelo AME e estender sua duração (Ludvigsson, 2003b). Os trabalhadores da saúde são partes-chave dessas iniciativas e devem ter a responsabilidade de apoiar as 
mulheres para que elas possam integrar o AM na vida cotidiana e nos locais de trabalho (ACOG, 2007).

Todavia, mesmo em um ambiente favorável com um profissional de saúde capacitado e disponível, muitas mães costumam confiar em seus próprios instintos e em conselhos recebidos de familiares e amigos, não obstante esses sejam contrários à recomendação clínica (Heinig et al., 2009; Racine et al., 2009).

Por essa razão, é preciso incentivar a aceitação cultural e a proteção ao AM, através da educação e da propaganda. Não há dúvida que estratégias de "marketing" afetam uma tomada de decisão, especialmente influenciando as práticas de alimentação infantil. Assim, campanhas para promover a lactação natural na mídia deveriam adotar uma abordagem mais abrangente de "marketing" social, utilizando um conjunto de técnicas e intervenções específicas para transformar o modo pelo qual um determinado segmento populacional percebe a questão do AM, e promover mudanças comportamentais sobre essa prática (Shealy et al., 2005). O ensino do AM também poderia ser incorporado a todos os níveis de educação, tanto formal quanto informal, em escolas, universidades, grupos de gestantes ou de pais, e nas comunidades, em geral (Besculides et al., 2005; ABM, 2008).

Apesar de todas as iniciativas desenvolvidas no Brasil para estimular a prática da amamentação e que permitiram um aumento das taxas de AME até o sexto mês e da duração mediana da amamentação, ainda estamos aquém do ideal recomendado. Portanto, para uma melhor assistência às nutrizes, novos modelos de cuidados de saúde em AM podem ser 
necessários (Shaikh e Smillie, 2008). Melhores resultados, no que diz respeito à manutenção do $\mathrm{AME}$ e do $\mathrm{AM}$, e à satisfação das mães com o apoio recebido, têm sido observados com a implantação "Iniciativa Unidade Básica Amiga da Amamentação" (Oliveira e Camacho, 2002; Oliveira et al., 2003; Cardoso et al., 2008).

Considerando esse fato, o Ministério da Saúde propôs a formação de um trabalho em rede, com foco na atenção básica, denominado "Rede Amamenta Brasil". Respeitando as diferenças locais e regionais, de forma a aumentar a resolutividade de suas ações e estimular o AM em todo território nacional, a "Rede Amamenta Brasil" promove troca de conhecimento e experiências entre os diversos profissionais integrantes da rede básica de saúde, que prestam cuidados aos usuários desses serviços, com o apoio de um grupo especializado. Através da Educação Permanente em Saúde seria estimulado o desenvolvimento de competências em AM, com treinamento de todas as categorias funcionais, incluindo agentes comunitários, agentes administrativos, técnicos de enfermagem, enfermeiros, médicos, dentistas, e se disponíveis, também os farmacêuticos, psicólogos, fonoaudiólogos, assistentes sociais e terapeutas ocupacionais (Brasil, 2008).

A questão da amamentação exclusiva deve ser uma prioridade da agenda, não apenas dos governos, mas da sociedade civil organizada. Educar a sociedade sobre o AM pode aumentar a consciência pública a respeito dos benefícios do $\mathrm{LH}$, criando uma atmosfera positiva em favor da amamentação e beneficiando as mulheres para que tomem uma decisão 
consciente a respeito da nutrição de seus filhos, e também sobre a exposição de lactentes amamentados a bicos e chupetas. 
6. CONCLUSÕES 


\section{CONCLUSÕES}

1. A prevalência do $A M$ em lactentes com idade inferior a um ano foi de $72,5 \%$.

2. A prevalência do $A M$ em menores de seis meses foi de $84,1 \%$, sendo que o índice de $A M$ exclusivo foi $43,7 \%$.

3. A prevalência do $A M$ em menores de quatro meses foi de $89,8 \%$, sendo que o índice de $A M$ exclusivo foi 53,9\%.

4. As freqüências de utilização de chupetas e mamadeiras em lactentes com idade inferior a um ano foram 51,3\% e 51,1\%, respectivamente.

5. Os fatores associados à ausência de AME em lactentes menores de seis meses, em análise multivariada foram: maior idade do lactente, uso de chupeta e menor escolaridade materna. 
7. ANEXOS 
ANEXO A - Definições e indicadores recomendados pela OMS (1991), utilizados pelo Projeto Amamentação e Municípios do ISSESSP ?

Termos e definições do Aleitamento Materno

ALEITAMENTO MATERNO: a criança recebe leite materno (diretamente do peito ou ordenhado).

ALEITAMENTO MATERNO EXCLUSIVO: a criança recebe apenas leite materno de sua mãe ou ama-de-leite, ou leite materno ordenhado, e não recebe outros líquidos ou sólidos com exceção de vitaminas, suplementos minerais ou medicamentos.

ALEITAMENTO MATERNO PREDOMINANTE: a fonte predominante de nutrição da criança é o leite materno. Porém, a criança também pode receber água e bebidas à base de água (água açucarada e com sabores, infusões, chá, etc); suco de frutas; solução de sais de hidratação oral (SRO); vitaminas, minerais e medicamentos em gotas ou xaropes, e líquidos cerimoniais (em quantidades limitadas).

ALEITAMENTO MATERNO EXCLUSIVO E ALEITAMENTO MATERNO PREDOMINANTE: juntas constituem o aleitamento materno completo.

ALIMENTAÇÃO COMPLEMENTAR: a criança recebe leite materno e alimentos sólidos (ou semi-sólidos).

ALIMENTAÇÃO COM MAMADEIRA: a criança recebe líquidos (incluindo leite materno) ou alimentos semi-sólidos em mamadeira. 
Grupos de idade para a medida de indicadores baseados nas recomendações sobre alimentação infantil.

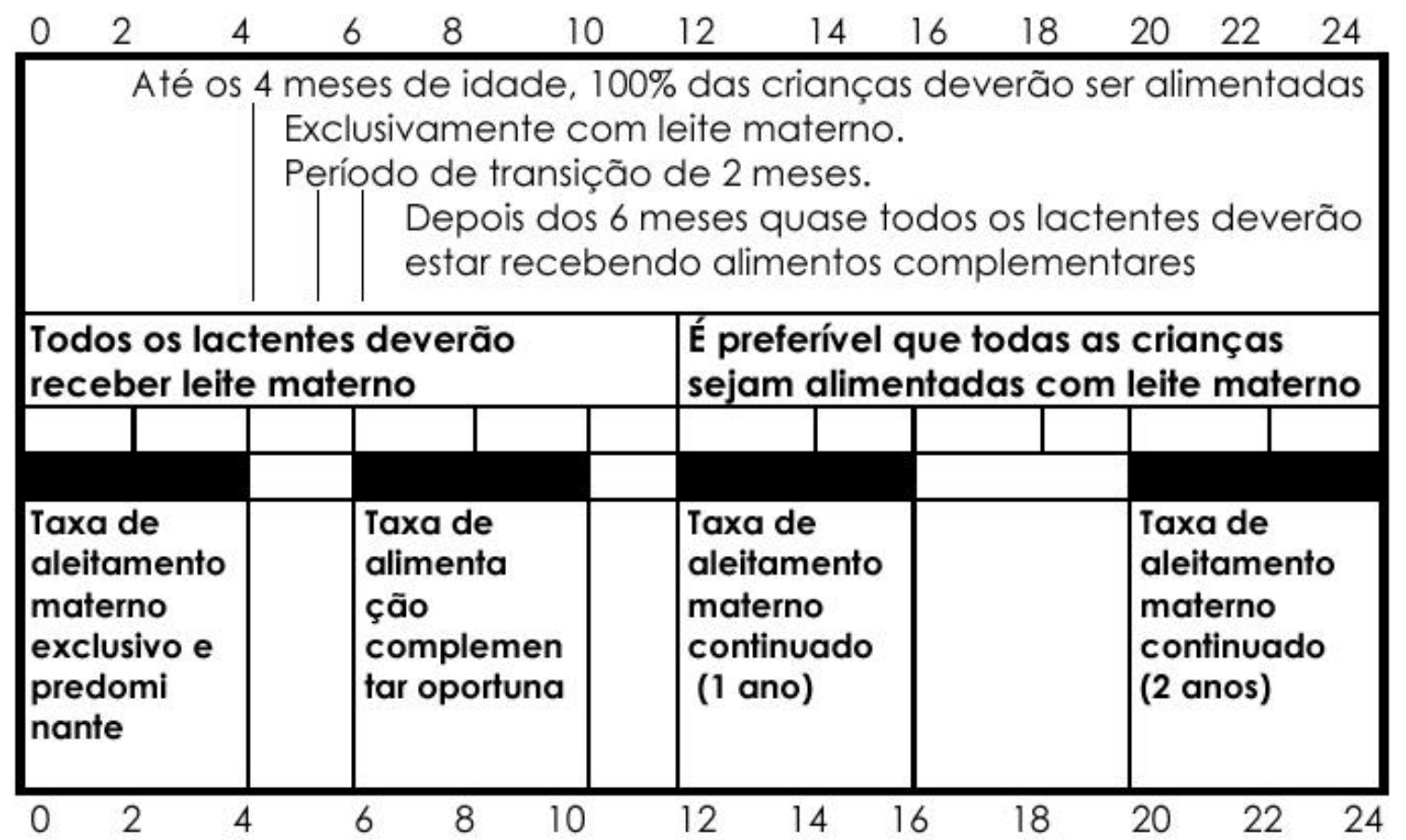

Observação: Em 2001 a Assembléia Mundial de Saúde aprovou a recomendação de $\mathrm{AME}$ até 0 6. mês e a introdução de alimentos complementares a partir dessa idade, com manutenção de aleitamento até os 2 anos de vida ou mais. Dessa forma, a taxa de amamentação exclusiva passa a ser medida também na faixa etária de 0 a 6 meses.

Propõe-se que os indicadores listados a seguir sejam obtidos utilizando-se dados atuais sobre alimentação infantil (current status), através de recordatório de 24 horas.

?Instituto de Saúde da Secretaria Estadual de Saúde de São Paulo (ISSESSP). Manual do Supervisor - Projeto Amamentação e Municípios. Núcleo de investigação em Nutrição. Núcleo de Investigação em Epidemiologia. São Paulo: IS-SESSP, 2007.

Disponível em

http://www.isaude.sp.gov.br/amamunic/tr2007/man_supervisor_2007.pdf 


\section{Indicadores}

\section{TAXA DE ALEITAMENTO MATERNO EXCLUSIVO (AME)}

Criancas $<4$ meses ( $<120$ dias) que estavam em AME nas últimas $24 \mathrm{~h}$ Crianças menores de 4 meses ( 120 dias) de idade

$\underline{\text { e }}$

Criancas $<6$ meses ( $<180$ dias) que estavam em AME nas últimas $24 \mathrm{~h}$ Crianças menores de 6 meses ( 180 dias) de idade

\section{TAXA DE ALEITAMENTO MATERNO PREDOMINANTE (AMP)}

Criancas $<4$ meses ( $<120$ dias) que estavam em AMP nas últimas $24 \mathrm{~h}$

Crianças menores de 4 meses (120 dias) de idade

$\underline{\mathrm{e}}$

Criancas $<6$ meses ( $<180$ dias) que estavam em AMP nas últimas $24 \mathrm{~h}$

Crianças menores de 6 meses ( 180 dias) de idade

TAXA DE ALEITAMENTO MATERNO EXCLUSIVO + PREDOMINANTE (AMEP)

Criancas $<4$ meses ( $<120$ dias) que estavam em AMEP nas últimas $24 \mathrm{~h}$

Crianças menores de 4 meses (120 dias) de idade

$\underline{\mathbf{e}}$

Criancas $<6$ meses ( $<180$ dias) que estavam em AMEP nas últimas $24 \mathrm{~h}$ Crianças menores de 6 meses (180 dias) de idade

TAXA DE ALIMENTAÇÃO COMPLEMENTAR OPORTUNA (ACO)

Crics. 6-9 meses (180-299 dias) amamentadas que receberam alimentos complementares nas últ. 24! Crianças 6-9 meses (180-299 dias) de idade

TAXA DE ALIMENTAÇÃO COM MAMADEIRA

Criancas $<12$ meses que receberam alimentos em mamadeira nas últimas $24 \mathrm{~h}$ Crianças $<12$ meses de idade 
ANEXO B - Formulários para anotação das crianças vacinadas

\section{REGISTRO DE COLETA DE DADOS - Unidade:}

Registre no quadro abaixo cada uma das crianças vacinadas com idade inferior a 1 ano. Basta contar seqüencialmente, linha a linha, e identificar com " $X$ " cada uma delas.

Os campos ESCUROS correspondem às crianças cujos acompanhantes devem ser entrevistados, que devem ser marcados com "E".

Em caso de recusa em participar por parte do acompanhante, marque com "R" o campo correspondente e entreviste o PRÓXIMO (este marcado com "E").

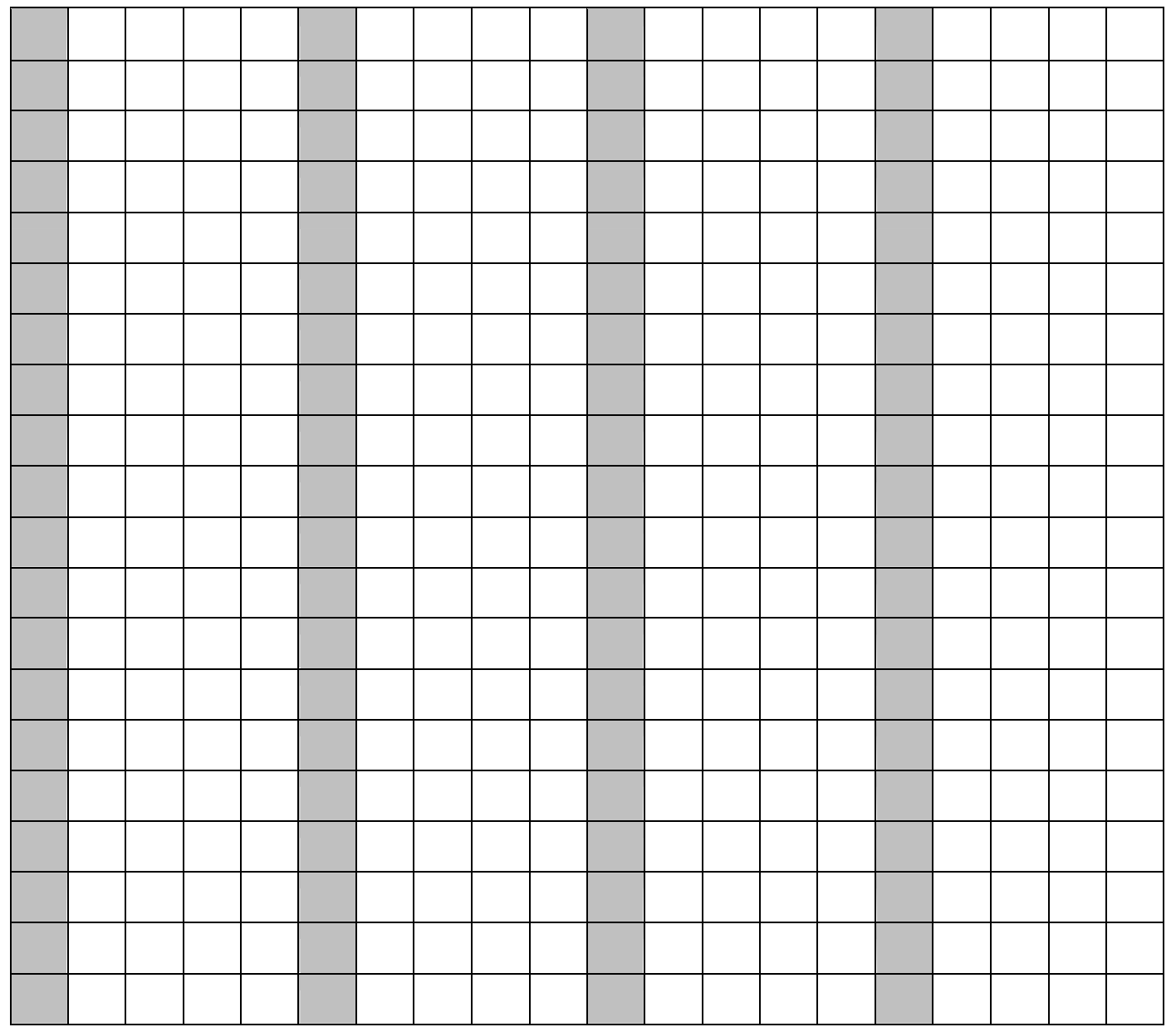




\section{REGISTRO DE COLETA DE DADOS - Unidade:}

Registre no quadro abaixo cada uma das crianças vacinadas com idade inferior a 1 ano. Basta contar seqüencialmente, linha a linha, e identificar com " $X$ " cada uma delas.

Os campos ESCUROS correspondem às crianças cujos acompanhantes devem ser entrevistados, que devem ser marcados com "E".

Em caso de recusa em participar por parte do acompanhante, marque com "R" o campo correspondente e entreviste o PRÓXIMO (este marcado com "E").

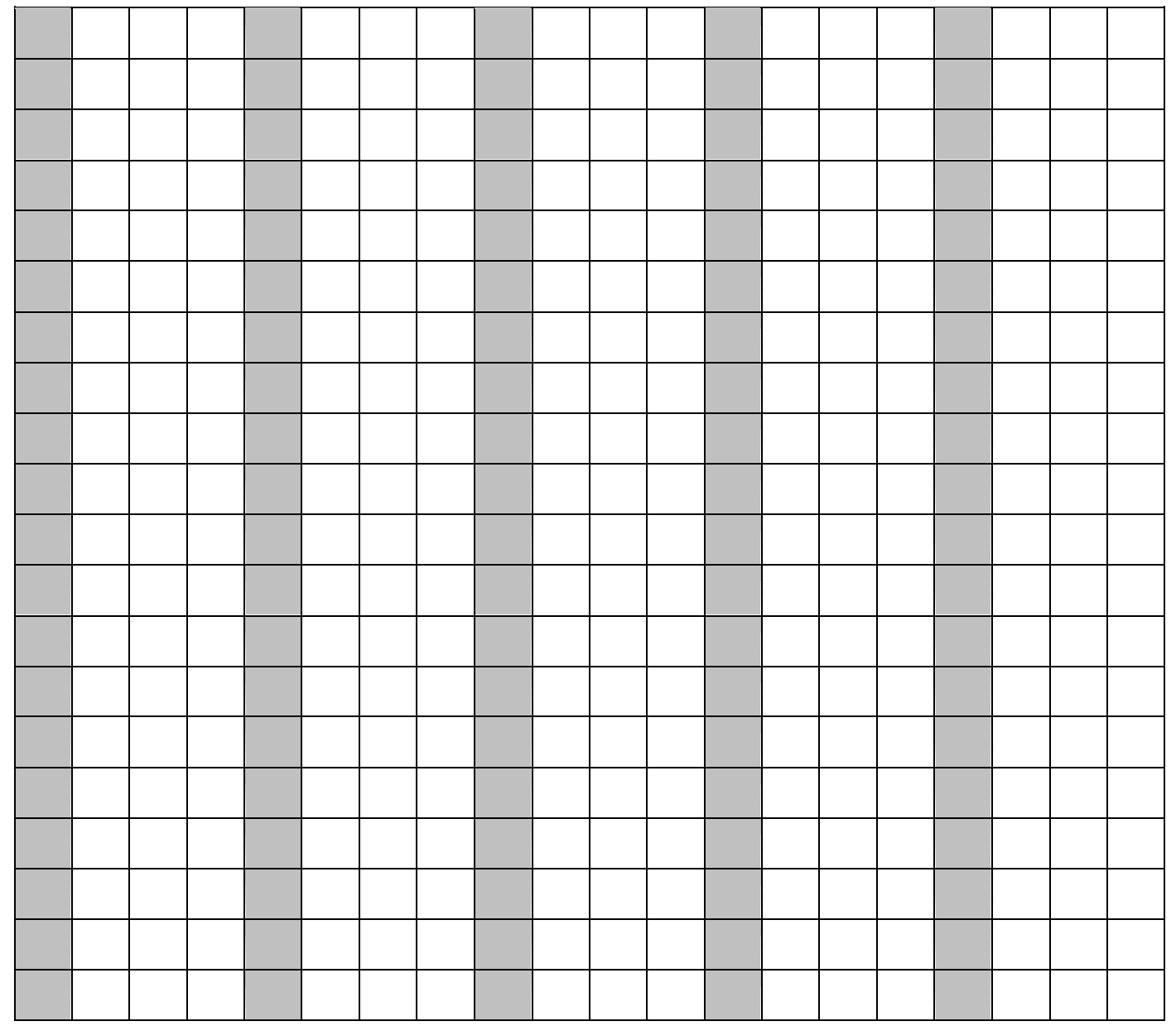




\section{REGISTRO DE COLETA DE DADOS - Unidade:}

Registre no quadro abaixo cada uma das crianças vacinadas com idade inferior a 1 ano. Basta contar seqüencialmente, linha a linha, e identificar com "X" cada uma delas.

Os campos ESCUROS correspondem às crianças cujos acompanhantes devem ser entrevistados, que devem ser marcados com "E".

Em caso de recusa em participar por parte do acompanhante, marque com "R" o campo correspondente e entreviste o PRÓXIMO (este marcado com "E").

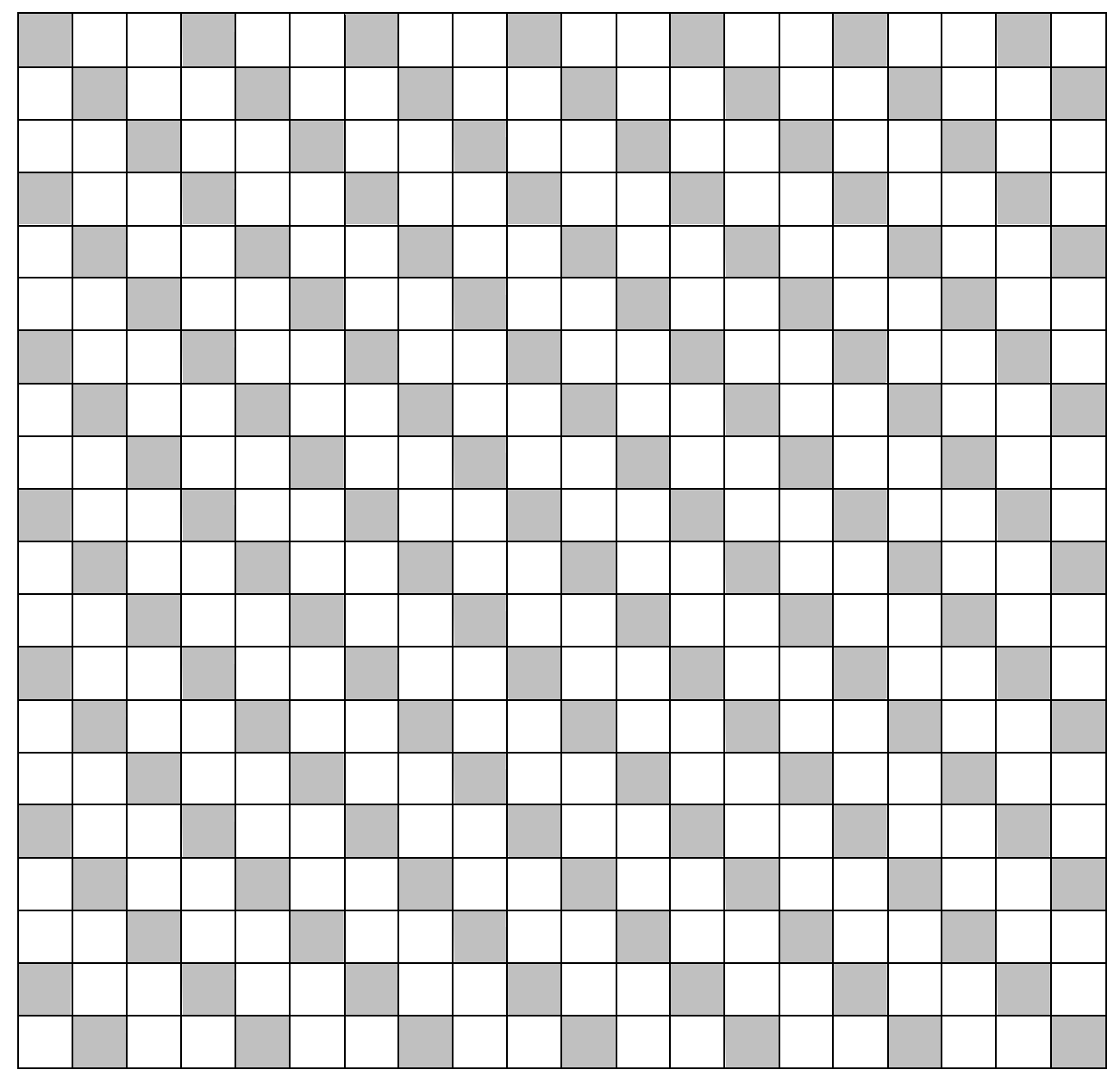




\section{REGISTRO DE COLETA DE DADOS - Unidade:}

Registre no quadro abaixo cada uma das crianças vacinadas com idade inferior a 1 ano. Basta contar seqüencialmente, linha a linha, e identificar com "X" cada uma delas.

Os campos ESCUROS correspondem às crianças cujos acompanhantes devem ser entrevistados, que devem ser marcados com "E".

Em caso de recusa em participar por parte do acompanhante, marque com "R" o campo correspondente e entreviste o PRÓXIMO (este marcado com "E").

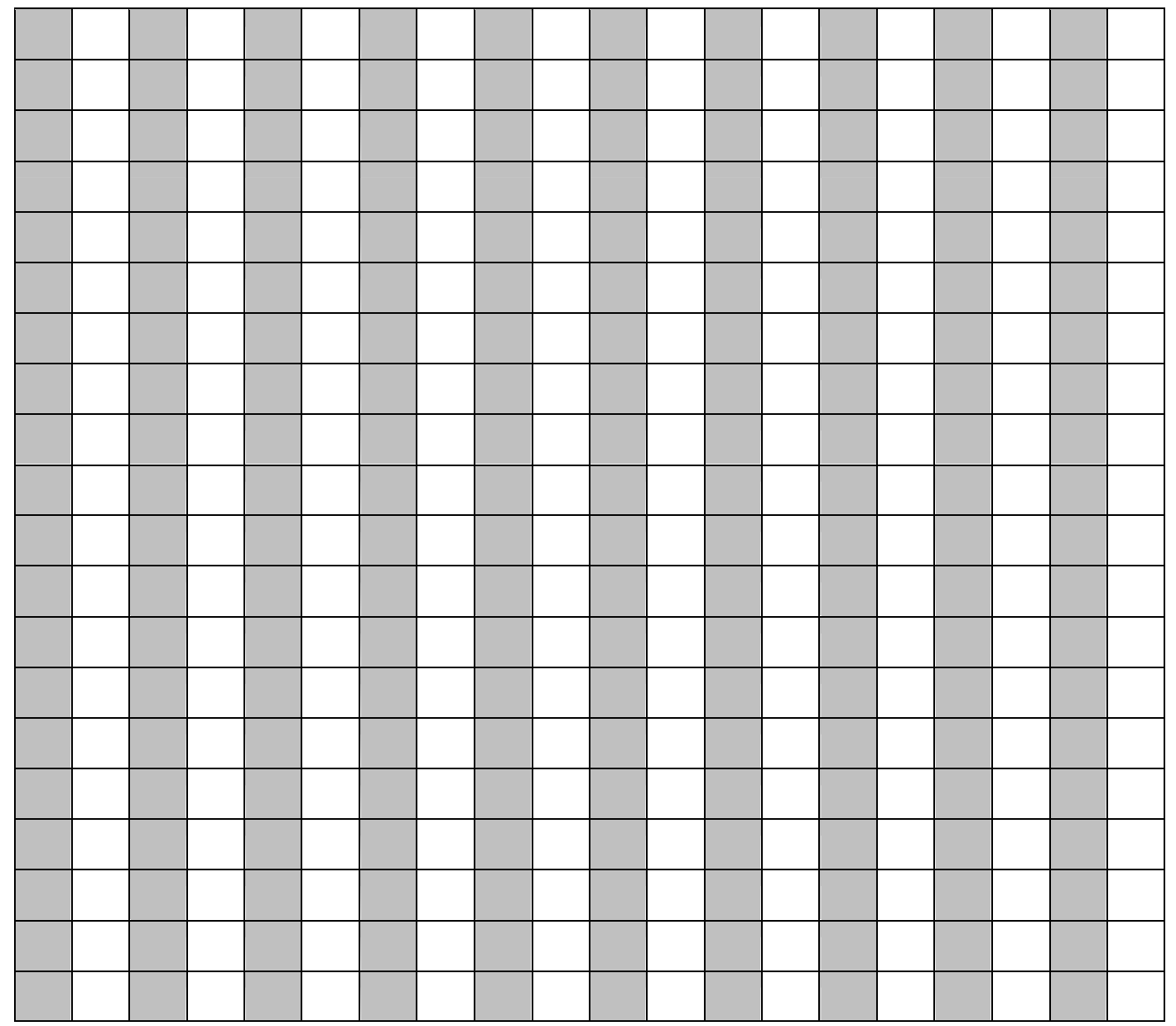




\section{REGISTRO DE COLETA DE DADOS - Unidade:}

Registre no quadro abaixo cada uma das crianças vacinadas com idade inferior a 1 ano. Nesta Unidade de Saúde os acompanhantes de todas as crianças devem ser entrevistados. Assim, basta contar seqüencialmente, linha a linha, e identificar com "E" cada uma das crianças cujos acompanhantes foram entrevistados.

Em caso de recusa em participar por parte do acompanhante, marque com "R" o campo correspondente e entreviste o PRÓXIMO (este marcado com "E").

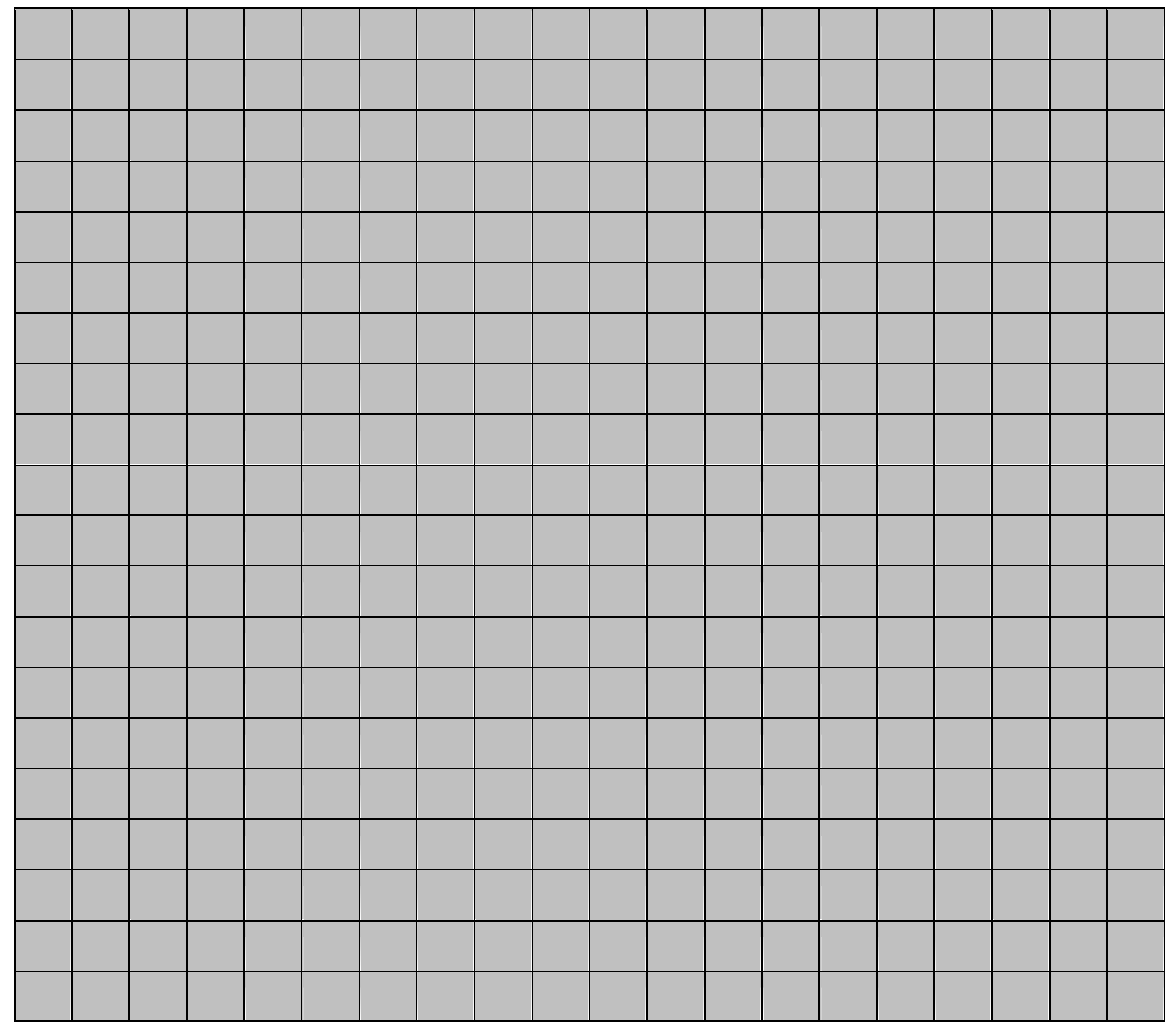


ANEXO C - Consentimento informado

\section{Termo de Consentimento Livre e Esclarecido}

Caro participante,

Estamos realizando uma pesquisa sobre hábitos alimentares de crianças menores de 1 ano de idade em vários postos de vacinação do município de Joinville. Os resultados deste estudo vão permitir melhorar a assistência à saúde das crianças em nossa cidade.

Peço, assim, sua colaboração hoje, solicitando que o(a) senhor(a) responda a um questionário.

Serão tomados todos os cuidados para manter o sigilo e o anonimato das informações fornecidas, visando resguardar sua identidade e privacidade.

Esclareço ainda que fica garantido o seu desejo de não participar do estudo, se assim o desejar e também de recusar-se a responder a quaisquer perguntas sem se justificar.

Desde já, agradeço sua atenção, interesse e colaboração.

DRA. SELMA CRISTINA FRANCO

ATENÇÃO: A sua participação em qualquer tipo de pesquisa é voluntária. Em caso de dúvida quanto aos seus direitos, escreva para o Comitê de Ética em Pesquisa da UNIVILLE. Endereço: Campus Universitário - Bom Retiro - Caixa Postal 246 CEP 89201-972 Joinville - SC, Fone: 461-9039. 
ANEXO D - Instrumento de coleta de dados

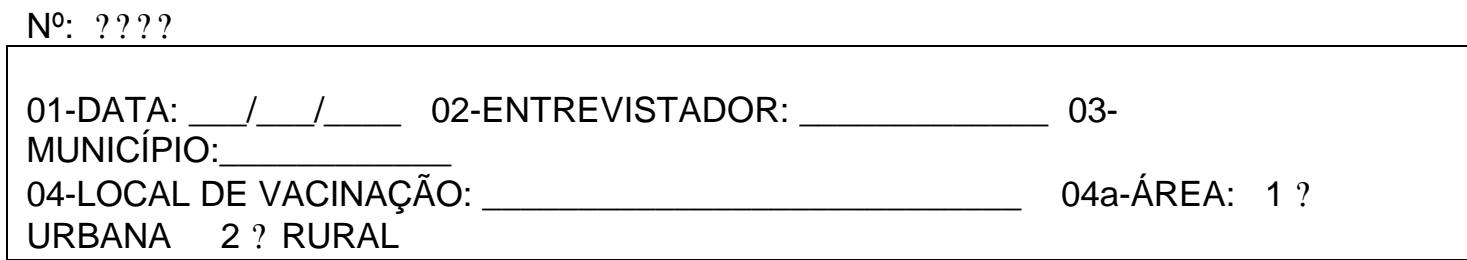

\section{FAZER AS PERGUNTAS DO QUADRO ABAIXO PARA TODAS AS CRIANÇAS COM} MENOS DE 1 ANO DE IDADE QUE COMPARECEREM À VACINAÇÃO

05-A SRA. (SR.) PODE ME DIZER O NOME DESTA CRIANÇA? (anote apenas o 1ำ nome) 06-DATA DE NASCIMENTO DA CRIANÇA: Vacinação) (copie da Caderneta de 06a-SEXO: ? Masculino ? Feminino 07-A SRA. É A MÃE DA CRIANÇA? 1 ? Sim 2 ? Não

\section{O QUE COMEU DE ONTEM PARA HOJE?}

A SRA. (OU SR.) PODE ME DIZER QUAIS ALIMENTOS ESTA CRIANÇA TOMOU OU COMEU DESDE ONTEM DE MANHÃ ATÉ HOJE DE MANHÃ?

EU VOU FALAR O NOME DE CADA ALIMENTO E A SRA. (SR.) ME RESPONDE SIM OU NÃO, ESTÁ BEM?

08-LEITE DE PEITO? 1 ? Sim 2 ? Não 3 ? Não sabe 09-SE TOMOU LEITE DE PEITO, QUANTAS VEZES? (Anotar 8 se for 8 vezes ou mais) 99? Não sabe

10-LEITE EM PÓ? 1 ? Sim 2 ? Não 3 ? Não sabe

11-SE TOMOU LEITE EM PÓ, QUAL A MARCA?

4? Não sabe

\section{? PREENCHIMENTO EXCLUSIVO PELO SUPERVISOR DE CAMPO: \\ 1 ? FÓRMULA INFANTIL 2 ? LEITE INTEGRAL 3 ? OUTRO TIPO DE LEITE EM} PÓ

12-OUTRO LEITE? 1 ? Sim 2 ? Não 3 ? Não sabe

13-MINGAU OU PAPA? 1? Sim 2 ? Não 3 ? Não sabe

14-SOPA DE LEGUMES? 1 ? Sim 2 ? Não 3 ? Não sabe

15-SE TOMOU SOPA, COM CARNE? 1 ? Sim 2 ? Não 3 ? Não sabe

16-COMIDA DE PANELA? 1 ? Sim 2 ? Não 3 ? Não sabe

17-SE COMEU COMIDA, COM CARNE? 1 ? Sim 2 ? Não 3 ? Não sabe

18-SE COMEU COMIDA, COM FEIJÃO? 1 ? Sim 2 ? Não 3 ? Não sabe

19-ÁGUA PURA? 1 ? Sim 2 ? Não 3 ? Não sabe

20-ÁGUA COM AÇÚCAR? 1 ? Sim 2 ? Não 3 ? Não sabe

21-CHÁ? 1 ? Sim 2 ? Não 3 ? Não sabe

22-SUCO DE FRUTA? 1 ? Sim 2 ? Não 3 ? Não sabe

23-FRUTA (EM PEDAÇO OU AMASSADA)? 1 ? Sim 2 ? Não 3 ? Não sabe

23a-OUTROS? 1 ? Sim 2 ? Não 3 ? Não sabe

24-ALGUM DESSES ALIMENTOS (OU LÍQUIDOS) FOI DADO POR MAMADEIRA OU

CHUQUINHA?

1 ? Sim 2 ? Não 3 ? Não sabe

25-A CRIANÇA CHUPA CHUPETA? 1 ? Sim 2 ? Não 3 ? Não sabe 


\section{FAZER AS PERGUNTAS DO QUADRO ABAIXO PARA TODAS AS CRIANÇAS MENORES DE 1 ANO}

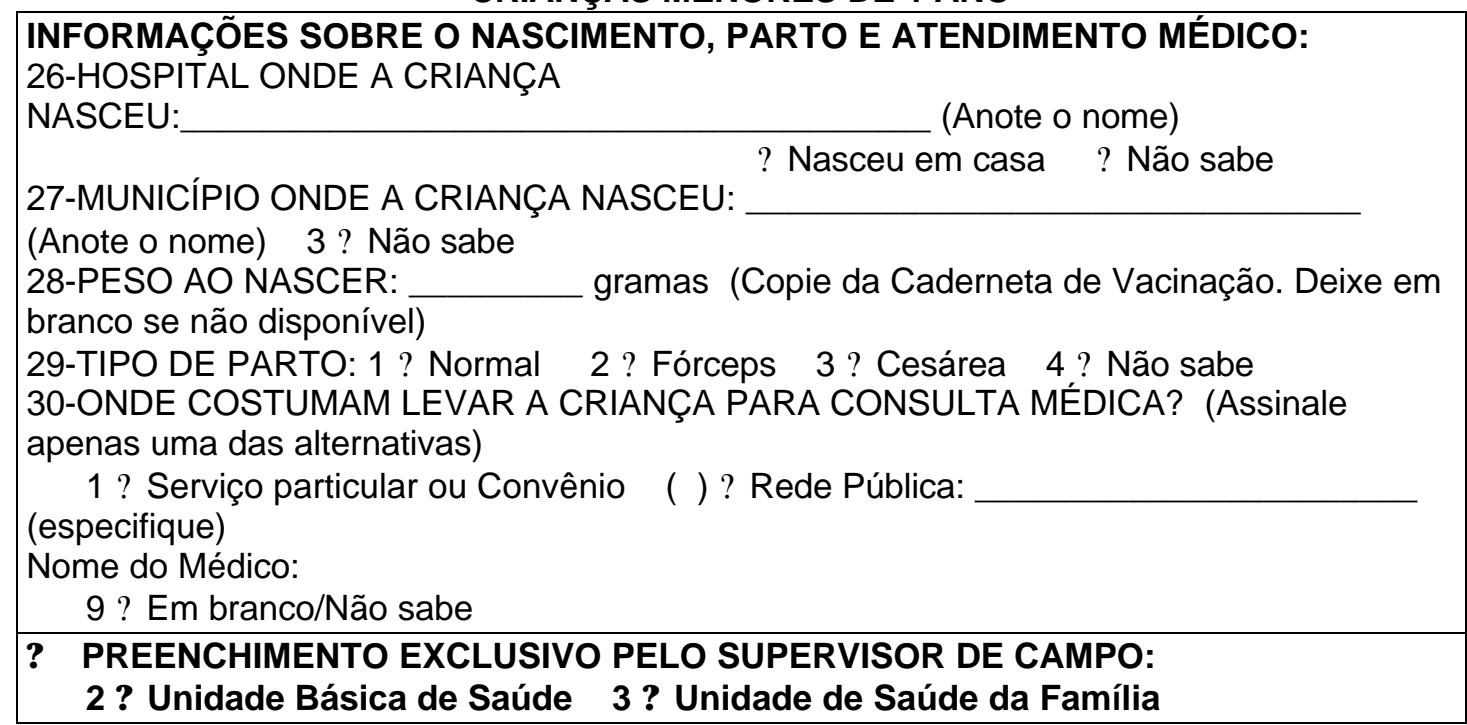

\section{FAZER AS PERGUNTAS DO QUADRO ABAIXO APENAS PARA AS CRIANÇAS MENORES DE 4 MESES}



\section{FAZER AS PERGUNTAS DO QUADRO ABAIXO APENAS QUANDO O ACOMPANHANTE DA CRIANÇA FOR A MÃE}

37-QUAL É A SUA IDADE? anos

38-ESTA CRIANÇA É SEU PRIMEIRO FILHO? 1 ? Sim 2 ? Não (Considere apenas os filhos nascidos vivos)

39-A SRA. SABE LER E ESCREVER? 1? Sim 2 ? Não

40-A SRA. ESTÁ ESTUDANDO? 1? Sim (Passe para a questão 42) 2 ? Não

41-A SRA. JÁ FREQÜENTOU A ESCOLA? 1? Sim 2? Não (Passe para a questão 44)

42-QUAL A ÚLTIMA SÉRIE QUE COMPLETOU?

43-E GRAU?

44-A SRA. TRABALHAVA FORA DE CASA QUANDO ENGRAVIDOU DESTA CRIANÇA?

1? Sim 2 ? Não

45-SE TRABALHOU DURANTE A GRAVIDEZ, TEVE LICENÇA MATERNIDADE?

1 ? Sim 2 ? Não (Passe para a questão 47) 3 ? Não se aplica (Passe para a questão 47)

46-AINDA ESTÁ DE LICENÇA MATERNIDADE? 1 ? Sim 2 ? Não

47-ATUALMENTE A SRA. ESTÁ TRABALHANDO FORA DE CASA? 1 ? Sim 2 ? Não

Observações: 


\section{ANEXO E}

\section{ANÁLISE DA INTERAÇÃO ENTRE USO DE CHUPETA E IDADE DOS LACTENTES SOBRE O AME \\ (Saída do software STATA 10.0)}



\footnotetext{
- estimates store A

- xi:poisson nexclusiv i.chupeta i.velhos trabalhan escol4, irr

i. chupeta I chupeta $0-1$

(naturally coded; Ichupeta 0 omitted)

i. velhos

Ivelhos $\overline{0}-1$

(naturally coded; Ivelhos $\overline{0}$ omitted)

Tteration $0: \quad$ log likelihood $=-574.41087$

Iteration 1: $\quad$ log likelihood $=-574.41081$

Poisson regression

$\begin{array}{llr}\text { Number of obs } & = & 691 \\ \text { LR chi2(4) } & = & 54.66 \\ \text { Prob > chi2 } & = & 0.0000 \\ \text { Pseudo } 2 & & 0.0454\end{array}$

Log likelihood $=-574.41081$

Pseudo R2

0454
}

\begin{tabular}{|c|c|c|c|c|c|c|}
\hline nexclusiv & IRR & Std. Err. & $z$ & $\mathrm{P}>|z|$ & [95\% Conf. & Interval] \\
\hline Ichupeta 1 & 1.691906 & .1835684 & 4.85 & 0.000 & 1.367799 & 2.09281 \\
\hline I velhos 1 & 1.52622 & .1632388 & 3.95 & 0.000 & 1.237588 & 1.882169 \\
\hline trabalhān & 1.174687 & .1535914 & 1.23 & 0.218 & .9091317 & 1.517811 \\
\hline escol 4 & .6286642 & .1172764 & -2.49 & 0.013 & .4361425 & .9061688 \\
\hline
\end{tabular}

estimates store $B$

lrtest B A

likelihood-ratio test

(Assumption: $B$ nested in A)

$\begin{array}{lr}\text { LR chiz(1) } & =0.50 \\ \text { Prob }>\text { chiz } & =\quad 0.4794\end{array}$


8. REFERÊNCIAS 


\section{REFERÊNCIAS}

Aarts C, Kylberg E, Hofvander Y, Gebre-Medhin M. Growth under privileged conditions of healthy Swedish infants exclusively breastfed from birth to 4-6 months: a longitudinal prospective study based on daily records of feeding. Acta Paediatr. 2003;92:145-51.

Abolyan LV. The Breastfeeding support and promotion in Baby-Friendly Maternity Hospitals and not-as-yet Baby-Friendly Hospitals in Russia. Breastfeed Med. 2006;1(2):71-8.

Abrão ACFV. Amamentação: uma prática que precisa ser aprendida ?editorial?. Pediatria (São Paulo). 2006;28(2):79-80.

Academy of Breastfeeding Medicine (ABM). Board of Directors. Position on breastfeeding. Breastfeed Med. 2008;3(4):267-70.

Aedo C. Evaluación económica de la prolongación del postnatal. Rev Chil Pediatr. 2007;78(1 Supl):10-50.

Agency for Healthcare Research and Quality (AHRQ). Breastfeeding and maternal and infant health outcomes in developed countries. Rockville, MD: Agency for Healthcare Research and Quality; April 2007. Available at: http://www.ahrq.gov/clinic/tp/brfouttp.htm. Acessado em 21/06/2008.

Aidam BA, Pérez-Escamilla R, Aidam J. Factors associated with exclusive breastfeeding in Accra, Ghana. Eur J Clin Nutr. 2005;59:789-96.

Albarenque S, Mas L, Ferreyra M, Marchisio MI, Gomila A, Armelini P. Lactancia materna y alimentación complementaria. Arch Argent Pediatr. $2005 ; 103(3):$

Almeida JAG. Amamentação: um híbrido natureza-cultura. Rio de Janeiro: Editora Fiocruz; 1999.

Almeida S, Bettiol H, Barbieri MA, Silva AAM, Ribeiro VS. Diferença notável nas taxas de parto cesariano em hospital público e hospital privado no Brasil. Cad Saude Publica. 2008;24(12):2909-18.

Al Tajir GK, Sulieman H, Badrinath P. Intragroup differences in risk factors for breastfeeding outcomes in a multicultural community. J Hum Lact. 2006;22(1):39-47.

American Academy of Pediatrics (AAP). Section on Breastfeeding. Breastfeeding and the use of human milk. Pediatrics. 2005;115(2);496-506. 
American College of Obstetricians and Gynecologists (ACOG). Committee on Health Care for Underserved Women and Committee on Obstetric Practice. Obstet Gynecol. 2007;109(2):479-80.

Anderson AK, Damio G, Himmelgreen DA, Peng Y, Segura-Pérez S, PérezEscamila R. Social capital, acculturation, and breastfeeding initiation among puerto rican women in the United States. J Hum Lact. 2004;20(1):39-45.

Andrade CLT, Szwarcwald CL, Castilho EA. Baixo peso ao nascer no Brasil de acordo com as informações sobre nascidos vivos do Ministério da Saúde, 2005. Cad Saude Publica. 2008;24(11):2564-72.

Araújo MFM, Schimtz BAS. Reassessment of Baby-friendly Hospitals in Brazil. J Hum Lact. 2007;23(3):246-52.

Araújo RMA, Almeida JAG. Aleitamento materno: o desafio de compreender a vivência. Rev Nutr. 2007;20(4):431-8.

Audi CAF, Corrêa MAS, Latorre MRDO. Alimentos complementares e fatores associados ao aleitamento materno e ao aleitamento materno exclusivo em lactentes até 12 meses de vida em Itapira, São Paulo, 1999. Rev Bras Saúde Mater Infant. 2003;3(1):85-93.

Balaban G, Silva GAP. Efeito protetor do aleitamento materno contra a obesidade infantil. J Pediatr (Rio J). 2004;80(1):7-16.

Barata RB. Inquérito Nacional de Saúde: uma necessidade? Ciênc Saúde Coletiva. 2006; 11(4):870-86.

Barría RM, Santander G, Victoriano T. Factors associated with exclusive breastfeeding at 3 months postpartum in Valdivia, Chile. J Hum Lact. 2008;24(4):439-45.

Barros AJD, Hirakata VN. Alternatives for logistic regression in crosssectional studies: an empirical comparison of models that directly estimate the prevalence ratio. BMC Med Res Methodol. 2003;3:21. Available from: http://www.biomedcentral.com/1471-2288/3/21.

Bartington S, Griffiths LJ, Tate AR, Dezateux Carol, Millennium Cohort Study Child Health Group. Are breastfeeding rates higher among mothers delivering in Baby Friendly accredited maternity units in the UK? Int $J$ Epidemiol. 2006;35(5):1178-86.

Bassichetto KC, Réa MF. Infant and young child feeding counseling: an intervention study. J Pediatr (Rio J). 2008;84(1):75-82. 
Beasley A, Amir LH. Infant feeding, poverty and human development. Int Breastfeed J. 2007;2:14. Available at: http://www.biomedcentral.com/1746$4358 / 2 / 14$.

Besculides M, Grigoryan K, Laraque F. Increasing Breastfeeding Rates in New York City, 1980-2000. Bull N Y Acad Med. 2005;82(2):198-206.

Bhandari N, Mazumder S, Bahl R, Martines J, Black RE, Bha MK. Use of multiple opportunities for improving feeding practices in under-twos within child health programmes. Health Policy Plan. 2005;20(5):328-36.

Blyth RJ, Creedy DK, Dennis CL, Moyle W, Pratt J, De Vries SM, Healy GN. Breastfeeding duration in an Australian population: the influence of modifiable antenatal factors. J Hum Lact. 2004;20(1):30-8.

Boccolini CS, Carvalho ML, Oliveira MIC, Leal MC, Carvalho MS. Fatores que interferem no tempo entre o nascimento e a primeira mamada. Cad Saude Publica. 2008;24(11):2681-94.

Bonuck KA, Freeman K, Trombley M. Country of origin and race/ethnicity: impact on breastfeeding intentions. J Hum Lact. 2005;21(3):320-6.

Brasil. Ministério da Saúde. Portaria no 2.799, de 18 de novembro de 2008. Institui, no âmbito do Sistema Único de Saúde (SUS), a Rede Amamenta Brasil. Diário Oficial da União. 200819 nov; Seção 1: n.․ 225.

Braun MLG, Giugliani ERJ, Soares MEM, Giugliani C, Oliveira AP, Danelon CMM. Evaluation of the impact of the Baby-Friendly Hospital Initiative on rates of breastfeeding. Am J Pub Health. 2003;93(8):1277-9.

Brown CA, Poag S, Kasprzycki C. Exploring large employers' an small employers' knowledge, attitudes, and practices on breastfeeding support in the workplace. J Hum Lact. 2001;17(1):39-46.

Bueno LGS, Teruya KM. Aconselhamento em amamentação e sua prática. $J$ Pediatr (Rio J). 2004;80(5 Supl):S126-30.

Buhimschi CS. Endocrinology of lactation. Obstet Gynecol Clin North Am. 2004;31(4):963-79.

Bulk-Bunschoten AMW, Van Bodegom S, Reerink JD, Pasker-de Jong PCM, De Groot CJ. Reluctance to continue breastfeeding in The Netherlands. Acta Paediatr. 2001;90(9):1047-53.

Bulk-Bunschoten AMW, Pasker-de Jong PCM, Van Wouwe JP, De Groot CJ. Ethnic variation in infant feeding practices in the Netherlands and weight gain at 4 months. J Hum Lact. 2008;24(1):42-9. 
Bunik M, Clark L, Zimmer LM, Jimenez LM, O'Connor ME, Crane LA, Kempe A. Early Infant Feeding Decisions in Low-Income Latinas. Breastfeed Med. 2006;1(4):225-35.

Cabana MD, Atkinson-McEvoya LR. The importance of generalism in academic pediatrics ?editorial?. Curr Opin Pediatr.2007;19(6):698-9.

Caldeira AP, Gonçalves E. Assessment of the impact of implementing the Baby-Friendly Hospital Initiative. J Pediatr (Rio J). 2007;83(2):127-32.

Caldeira AP, Fagundes GC, Aguiar GN. Intervenção educacional em equipes do Programa de Saúde da Família para promoção da amamentação. Rev Saude Publica. 2008;42(6):1027-33.

Calnen G. Paid maternity leave and its impact on breastfeeding in the United States: an historic, economic, political, and social perspective. Breastfeed Med. 2007;2(1):34-44.

Camilo DF, Carvalho RVB, Oliveira EF, Moura EC. Prevalência da amamentação em crianças menores de dois anos vacinadas nos centros de saúde escola. Rev Nutr. 2004;17(1):29-36.

Cardoso LO, Vicente AS, Damião JJ, Rito RV.The impact of implementation of the Breastfeeding Friendly Primary Care Initiative on the prevalence rates of breastfeeding and causes of consultations at a basic healthcare center. $J$ Pediatr (Rio J). 2008;84(2):147-53.

Carvalhaes MABL, Parada CMGL, Costa MP. Factors associated with exclusive breastfeeding in children under four months old in Botucatu-SP, Brazil. Rev Latino-am Enfermagem. 2007;15(1):62-9.

Carvalhaes MABL, Parada CMGL, Manoel CM, Venancio SI. Diagnóstico da situação do aleitamento materno em área urbana do Sudeste do Brasil: utilização de metodologia simplificada. Rev Saude Publica. 1998;32(5):4306.

Caspi A, Williams B, Kim-Cohen J, Craig IW, Milne BJ, Poulton R, Schalkwyk LC, Taylor A, Werts $\mathrm{H}$, Moffitt TE. Moderation of breastfeeding effects on the IQ by genetic variation in fatty acid metabolism. Proc Natl Acad Sci USA. 2007;104: 18860-5.

Cattaneo A, Davanzo R, Ronfani L. Are data on the prevalence and duration of breastfeeding reliable? The case of Italy. Acta Paediatr. 2000;89(1):88-93.

Cernadas JM, Noceda G, Barrera L, Martinez AM, Garsd A. Maternal e perinatal factors influencing the duration of exclusive breastfeeding during the first 6 months of life. J Hum Lact. 2003;19(2):136-44. 
Chaves RG, Lamounier JA, César CC. Factors associated with duration of breastfeeding. J Pediatr (Rio J). 2007;83(3):241-6.

Chien L, Chu K, Tai C, Lin C. National prevalence of breastfeeding in Taiwan. J Hum Lact. 2005;21(3):338-44.

Click ER. Developing a worksite lactation program. MCN Am J Matern Child Nurs. 2006;31(5):313-7.

Coates MM. Tides in breastfeeding practices. In: Riordan J, Auerbach KG. Breastfeeding and human lactation. 1.ed. Boston: Jones and Bartlett Publishers; 1998. p.3-28.

Conill EM. Ensaio histórico-conceitual sobre a Atenção Primária à Saúde: desafios para a organização de serviços básicos e da Estratégia Saúde da Família em centros urbanos no Brasil. Cad Saude Publica. 2008;24(1 Supl):7-27.

Cotrim LC, Venancio SI, Escuder MML. Uso de chupeta e amamentação em crianças menores de quatro meses no estado de São Paulo. Rev Bras Saúde Mater Infant. 2002;2(3):245-52.

Coutinho SB, Lira PIC, Lima MC, Ashworth A. Comparison of the effect of two systems for the promotion of exclusive breastfeeding. Lancet. 2005;366(9491):1094-100.

Cunha AJLA, Leite AM, Machado MMT. Breastfeeding and Pacifier use in Brazil. Indian J Pediatr. 2005;72(3):13-6.

Damião JJ. Influence of mothers' schooling and work on the practice of exclusive breastfeeding. Rev Bras Epidemiol. 2008;11(3):442-52.

Del Ciampo LA, Junqueira MJG, Ricco RG, Daneluzzi JC, Ferraz IS, Martinelli Júnior CE. Tendência secular do aleitamento materno em uma unidade de atenção primária à saúde materno-infantil em Ribeirão Preto, São Paulo. Rev Bras Saúde Mater Infant. 2006;6(4):391-6.

Delgado-Becerra A, Arroyo-Cabrales LM, Díaz-García MA, Quezada-Salazar CA. Prevalencia y causas de abandono de lactancia materna en el alojamiento conjunto de una institución de tercer nivel de atención. Bol Med Hosp Infant Mex. 2006;63(1):31-9.

Dennis, CL. Theoretical under pinnings of breastfeeding confidence: a selfefficacy framework. J Hum Lact. 1999;15(3):195-201.

Dhandapany G, Bethou A, Arunagirinathan A, Ananthakrishnan S. Antenatal counseling on breastfeeding - is it adequate? A descriptive study from Pondicherry, India. Int Breastfeed J. 2008;3:5. Available from: 
http://www.internationalbreastfeedingjournal.com/content/pdf/1746-4358-35.pdf.

Díaz Tabares O, Soler Quintana ML, Ramos Rodríguez AO, González Masón L. Aspectos epidemiológicos relacionados con el tipo de lactancia durante el primer año de vida. Rev Cubana Med Gen Integr. 2001;17(4):33643.

Dillaway HE, Douma Mari E. Are pediatric offices "supportive" of breastfeeding? Discrepancies between mothers' and healthcare professionals' reports. Clin Pediatr. 2004;43(5):417-30.

Donath SM, Amir LH. Effect of gestation on initiation and duration of breastfeeding. Arch Dis Child Fetal Neonatal Ed. 2008;93(6):448-50.

Dykes F, Moran VH, Burt S, Edwards J. Adolescent mothers and breastfeeding: experiences and support needs an exploratory study. J Hum Lact. 2003;19(3):391-401.

Ekström A, Widström AM, Nissen E. Duration of breastfeeding in Swedish primiparous and multiparous women. J Hum Lact. 2003;19(2):172-8.

Engebretsen IMS, Wamani $\mathrm{H}$, Karamagi C, Semiyaga N, Tumwine J, Tylleskär T. Low adherence to exclusive breastfeeding in Eastern Uganda: a community-based cross-sectional study comparing dietary recall since birth with 24-hour recall. BMC Pediatrics. 2007;7:10. Available from: http://www.biomedcentral.com/1471-2431/7/10.

Escobar AMU, Ogawa AR, Hiratsuka M, Kawashita MY, Teruya PY, Grisi S, Tomikawa S. O. Aleitamento materno e condições socioeconômico-culturais: fatores que levam ao desmame precoce. Rev Bras Saúde Mater Infant. 2002;2(3):253-61.

Espírito Santo LC, Oliveira LD, Giugliani ERJ. Factors associated with low incidence of exclusive breastfeeding for the first 6 months. Birth. 2007;34(3):212-9.

European Society for Pediatric Gastroenterology, Hepatology, and Nutrition (ESPGHAN). Committee on Nutrition. Complementary feeding: a commentary by the ESPGHAN Committee on Nutrition. $J$ Pediatr Gastroenterol Nutr. 2008;46(1):99-110.

Evans KC, Evans RG, Royal R, Esterman AJ, James SL. Effect of caesarean section on breast milk transfer to the normal term newborn over the first week of life. Arch Dis Child Fetal Neonatal Ed. 2003;88(5):380-2.

Falcão MC. Fetal programming and future disease. ?editorial?. Rev Hosp Clin Fac Med S Paulo. 2004;59(6):319-20. 
Faleiros JJ, Kalii G, Casarin DP, Laque Jr. PA, Santos IS. Avaliação do impacto de um programa de puericultura na promoção da amamentação exclusiva. Cad Saude Publica. 2005;21(2):482-9.

Faleiros FTV, Trezza EMC, Carandina L. Aleitamento materno: fatores de influência na sua decisão e duração. Rev Nutr. 2006;19(5):623-30.

Feldman-Winter LB, Schanler RJ, O'Connor KG, LawrenceRA. Pediatricians and the promotion and support of breastfeeding. Arch Pediatr Adolesc Med. 2008;162(12):1142-9.

Ferreira L, Parada CMGL, Carvalhaes MABL. Tendência do aleitamento materno em município da região centro-sul do estado de São Paulo: 19951999-2004. Rev Nutr. 2007;20(3):265-73.

Figueiredo MG, Sartorelli DS, Zan TAB, Garcia E, Si Iva LC, Carvalho FLP, Pascotto RC, Macri $S$, Cardoso MA. Inquérito de avaliação rápida das práticas de alimentação infantil em São José do Rio Preto, São Paulo, Brasil. Cad Saude Publica. 2004;20(1):172-9.

Flores M, Rivera Pasquel M, Maulén I, Rivera J. Exclusive breastfeeding in 3 rural localities in México. J Hum Lact. 2005;21(3):259-65.

Foo LL, Quek SJS, Ng SA, Lim MT, Deurenberg-Yap M. Breastfeeding prevalence and practices among Singaporean Chinese, Malay and Indian mothers. Health Promot Int. 2005;20(3):276-83.

França GVA, Brunken GS, Silva SM, Escuder MM, Venancio SI. Determinantes da amamentação no primeiro ano de vida em Cuiabá, Mato Grosso. Rev Saude Publica. 2007;41(5):711-8.

França MCT, Giugliani ERJ, Oliveira LD, Weigert EML, Espírito Santo LC, Köhler CV, Bonilha ALL. Uso de mamadeira no primeiro mês de vida: determinantes e influência na técnica de amamentação. Rev Saude Publica. 2008;42:607-14.

Freedman LP, Waldman RJ, Pinho H, Wirth ME, Chowdhury AMR, Rosenfield A. UN Millennium Project 2005. Who's got the power? Transforming health systems for women and children. Summary version of the report of the Task Force on Child Health and Maternal Health. New York:USA:2005.

Giugliani ERJ. Indicadores do aleitamento materno: a caminho da uniformização. ?editorial?. J Pediatr (Rio J). 1998;74(1):1-2.

Gomes PTT. Práticas alimentares de crianças menores de 1 ano que compareceram na segunda etapa da campanha nacional de vacinação nos postos de saúde fixos na cidade de Guarapuava - PR, em 2004 
?dissertação? Ribeirão Preto: Escola de Enfermagem de Ribeirão Preto, Universidade de São Paulo; 2005.

Goulet C, Lampron A, Marcil I, Ross L. Attitudes and subjective norms of male and female adolescents toward breastfeeding. $J$ Hum Lact. 2003;19(4):402-10.

Griffiths LJ, Tate AR, Dezateux C, Millennium Cohort Study Child Health Groupy. The contribution of parental and community ethnicity to breastfeeding practices: evidence from the Millennium Cohort Study. Int $J$ Epidemiol. 2005;34(6):1378-86.

Grjibovski AM, Yngve A, Bygren LO, Sjöström M. Socio-demographic determinants of initiation and duration of breastfeeding in northwest Russia. Acta Paediatr. 2005;94(5):588-94.

Gusmão L. Lula sanciona lei que aumenta período da licença-maternidade para 6 meses. Folha Online, São Paulo. 2008 set 10; Caderno Dinheiro.

Disponível em:

http://www1.folha.uol.com.br/folha/dinheiro/ult91u443189.shtml.

Habicht JP, Victora CG, Vaughan JP. Evaluation designs for adequacy, plausibility and probability of public health programme performance and impact. Int. J. Epidemiol. 1999;28(1):10-18.

Haiek LN, Gauthier DL, Brosseau D, Rocheleau L. Understanding breastfeeding behavior: rates and shifts in patterns in Québec. J Hum Lact. 2007;23(1):24-31.

Harris V, Hall D. Why breast feeding fails. Arch Dis Child. 2007;92(1):84.

Hartmann PE. The lactating breast: an overview from down under. Breastfeed Med. 2007;2(1):3-9.

Heinig MJ. Special issue: cross-cultural determinants of infant-feeding practices, part 1 ?editorial?. J Hum Lact. 2001;17(3):201-2.

Heinig MJ. Promotion and support of optimal feeding practices for infants and young children: a global challenge, a global responsability ?editorial?. J Hum Lact. 2004;20(2):137-9.

Heinig MJ. Using organizational theory to promote breastfeeding accomodation in the workplace ?editorial?. J Hum Lact. 2007;23(2):141-2.

Heinig MJ. Are there risks to using risk-based messages promote breastfeeding? ?editorial?. J Hum Lact. 2009;25(1):7-8. 
Heinig MJ, Ishii KD, Bañuelos JL, Campbell E, O'Loughlin C, Becerra LEV. Sources and Acceptance of Infant-Feeding Advice Among Low-Income Women. J Hum Lact. 2009; 25(2):163-72.

Hewat RJ. Research and breastfeeding. In: Riordan J, Auerbach KG. Breastfeeding and human lactation. 2.ed. Boston: Jones and Bartlett Publishers; 1998. p.747-74.

Hofvander Y. Breastfeeding and the Baby Friendly Hospitals Initiative (BFHI): organization, response and outcome in Sweden and other countries. Acta Paediatr. 2005;94(8):1012-6.

Horta BL, Bahl R, Martines JC, Victora CG. Evidence on the long-term effects of breastfeeding. Systematic reviews and meta-analyses. Geneva, Switzerland: World Health Organization; 2007.

Howard CR, Howard FM, Lanphear B, Eberly S, deBlieck EA, Oakes D, Lawrence RA. Randomized clinical trial of pacifier use and bottle-feeding or cupfeeding and their effect on breastfeeding. Pediatrics. 2003;111(3):511-8.

Hüppi, PS. Nutrition for the Brain. Pediatr Res. 2008;63(3):229-31.

Ilabaca J, Atalah E. Tendencia de la lactancia materna en el Servicio de Salud Metropolitano Sur. Rev Chil Pediatr. 2002a;73(2):127-34.

Ilabaca J, Atalah E. Comparación de la prevalencia y porcentaje de acuerdo entre dos métodos de análisis de la lactancia materna. Rev Chil Pediatr. 2002b;73(6):583-9.

Issler RMS. Níveis de pobreza e sua repercussão no estado de saúde de populações de baixa renda: um estudo em Porto Alegre ?dissertação?. Porto Alegre: Faculdade de Medicina, Universidade Federal do Rio Grande do Sul; 1992.

Joana Briggs Institute. Early childhood pacifier use in relation to breastfeeding, SIDS, infection, and dental malocclusion. Nurs Stand. 2006;20(38):52-5.

Johnston ML, Esposito N. Barriers and facilitators for breastfeeding among working women in the United States. J Obstet Gynecol Neonatal Nurs. 2007;36(1):9-20.

Jóia ICOS. Percursos ambíguos: percepções de lactantes usuárias de uma unidade básica do município do Rio de Janeiro acerca dos primeiros meses de amamentação ?dissertação?. Rio de Janeiro: Programa de PósGraduação em Saúde Coletiva, Universidade Federal do Rio de Janeiro; 2006. 
Kalanda BF, Verhoeff FH, Brabin BJ. Breast and complementary feeding practices in relation to morbidity and growth in Malawian infants. Eur J Clin Nutr. 2006;60(3):401-7.

Kalton G. Introduction to survey sampling. lowa: Sage Publications; 1983.

Kamudoni P, Maleta K, Shi Z, Holmboe-Ottesen G. Infant feeding practicesin the first 6 months and associated factors in a rural and semiurban community in Magochi district, Malawi. J Hum Lact. 2007;23(4):325-32.

Kitoko PM, Rea MF, Venancio SI et al. Breastfeeding in two brazilian state capitals: a comparative analysis. Cad Saude Publica. 2000;16(4):1111-9.

Klaus $\mathrm{MH}$, Klaus $\mathrm{PH}$. The amazing newborn. Massachussetts: AddisonWesley Publishing Company; 1992.

Kosmala-Anderson J, Wallace LM. Breastfeeding works: the role of employers in supporting women who wish to breastfeed and work in four organizations in England. J Pub Health (Oxf). 2006;28(3):183-91.

Kovach AC. A 5-year follow-up study of hospital breastfeeding policies in the Philadelphia area: a comparison with the ten steps. J Hum Lact. 2002;18(2):144-54.

Kramer M, Chalmers B, Hodnett ED, Sevkovskaya Z, Dzikovich I, Shapiro S, Collet J, Vanilovich I, Mezen I, Ducruet T, Shishko G, Zubovich V. Mknuik D, Gluchanina E, Dombrovskiy V, Ustinovitch A, Kot T, Bogdanovich N, Ovchinikova L, Helsing $\mathrm{E}$. Promotion of Breastfeeding Intervention Trial (PROBIT): a randomized trial in the Republic of Belarus. JAMA. $2001 ; 285(4): 413-20$.

Kramer MS, Aboud F, Mironova E, Vanilovich I, Platt RW, Matush L, Igumnov S, Fombonne E, Bogdanovich N, Ducruet T, Collet JP, Chalmers B, Hodnett E, Davidovsky S, Skugarevsky O, Trofimovich O, Kozlova L, Shapiro S. Breastfeeding and child cognitive development: new evidence from a large randomized trial. Arch Gen Psychiatry. 2008;65(5):578-84.

Kronborg $\mathrm{H}$, Vaeth $\mathrm{M}$. The influence of psychosocial factors on the duration of breastfeeding. Scand J Public Health. 2004;32(3):210-6.

Kruse L, Denk CE, Feldman-Winter L, Rotondo FM. Comparing sociodemographic and hospital influences on breastfeeding initiation. Birth. $2005 ; 32(2): 81-5$.

Labbok M. The Immunological secrets of breastfeeding: implications for best practice ?independent study module?. Raleigh (North Carolina): International Lactation Consultant Association, 2006. 
Labbok MH, Wardlaw T, Blanc A, Clark D, Terreri N. Trends in exclusive breastfeeding: findings from the 1990`s. J Hum Lact. 2006;22(3):272-6.

Lamounier JA. Experiência iniciativa Hospital Amigo da Criança. Rev Ass Med Brasil. 1998;44(4):319-24.

Lamounier JA. The influence of nipples and pacifiers on breastfeeding duration ?editorial?. J Pediatr (Rio J). 2003;79(4):284-6.

Lamounier JA, Bouzada MCF, Janneu AMS, Maranhão AGK, Araújo MFM, Vieira GO, Vieira TO. Iniciativa Hospital Amigo da Criança, mais de uma década no Brasil: repensando o futuro. Rev Paul Pediatr. 2008;26(2):161-9.

Lande B, Andersen LF, Baerug A, Trygg KU, Lund-Larsen K, Veierod MB, Bjorneboe GA. Infant feeding practices and associated factors in the first six months of life: The Norwegian Infant Nutrition Survey. Acta Paediatr. 2003;92(2):152-61.

Lawlor DA. The developmental origins of health and disease: where do we go from here? ?commentary?. Epidemiology. 2008;19(2):206-8.

Lawoyin TO, Olawuyi JF, Onadeko MO. Factors associated with exclusive breastfeeding in Ibadan, Nigeria. J Hum Lact. 2001;17(4):321-5.

Lawrence RA. Breastfeeding: a guide for the medical profession. 4.ed. St. Louis: Mosby, 1994.

Lawrence RA. The eradication of poverty one child at a time through breastfeeding: a contribution to the global theme issue on poverty and human development. Breastfeed Med. 2007;2(4):193-4.

Leone C. Aspectos metodológicos de pesquisa em aleitamento materno. In: Issler H. O aleitamento materno no contexto atual: políticas, práticas e bases científicas. São Paulo: Sarvier; 2008. p.577-86.

Li D, Willinger M, Petitti DB, Odouli R, Liu L, Hoffman HJ. Use of a dummy (pacifier) during sleep and risk of sudden infant death syndrome (SIDS): population based case-control study. BMJ. 2006;332(7532);18-22.

Li L, Zhang M, Scott JA, Binns CW. Factors associated with the initiation and duration of breastfeeding by chinese mothers in Perth, Western Australia. $J$ Hum Lact. 2004;20(2):188-95.

Li L, Zhang M, Scott JA, Binns CW. Infant feeding practices in home countries and Australia: Perth Chinese mothers survey. Nutr Diet. 2005;62:82-8. 
Li R, Darling N, Maurice E, Barker L, Grummer-Strawn LM. Breastfeeding rates in the United States by characteristics of the child, mother, or family: the 2002 National Immunization Survey. Pediatrics. 2005;115:e31-7. Available from: http://www.pediatrics.org/cgi/doi/10.1542/peds.2004-0481.

Li R, Zhao Z, Mokdad A, Barker L, Grummer-Strawn L. Prevalence of breastfeeding in the United States: the 2001 National Immunization Survey. Pediatrics. 2003;111(5):1198 -201.

Libbus MK. Breastfeeding attitudes in a sample of spanish-speaking hispanic-american women. J Hum Lact. 2000;16(3):216-20.

Libbus MK, Bullock LFC. Breasfeeding and employment: an assessment of employer attitudes. J Hum Lact. 2002;18(1):24-51.

Lima TM, Osório MM. Perfil e fatores associados ao aleitamento materno em crianças menores de 25 meses da região nordeste do Brasil. Rev Bras Saúde Mater Infant. 2003;3(3):305-14.

Ludvigsson JF. Breastfeeding intentions, patterns, and determinants in infants visiting hospitals in La Paz, Bolívia. BMC Pediatrics. 2003a;3:5. Available from: http://www.biomedcentral.com/1471-2431/3/5.

Ludvigsson JF. Breastfeeding in Bolivia - information and attitudes. BMC Pediatrics. 2003b;3:4. Available from: http://www.biomedcentral.com/14712431/3/4.

Ludvigsson JF, Ludvigsson J. Socio-economic determinants, maternal smoking and coffee consumption, and exclusive breastfeeding in 10205 children. Acta Paediatr. 2005;94(9):1310-9.

Marrone S, Vogeltanz-Holm N, Holm J. Attitudes, knowledge, and intentions related to breastfeeding among university undergraduate women and men. $J$ Hum Lact. 2008;24(2):186-92.

Martens PJ. Does breastfeeding education affect nursing staff beliefs, exclusive breastfeeding rates, and Baby-Friendly Hospital Initiative compliance? The experience of a small, rural canadian hospital. J Hum Lact. 2000;16(4):309-18.

Martin RM, Gunnel D, Smith GD. Breastfeeding in infancy and blood pressure in later life: systematic review and meta-analysis. Am J Epidemiol. 2005;161(1):15-26.

Mascarenhas ML, Albernaz EP, da Silva MB, da Silveira RB. Prevalence of exclusive breastfeeding and its determiners in the first 3 months of life in the South of Brazil. J Pediatr (Rio J). 2006;82(4):289-94. 
Massad E, Menezes RX, Silveira PSP, Ortega NRS. Métodos quantitativos em medicina. São Paulo: Manole; 2004.

Mayer-Davis EJ, Dabelea D, Lamichhane AP, D'Agostino RB, Liese AD, Thomas J, Mckeown RE, Hamman RF. Breast-feeding and type 2 diabetes in the youth of three ethnic groups. Diabetes Care. 2008;31(3):470-5.

McCarter-Spaulding D. Is breastfeeding fair? Tensions in feminist perspectives on breastfeeding and the family. J Hum Lact. 2008;24(2):20612.

McGovern P, Dowd B, Gjerdingen D, Gross CR, Kenney S, Ukestad L, McCaffrey D, Lundberg U. Postpartum health of employed mothers 5 weeks after childbirth. Ann Fam Med. 2006;4(2):159-67.

Melo AMCA, Cabral PC, Moura EA, Duque LM, Menezes AEB, Wanderley LG. Conhecimentos e atitudes sobre aleitamento materno em primíparas da cidade do Recife, Pernambuco. Rev Bras Saúde Mater Infant. 2002;2(2):13742.

Menéndez RD, Cruz DV, Rosales ZS, Mas MA. Factores psicosociales que influyen en el abandono de la lactancia materna. Rev Cubana Pediatr. 1999;71(2):72-9.

Merewood A, Patel B, Newton KN, MacAuley LP, Chamberlaim LB, Francisco P, Mehta SD. Breastfeeding duration rates and factors affecting continued breastfeeding among infants born at an inner-city US BabyFriendly Hospital. J Hum Lact. 2007; 23(2):157-64.

Merten M, Dratva J, Ackermann-Liebrich U. Do Baby-Friendly Hospitals influence breastfeeding duration on a national level? Pediatrics. 2005;116(5):e702-8.

Minagawa AT, Oliveira IMV, Fujimori E, Laurenti D, Montero RMJM. Perfil do aleitamento materno em menores de 2 anos na cidade de Itupeva, SP, Brasil. Arch Latinoam Nutr. 2005;55(2):132-9.

Ministério da Saúde (MS). PNDS 2006. Pesquisa Nacional de Demografia e Saúde da Criança e da Mulher. Relatório. Brasília (DF): Ministério da Saúde; 2008.

Disponível em: http://bvsms.saude.gov.br/bvs/pnds/img/relatorio_final_pnds2006.pdf.

Mlay RS, Keddy B, Stern PN. Demands out of context: Tanzanian women combining exclusive breastfeeding with employment. Health Care Women Int. 2004;25(3):242-54.

Moreira LA. O estudo do impacto do aleitamento materno na cárie dentária em crianças de 2 a 12 anos de idade. Campinas, 2007 ?tese?. Campinas: 
Curso de Pós-graduação em Saúde da Criança e do Adolescente, Faculdade de Ciências Médicas da Universidade Estadual de Campinas; 2007.

Mossman M, Heaman M, Dennis C, Morris M. The influence of adolescent mother's breastfeeding confidence and attitudes on breastfeeding initiation and duration. J Hum Lact. 2008;24(3):268-77.

Nascimento MBR, Issler $\mathrm{H}$. Breastfeeding the premature infant: experience of a Baby-Friendly Hospital in Brazil. J Hum Lact. 2005;21(1):47-52.

Neiva FCB, Cattoni DM, Ramos JLA, Issler H. Desmame precoce: implicações para o desenvolvimento motor-oral. J Pediatr (Rio J). 2003;79(1):7-12.

Nelson EAS, Yu LM, Willians S. International child care practices study: breastfeeding and pacifier use. J Hum Lact. 2005;21(3):289-95.

Neumann NA, Victora CG, Valle NJ, Cesar JA, Horta BL, Lima SM, Barros FC. Impacto da Pastoral da Criança sobre a nutrição de menores de cinco anos no Maranhão: uma análise multinível. Rev Bras Epidemiol. 2002;5(1):30-40.

Nevo N, Rubin L, Tamir A, Levine A, Shaoul R. Infant feeding patterns in the first 6 months: an assessment in full-term infants. $J$ Pediatr Gastroenterol Nutr. 2007; 45(2):234-9.

Newton KN, Chaudhuri J, Grossman X, Merewood A. Factors associated with exclusive breastfeeding among latina women giving birth at an inner-city Baby-Friendly Hospital. J Hum Lact. 2009;25(1):28-33.

OlaOlorun FM, Lawoyin TO. Health worker's support for breastfeeding in Ibadan, Nigeria. J Hum Lact. 2006;22(2):188-94.

Oliveira MIC, Camacho LAB. Impacto das Unidades Básicas de Saúde na duração do aleitamento materno exclusivo. Rev Bras Epidemiol. 2002;5(1):41-51.

Oliveira MIC, Camacho LAB, Tedstone AE. A method for the evaluation of primary health care units' practice in the promotion, protection, and support of breastfeeding: results from the state of Rio de Janeiro, Brasil. J Hum Lact. 2003;19(3):365-73.

Ong G, Yap M, Foo LL, Tai BC. Impact of working status on breastfeeding in Singapore: evidence from the National Breastfeeding Survey 2001. Eur J Pub Health. 2005;15(4):424-30. 
Organización Panamericana de la Salud/ Organización Mundial de la Salud (OPAS/OMS). Indicadores para evaluar las prácticas de la lactancia materna. Geneva, Suíza: Organización Mundial de la Salud; 1991.

Ossandón MM, llabaca MJ, Gajardo OC, Castillo BN, Namur RL. Fomento de la lactancia materna, programa Iniciativa Hospital Amigo del Niño y la Madre, en Hospital Barros Luco Trudeau. Rev Chil Pediatr. 2000;71(2):98-106.

Osis MJD, Duarte GA, Pádua KS, Ellen Hardy E, Sandoval LEM, Bento SF. Aleitamento materno exclusivo entre trabalhadoras com creche no local de trabalho. Rev Saude Publica. 2004;38(2):172-9.

Otoo GE, Lartey AA, Pérez-Escamilla R. Perceived incentives and barriers to exclusive breastfeeding among periurban ghanaian women. J Hum Lact. 2009; 25(1);34-41.

Palmer B. The influence of breastfeeding on the development of the oral cavity: a commentary. J Hum Lact. 1998;114(2):93-8.

Pande $\mathrm{H}$, Unwin $\mathrm{C}$, Haheim LL. Factors associated with the duration of breastfeeding: analysis of the primary and secondary responders to a selfcompleted questionnaire. Acta Paediatr. 1997;86:173-7.

Park YK, Meier ER, Song WO. Characteristics of teenage mothers and predictors of breastfeeding initiation in the Michigan WIC program in 1995. J Hum Lact. 2003; 19(1):50-6.

Patel RR, Liebling RE, Murphy DJ. Effect of operative delivery in the second stage of labor on breastfeeding success. Birth. 2003;30(4):255-60.

Pechlivani F, Vassilakou T, Sarafidou J, Zachou T, Anastasiou CA, Sidossis LS. Prevalence and determinants of exclusive breastfeeding during hospital stay in the area of Athens, Greece. Acta Paediatr. 2005;94(7):928-34.

Pereira MJB, Reis MCG, Nakano AMS, Santos CB, Villela MRGB, Lourenço MCP. Indicadores do aleitamento materno no município de Ribeirão Preto, São Paulo. Rev Bras Epidemiol. 2004;7(1):36-43.

Peres KG, Barros AJD, Peres MA, Victora CG. Effects of breastfeeding and sucking habits on malocclusion in a birth cohort study. Rev Saude Publica. 2007a;41(3):343-50.

Peres KG, Latorre MRDO, Sheiham A, Peres MA, Victora CG, Barros FC. Social and biological early life influences on the prevalence of open bite in Brazilian 6-year-olds. Int J Paediatr Dent. 2007b;17(1):41-9.

Pérez-Escamilla R. Análisis crítico de la investigacion en el campo de la lactancia materna y la salud materno infantil. In: Issler $\mathrm{H}$. $\mathrm{O}$ aleitamento 
materno no contexto atual: políticas, práticas e bases científicas. São Paulo: Sarvier; 2008. p.569-76.

Peters E, Wehkamp K, Felberbaum RE, Krüger D, Linder R. Breastfeeding duration is determined by only a few factors. Eur $J$ Pub Health. 2005;16(2):162-7.

Petersen MR, Deddens JA. A comparison of two methods for estimating prevalence ratios. BMC Med Res Methodol. 2008;8:9. Available from: http://www.biomedcentral.com/1471-2288/8/9.

Philipp BL, Merewood A. The Baby-Friendly way: the best breastfeeding start. Pediatr Clin North Am. 2004;51(3):761-83.

Philipp BL, Merewood A, Gerendas EJ, Bauchner H. Breastfeeding Information in Pediatric Textbooks Needs Improvement. J Hum Lact. 2004;20(2):206-10.

Philipp BL, Radford A. Baby-Friendly: snappy slogan or standard of care? Arch Dis Child Fetal Neonatal Ed. 2006;91(2):145-9.

Pisacane A, Continisio Gl, Aldinucci M, D'Amora S, Continisio P. A Controlled Trial of the Father's Role in Breastfeeding Promotion. Pediatrics. 2005;116(4):e494-8.

Potter JE, Hopkins K, Faúndes A, Perpétuo I. Women's autonomy and scheduled cesarean sections in Brazil: a cautionary tale. Birth. 2008;35(1):33-40.

Racine EF, Frick KD, Strobino D, Carpenter LM, Milligan R, Pugh LC. How Motivation Influences Breastfeeding Duration Among Low-Income Women. $J$ Hum Lact. 2009;25(2):173-81.

Raju TNK. Continued barriers for breastfeeding in public and the workplace. $J$ Pediatr. 2006(5);148:677-9.

Ramos CV, Almeida JAG, Alberto NSMC, João Batista Mendes Teles JBM, Saldiva SRDM. Diagnóstico da situação do aleitamento materno no Estado do Piauí, Brasil. Cad Saude Publica. 2008;24(8):1753-62.

Rao MR, Hediger ML, Levine RJ, Na. cy AB, Vik T. Effect of breastfeeding on cognitive development of infants born small for gestational age. Acta Paediatr. 2002; 91(3):267-74.

Réa MF. Reflexões sobre a amamentação no Brasil: de como passamos a 10 meses de duração. Cad Saude Publica. 2003a;19(1 Supl):37-45. 
Réa MF. O pediatra e a amamentação exclusiva ?editorial?. J Pediatr (Rio J). 2003b;79(6):479-80.

Réa MF, Venancio SI, Batista LE, Santos RG, Greiner T. Possibilidades e limitações da amamentação entre mulheres trabalhadoras formais. Rev Saude Publica. 1997; 31(2):149-56.

Réa MF, Venancio SI, Batista LE, Santos RG, Greiner T. Determinants of the breastfeeding pattern among working women in São Paulo. J Hum Lact. 1999;15(3): 233-9.

Ribeiro NME, Ribeiro MAS. Aleitamento materno e cárie do lactente e do pré-escolar: uma revisão crítica. J Pediatr (Rio J). 2004;80(5 Supl):S199-210.

Righard L. The baby is breastfeeding - not the mother ?editorial?. Birth 2008;35(1):1-2.

Rodriguez-Palmero M, Koletzko B, Kunz C, Jensen R. Nutritional and biochemical properties of human milk, part II: lipids, micronutrients and bioactive factors. Clin Perinatol. 1999;26(2):335-59.

Sales RL, Silva MMS, Costa NMB, Euclydes MP, Eckhardt VF, Rodrigues CMA, Tinoco ALA. Desenvolvimento de um inquérito para avaliação da ingestão alimentar de grupos populacionais. Rev Nutr. 2006; 19(5) 539-52.

Santiago LB, Bettiol H, Barbieri MA, Guttierrez MRP, Del Ciampo LA. Incentivo ao aleitamento materno: a importância do pediatra com treinamento específico. J Pediatr (Rio J). 2003;79(6):504-12.

Santos Neto ET, Oliveira AE, Zandonade E, Molina MCB. Pacifier use as a risk factor for reduction in breastfeeding duration: a systematic review. Rev Bras Saude Mater Infant. 2008;8(4):377-89.

Schluter PJ, Carter S, Percival T. Exclusive and any breast-feeding rates of Pacific infants in Auckland: data from the Pacific Islands Families First Two Years of Life study. Public Health Nutr. 2006;9(6):692-9.

Scott JA, Landers MCG, Hughes RM, Binns CW. Psychosocial factors associated with the abandonment of breastfeeding prior to hospital discharge. J Hum Lact. 2001; 17(1):24-30.

Scott JA, Binns CW, Graham KI, Oddy WH. Temporal Changes in the Determinants of Breastfeeding Initiation. Birth. 2006;33(1):37-45.

Secretaria Municipal da Saúde de Joinville (SMS). Relatório anual de gestão 2007. Joinville: Prefeitura Municipal de Joinville; 2008. Disponível em: http://www.saudejoinville.sc.gov.br/_downloads/_upcaa/documentos/Relatori oGestao2007Joinville.pdf. 
Sellen DW. Weaning, complementary feeding, and maternal decision making in a rural east african pastoral population. J Hum Lact. 2001a;17(3):233-44.

Sellen DW. Comparison of infant feeding patterns reported for nonindustrial populations with current recommendations. J Nutr. 2001b;131(10):2707-15.

Sena MCF, Silva EF, Pereira MG.Prevalência do aleitamento materno no Distrito Federal, Brasil. Cad Saude Publica. 2002;18(3):613-21.

Sena MCF, Silva EF, Pereira MG. Prevalência do aleitamento materno nas capitais brasileiras. Rev Assoc Med Bras. 2007a;53(6):520-4

Sena MCF, Silva EF, Pereira MG. Tendência do aleitamento materno no Brasil no último quarto do Século XX. Rev Bras Epidemiol. 2007b;10(4):499505.

Sertório SCM, Silva IA. As faces simbólica e utilitária da chupeta na visão de mães. Rev Saude Publica. 2005;39(2):156-62.

Sguassero Y, de Onis M, Carroli G. Efectividad de la alimentación suplementaria en países en vias de desarrollo: revisión sistemática. Arch Argent Pediatr. 2007;105(3):198-205.

Shaikh U, Smillie CM. Physician-led outpatient breastfeeding medicine clinics in the United States. Breastfeed Med. 2008;3(1):28-33.

Shealy KR, Li R, Benton-Davis S, Grummer-Strawn LM. The CDC Guide to Breastfeeding Interventions. Atlanta: U.S. Department of Health and Human Services, Centers for Disease Control and Prevention, 2005. Available at: http://www.cdc.gov/breastfeeding/pdf/breastfeeding_interventions.pdf.

Shiva F, Padyabm M. Risk Factors for Early Termination of Breast-Feeding in First-time Mothers. Middle East journal of family medicine [electronic resource] 2008;6(2):18-21.

Silva AP, Souza N. Prevalência do aleitamento materno. Rev Nutr. 2005;18(3):301-10.

Silva NN. Amostragem probabilística. São Paulo: EDUSP; 1998.

Silva SM, Brunken GS, França GVA, Escuder MM, Venancio SY. Evolução do aleitamento materno em uma capital da Região Centro-Oeste do Brasil entre 1999 e 2004. Cad Saude Publica. 2007;23(7):1539-46.

Silveira FJF, Lamounier JA. Prevalência do aleitamento materno e práticas de alimentação complementar em crianças com até 24 meses de idade na região do Alto Jequitinhonha, Minas Gerais. Rev Nutr. 2004;17(4):437-47. 
Silveira FJF, Lamounier JA. Fatores associados à duração do aleitamento materno em três municípios na região do Alto Jequitinhonha, Minas Gerais, Brasil. Cad Saude Publica 2006;22(1):69-77.

Silveira RB, Albernaz E, Zuccheto LM. Fatores associados ao início da amamentação em uma cidade do sul do Brasil. Rev Bras Saúde Mater Infant. 2008; 8(1):35-43.

Simon VGN, Souza JMP, Souza SB. Introdução de alimentos complementares e sua relação com variáveis demográficas e socioeconômicas, em crianças no primeiro ano de vida, nascidas em Hospital Universitário no município de São Paulo. Rev Bras Epidemiol. 2003;6(1):29-38.

Simon VGN, Souza JMP, Souza SB. Aleitamento materno, alimentação complementar, sobrepeso e obesidade em pré-escolares. Rev Saude Publica. 2009;43(1):60-9.

Siqueira RS, Monteiro CA. Amamentação na infância e obesidade na idade escolar em famílias de alto nível socioeconômico. Rev Saude Publica. 2007;41(1):5-12.

Slusser WM, Lange L, Dickson V, Hawkes C, Cohen R. Breast milk expression in the workplace: a look at frequency and time. $J$ Hum Lact. 2004;20(2);164-9.

Slykerman RF, Thompson JMD, Becroft DMO, Robinson E, Pryor JE, Clark PM, Wild CJ, Mitchell EA. Breastfeeding and intelligence of preschool children. Acta Paediatr. 2005;94(7):832-7.

Soares MEM, Giugliani ERJ, Braun ML, Salgado ACN, Oliveira AP, Aguiar PR. Uso de chupeta e sua relação com o desmame precoce em população de crianças nascidas em Hospital Amigo da Criança. J Pediatr (Rio J.). 2003;79(4):309-16.

Sociedade Brasileira de Pediatria (SBP). Departamento de Nutrologia. Manual de orientação: alimentação do lactente, alimentação do pré-escolar, alimentação do escolar, alimentação do adolescente, alimentação na escola ?manual?. São Paulo: Sociedade Brasileira de Pediatria, Departamento de Nutrologia; 2006.

Sousa FGM, Araújo TL. Padrão alimentar de crianças de 6 a 24 meses em área rural do Maranhão. Acta Paul Enferm. 2005;18(2):172-7.

Souza JMP. A estatística e o aleitamento materno. In: Issler H. O aleitamento materno no contexto atual: políticas, práticas e bases científicas. São Paulo: Sarvier; 2008. p.591-600. 
Souza LMM, Almeida JAG. História da alimentação do lactente no Brasil - do leite fraco à biologia da excepcionalidade. Rio de Janeiro: Revinter; 2005.

Souza SB. Pesquisa do aleitamento materno em saúde pública. In: Issler H. O aleitamento materno no contexto atual: políticas, práticas e bases científicas. São Paulo: Sarvier; 2008. p.587-91.

Souza SB, Szarfarc SC, Souza JMP. Prática alimentar no primeiro ano de vida, em crianças atendidas em Centros de Saúde Escola do município de São Paulo. Rev Nutr. 1999;12(2):167-74.

Spear HJ. Breastfeeding behaviors and experiences of adolescent mothers. MCN Am J Matern Child Nurs. 2006;31(2):106-13.

Stanner S, Smith E. Breastfeeding: early influences on later health. British Nutrition Foundation Nutrition Bulletin. 2005:30:94-102.

Suaréz Gil P, Alonso Lorenzo JC, López Diaz AJ, Martin Rodríguez D, Martínez Suárez. Prevalencia e duración de la lactancia materna em Astúrias. Gac Sanit. 2000;15(2):104-10.

Tanner EM, Finn-Stevenson M. Nutrition and brain development: social policy implications. Am J Orthopsychiatry. 2002;72(2):182-93.

Taveras EM, Li R, Grummer-Strawn L, Richardson M, Marshall R, Rêgo VH, Miroshnik I, Lieu TA. Opinions and practices of clinicians associated with continuation of exclusive breastfeeding. Pediatrics. 2004;113(4):e283-90.

Tomasi E, Victora CG, Olinto MTA. Padrões e determinantes do uso de chupeta em crianças. J Pediatr (Rio J). 1994;70(3):167-71.

Tully MR. Working e breastfeeding: helping moms and employers figure it out. AWHONN Lifelines. 2005;9(3):198-203.

Ummarino M, Albano F, De Marco G, Mangani S, Aceto B, Ummarino D, Correra A, Giannetti E, De Vizia B, Guarino A. Short duration of breastfeeding and early introduction of cow's milk as a result of mothers' low level of education. Acta Paediatr. 2003;92(441 Suppl):12-17.

UNICEF (Fondo de las Naciones Unidas para la Infancia). Lactancia materna: una estrategia para mejorar la salud, el crecimiento y la nutrición del lactante y del niño pequeño. Montevideo, Uruguay: UNICEF Uruguay/IBFAN/Red Uruguaya de Apoyo a la Nutrición Infantil; 2004.

UNICEF (Fundo das Nações Unidas para a Infância). Iniciativa Hospital Amigo da Criança ?apostila revista, atualizada e ampliada para o cuidado integrado?. Módulo 4: auto-avaliação e monitoramento do hospital. Brasília: Editora do Ministério da Saúde; 2009. 
United Nations Children's Fund (UNICEF). The state of the worlds children 2008: child survival. New York, USA: United Nations Children 's Fund; 2007.

Van Esterik P. Contemporary trends in infant feeding research. Annu Rev Anthropol. 2002;31:257-78.

Vannuchi MTO, Thomson Z, Escuder MML, Tacla MTG, Vezozzo KMK, Castro LMCP, Oliveira MMB, Venâncio SI. Perfil do aleitamento materno em menores de um ano no Município de Londrina, Paraná. Rev Bras Saúde Mater Infant. 2005;5(2): 155-62.

Vasconcelos MGL, Lira PIC, Lima MC. Duração e fatores associados ao aleitamento materno em crianças menores de 24 meses de idade no estado de Pernambuco. Rev Bras Saúde Mater Infant. 2006;6 (1): 99-105.

Venancio SI. Determinantes individuais e contextuais do aleitamento materno exclusivo nos primeiros seis meses de vida em cento e onze municípios do estado de São Paulo. São Paulo, 2002 ?tese? São Paulo: Faculdade de Saúde Pública, Universidade de São Paulo; 2002.

Venancio SI, Escudera MML, Kitoko P, Rea MF, Monteiro CA. Freqüência e determinantes do aleitamento materno em municípios do Estado de São Paulo. Rev Saude Publica. 2002;36(3):313-8.

Venancio SI, Monteiro CA. Individual and contextual determinants of exclusive breastfeeding in São Paulo, Brazil: a multilevel analysis. Public Health Nutr. 2006;9(1):40-46.

Venancio SI, Saldiva SRDM, Mondini L, Levy RB, Escuder MML. Early interruption of exclusive breastfeeding and associated factors, State of São Paulo, Brazil. J Hum Lact 2008;24(2);168-74.

Vianna RPT, Rea MF, Venancio SI, Escuder MM. Breastfeeding practices among paid working mothers in Paraíba State, Brazil: a cross-sectional study. Cad Saude Publica. 2007;23(10):2403-9.

Victora CG, Behague DP, Barros FC, Olinto MTA, Weiderpass E. Pacifier use and short breastfeeding duration: cause, consequence, or coincidence. Pediatrics. 1997;99:445-53.

Victora CG, Matijasevich A, Santos IS, Barros AJD, Horta BL, Barros FC. Breastfeeding and feeding patterns in three birth cohorts in Southern Brazil: trends and differentials. Cad Saude Publica. 2008;24(3 Suppl):409-16.

Victora CG, Tomasi E, Olinto MTA, Barros FC. Use of pacifiers and breastfeeding duration. Lancet 1993;341(8842):404-6. 
Vieira GO, Glisser M, Araújo SPT, Sales AN. Indicadores do aleitamento materno na cidade de Feira de Santana, Bahia. J. Pediatr. (Rio J.). 1998;74(1):11-6.

Vieira GO, Silva LR, Vieira TO, Almeida JAG, Cabral VA. Hábitos alimentares de crianças menores de 1 ano amamentadas e nãoamamentadas. J Pediatr (Rio J). 2004;80(5):411-6.

Volpini CCA, Moura EC. Determinantes do desmame precoce no distrito noroeste de Campinas. Rev Nutr. 2005;18(3):311-9.

Yawman D. Reflections on the Baby-Friendly Hospital Initiative. Pediatr Ann. 2003;32(5):360-1.

Yesildal N, Aytar G, Kocabay K, Mayda AS, Dagli SC, Bahcebasi T. Breastfeeding practices in Duzce, Turkey. J Hum Lact. 2008;24(4);393-400.

Wang X, Wang Y, Kang C. Feeding practices in 105 counties of rural China. Child: Care, Health \& Development. 2005;31(4):417-23.

Wayland C. Padrões de amamentação em Rio Branco, Acre, Brasil: um estudo sobre fatores associados com o desmame. Cad Saude Publica. 2004;20(6):1757-61.

Wenzel D. Aleitamento materno: estudo nacional da prevalência e determinantes no Brasil, nas macro-regiões e áreas urbanas e rurais. ?tese?. São Paulo: Faculdade de Saúde Pública, Universidade de São Paulo; 2008.

Weyermann M, Rothenbacher D, Brenner H. Duration of breastfeeding and risk of overweight in childhood: a prospective birth cohort study from Germany. Int J Obes. 2006;30:1281-7.

World Health Organization (WHO). Global strategy for infant and young child feeding. Geneva, Switzerland: World Health Organization; 2003.

World Health Organization (WHO). The World Health Report 2005: make every mother and child count. Geneva, Switzerland: World Health Organization; 2005.

Worugji INE, Etuk SJ. The National Breastfeeding Policy in Nigeria: The Working Mother and the Law. Health Care Women Int. 2005;26(7):534-54.

Wright CM, Parkinson K, Scott J. Breast-feeding in a UK urban context: who breast-feeds, for how long and does it matter? Pub Health Nutr. 2006:9(6):686-91. 
Wyrwoll CS, Mark PJ, Waddell BJ. Developmental programming of renal glucocorticoid sensitivity and the renin-angiotensin system. Hypertension. 2007;50(3):579-84.

Zaghloul S, Harrison GG, Fendley HF, Pierce R, Morrisey C. Correlates of breastfeeding initiation in Southeast Arkansas. South Med J. 2004;97(5):44650.

Zocchetti C, Consonni D, Bertazzi PA. Relationship between prevalence rate ratios and odds ratios in cross- sectional studies. Int J Epidemiol. 1997;26(1): 220-3. 